Portland State University

PDXScholar

10-23-1992

\title{
The Use of Laboratory Testing to Understand the Behavior of Collapsible Soil Upon Wetting
}

Martha H. Denham

Portland State University

Follow this and additional works at: https://pdxscholar.library.pdx.edu/open_access_etds

Part of the Civil Engineering Commons

Let us know how access to this document benefits you.

\section{Recommended Citation}

Denham, Martha H., "The Use of Laboratory Testing to Understand the Behavior of Collapsible Soil Upon Wetting" (1992). Dissertations and Theses. Paper 4664.

https://doi.org/10.15760/etd.6548

This Thesis is brought to you for free and open access. It has been accepted for inclusion in Dissertations and Theses by an authorized administrator of PDXScholar. Please contact us if we can make this document more accessible: pdxscholar@pdx.edu. 
AN ABSTRACT OF THE THESIS OF Martha H. Denham for the Master of Science in Civil Engineering presented October 23, 1992.

Title: The Use of Laboratory Testing to Understand the Behavior of Collapsible Soil Upon Wetting.

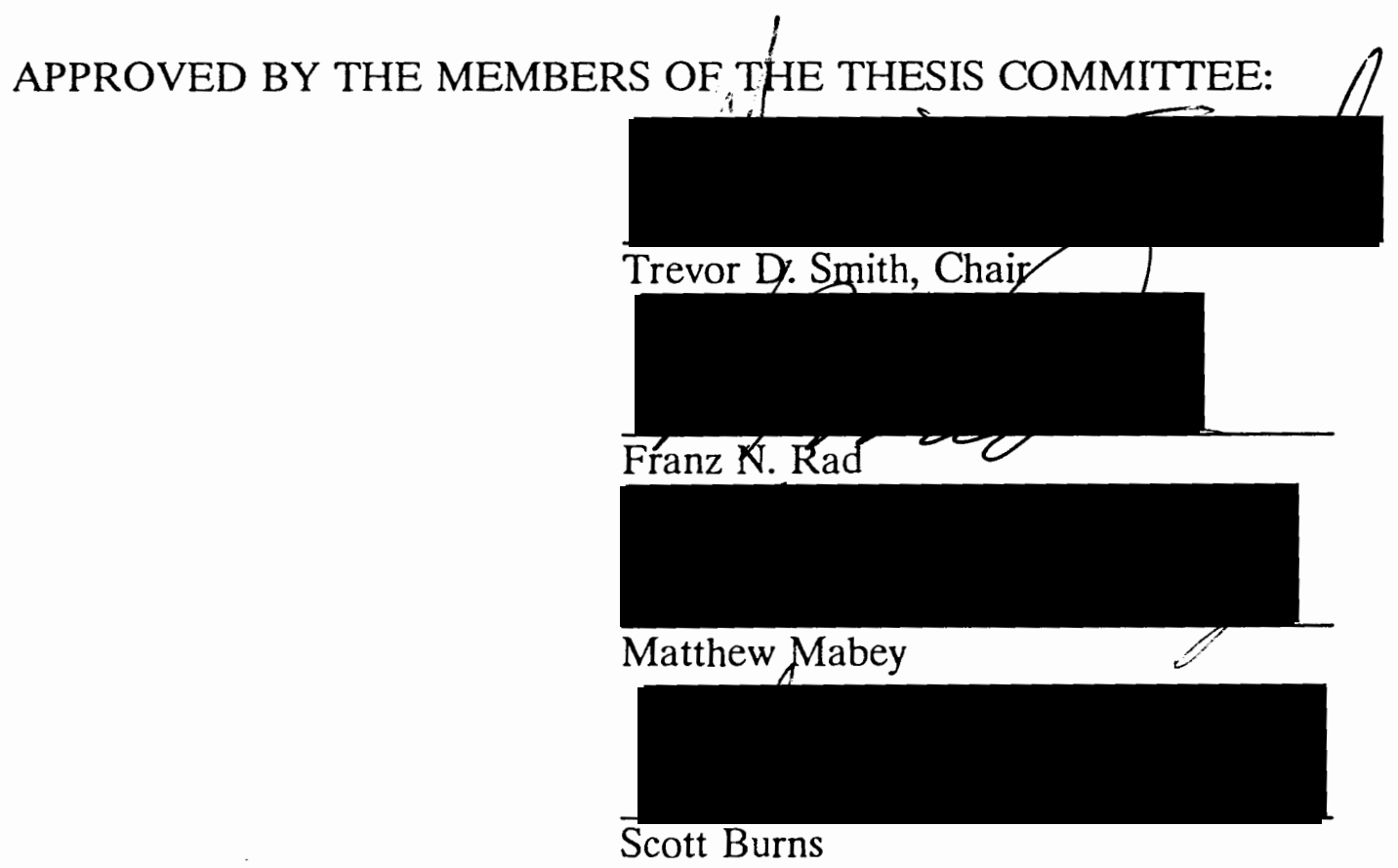

In developing a constitutive model that could predict the settlement due to the collapse, several goals needed to be met. These were to gain an understanding of the collapse phenomenon, knowing the soil properties at the natural water content and how they change after collapse, and develop and test the new model. It was felt that laboratory testing could be of use. 
The types of test conducted included use of the Oedometer, Pressuremeter, and Triaxial tests. The material that was used for the testing was a "generic" soil manufactured out of diatomite. In all of the tests the soil was tested dry and saturated in order to establish state limits of the soil. Next, the soil was loaded dry then inundated which initiated the collapse of the soil. The stress and strains were continually recorded. From the testing it was concluded that there is a stress-strain region where after collapse the soil looses considerable strength. With increasing stress and strain the soil eventually becomes stronger. From the triaxial tests, the stress-strain data from this "region of collapse" was used in a constitutive model. Stress paths from the Oedometer and Pressuremeter tests were then successfully applied to the model.

The constitutive model used was an elasto plastic model. The elastic and plastic strain components were provided using functions for yielding, hardening, plastic potential, and failure as proposed by Paul Lade in his work on cohesionless, frictional materials.

Results from the conventional triaxial shear tests and isotropic compression tests were used to derive the values of the functions for the model. The end result was three dimensional surfaces for failure, yielding, plastic work and plastic potential for the dry and saturated soil in the zone of collapse. 
THE USE OF LABORATORY TESTING TO UNDERSTAND THE BEHAVIOR OF COLLAPSIBLE SOIL UPON WETTING

by
MARTHA H. DENHAM

A thesis submitted in partial fulfillment of the requirements for the degree of

MASTER OF SCIENCE

in

CIVIL ENGINEERING

Portland State University

1993 


\section{TO THE OFFICE OF GRADUATE STUDIES:}

The members of the Committee approve the thesis of Martha H. Denham presented October 23, 1992.
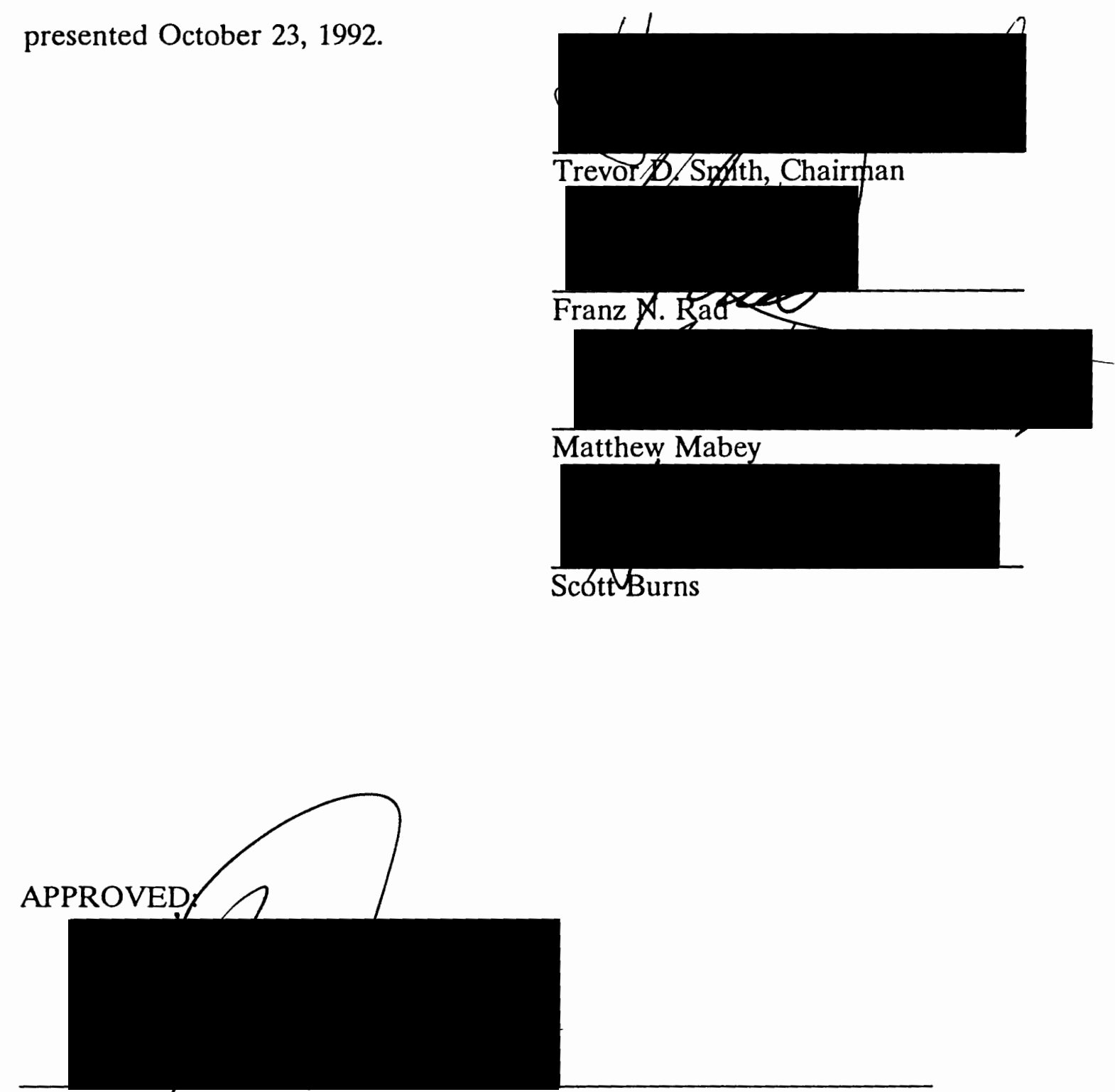

Franz N. Rad, Department of Civil Engineering

Roy W. Koch/Vice Provost for Graduate Studies and Research 


\section{DEDICATION}

This dedication is to my husband, Bob, and my son, John Denham. Bob's love, patience, and belief in my endeavors helped my dream of an education come true. John is only one year old and does not know what a thesis is. My hope is that someday John will value education as much as his parents do, and that he will be reading works such as this in the literature review for his thesis. 


\section{ACKNOWLEDGMENTS}

This study was part of a research project financed by a grant from the United States Department of Agriculture-Soil Conservation Service.

The author wishes to thank Clifton Deal of the Soil Conservation Service for his interest and guidance in the project. Thanks to Trevor D. Smith for his support, instruction, and guidance. Also, to Bob Slyh, my gratitude. Bob's instruction and assistance in the laboratory testing was greatly appreciated. Thanks to Steve Speer for building my testing equipment. Special thanks goes to Oil Dry Incorporated, particularly Dan Yancy, Plant Manager, for providing the ground diatomite that was used for the testing material. Thank you to the entire research team. The comradery and spirit of the group made this an enjoyable project to work on.

Finally, thanks to my husband, Bob. Not only did he give financial support but emotional support as well. 


\section{TABLE OF CONTENTS}

PAGE

ACKNOWLEDGEMENTS $\ldots \ldots \ldots \ldots \ldots \ldots \ldots \ldots \ldots$ iii

LIST OF TABLES $\ldots \ldots \ldots \ldots \ldots \ldots \ldots \ldots \ldots \ldots \ldots \ldots \ldots \ldots \ldots$ ix

LIST OF FIGURES $\ldots \ldots \ldots \ldots \ldots \ldots \ldots \ldots \ldots \ldots \ldots \ldots \ldots \ldots \ldots \ldots$

\section{CHAPTER}

I INTRODUCTION $\ldots \ldots \ldots \ldots \ldots \ldots \ldots \ldots \ldots \ldots \ldots$

Collapsible Soils $\ldots \ldots \ldots \ldots \ldots \ldots \ldots \ldots \ldots \ldots \ldots$

Soil Conservation Service Debris Fan Soils . . . . . . . . 2

Investigation and Solutions to Cracked Dams $\ldots \ldots \ldots \ldots \ldots$

Laboratory Testing $\ldots \ldots \ldots \ldots \ldots \ldots \ldots \ldots \ldots \ldots$

II $\quad$ BACKGROUND $\ldots \ldots \ldots \ldots \ldots \ldots \ldots \ldots \ldots$

Manufactured Material $\ldots \ldots \ldots \ldots \ldots \ldots \ldots \ldots$

Laboratory Testing $\ldots \ldots \ldots \ldots \ldots \ldots \ldots \ldots \ldots \ldots$

Triaxial Testing $\ldots \ldots \ldots \ldots \ldots \ldots \ldots \ldots \ldots \ldots \ldots$

Pressuremeter Testing $\ldots \ldots \ldots \ldots \ldots \ldots \ldots \ldots \ldots \ldots$

III MANUFACTURED COLLAPSIBLE SOIL $\ldots \ldots \ldots \ldots \ldots \ldots$

Introduction $\ldots \ldots \ldots \ldots \ldots \ldots \ldots \ldots \ldots \ldots \ldots \ldots \ldots$

Objectives

Soil Requirements

Christmas Valley Diatomite 
Preliminary Collapse Test-Solid Form $\ldots \ldots \ldots \ldots \ldots \ldots 17$

Objective

Preliminary Test For Collapse

Specimen Preparation

Test Procedure

Test Results

Collapse Potential of Different Grain Sizes $\ldots \ldots \ldots \ldots \ldots 18$
Apparatus
Sample Preparation
Test Procedures
Test Results

Collapse Potential Repeatability .............. 21

Soil Manufacturing $\ldots \ldots \ldots \ldots \ldots \ldots \ldots \ldots \ldots \ldots \ldots$

Introduction

Gradation Alternative

Suitability Tests

Acquisition of Material

IV OEDOMETER TESTING $\ldots \ldots \ldots \ldots \ldots \ldots \ldots \ldots \ldots$

Objectives $\ldots \ldots \ldots \ldots \ldots \ldots \ldots \ldots \ldots \ldots \ldots \ldots \ldots \ldots$

Establishment of Upper/Lower Boundaries

Verification of the Lower Boundary

Influence of Moisture Content on Collapse Strain

Test Preparation $\ldots \ldots \ldots \ldots \ldots \ldots \ldots \ldots \ldots \ldots \ldots \ldots$

Material

Test Series 1 - Upper/Lower Compression Boundaries . . . . . 37

Test Procedures

Test Results

Test Series 2 - Single Oedometer Collapse Strain ...... 41

Test Procedures 
Test Results

Oedometer Test Series 3 - Collapse Strain vs.

Water Content ..................... 43

Test Procedures

Test Results

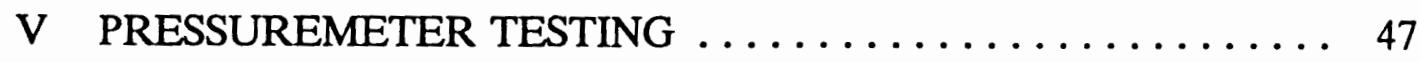

Objectives $\ldots \ldots \ldots \ldots \ldots \ldots \ldots \ldots \ldots \ldots \ldots \ldots \ldots$

Strength Characteristics

Apparatus . . . . . . . . . . . . . 47

Pressuremeter

Confinement Pressure Cell-Design Criteria

Testing Cell

Test Preparation $\ldots \ldots \ldots \ldots \ldots \ldots \ldots \ldots \ldots \ldots \ldots$

Material

Test Set-Up

Test Procedures

Data Reduction

Test Series 1 - Dry Soil/Strain Controlled ............ 54

Test Objectives

Test Procedures

Test Results

Test Series 2 - Dry/Strain Controlled ............ 58

Test Procedures

Test Results

Test Series 3 - Dry to Wet/Strain Controlled .......... 61

Test Objectives

Test Procedures

Test Resuits 
Test Series 4 - Dry to Wet/Pressure Controlled ........ 63

Test Objectives

Test Procedures

Test Results

Test Series 5 - Dry to Wet $\ldots \ldots \ldots \ldots \ldots \ldots \ldots \ldots 6$

Test Objectives

Test Procedures

Test Results

Test Series 6 - Saturated Pressure Controlled ......... 69

Test Objectives

Test Results

VI TRIAXIAL TESTING $\ldots \ldots \ldots \ldots \ldots \ldots \ldots \ldots \ldots \ldots$

Objectives $\ldots \ldots \ldots \ldots \ldots \ldots \ldots \ldots \ldots \ldots \ldots \ldots \ldots \ldots \ldots$

Stress States

Stress Paths

Testing Program

Apparatus and Equipment $\ldots \ldots \ldots \ldots \ldots \ldots \ldots \ldots$

Triaxial Assembly

Data Acquisition

Diameter Collar

Test Preparation $\ldots \ldots \ldots \ldots \ldots \ldots \ldots \ldots \ldots \ldots \ldots$

Material

Set Up

Data Reduction .................... 77

Reduction of Data From EDGGE

Stress Computation

Test Series $1-$ Dry Soil ................. 78

Series Procedure 
Series Results

Series 2 Tests - Saturated Soil $\ldots \ldots \ldots \ldots \ldots \ldots \ldots .62$

Series Procedure

Series Results

Series 3 Tests - Dry Then Saturated $\ldots \ldots \ldots \ldots \ldots \ldots .86$

Test Procedure

Series 3 Test Results

Creep Tests ...................... 90

Creep Test Procedure

Creep Test Results

Strain Controlled Test ................... 97

Procedures

Test Results

VII CONSTITUTIVE MODEL $\ldots \ldots \ldots \ldots \ldots \ldots \ldots \ldots \ldots$

Introduction $\ldots \ldots \ldots \ldots \ldots \ldots \ldots \ldots \ldots \ldots \ldots \ldots \ldots \ldots \ldots$

Model Parameters . . . . . . . . . . . . . . . . . 101

Elastic Strains

Yield Criteria

Failure Criterion

Plastic Potential

Resulting CVD Failure Model . . . . . . . . . . . 123

Plastic Work

Plastic Potential

Oedometer and Pressuremeter

VIII CONCLUSIONS AND RECOMMENDATIONS . . . . . . . 129

REFERENCES USED . . . . . . . . . . . . . . 135 


\section{LIST OF TABLES}

TABLE

PAGE

I Collapse Potential of the Various Grain Sizes and

Gradations of Diatomite $\ldots \ldots \ldots \ldots \ldots \ldots \ldots . \ldots \ldots$

II Summary of Pressuremeter Testing Results $\ldots \ldots \ldots \ldots \ldots$

III Principal Stresses and Stress Invariants for the Conventional

Triaxial Test Results on CVD at Failure .......... 103

IV Constitutive Parameter Values for CVD and Various Other

Frictional Materials $\ldots \ldots \ldots \ldots \ldots \ldots \ldots \ldots \ldots$ 


\section{LIST OF FIGURES}

FIGURE

PAGE

1. Location of Christmas Valley and geologic formation of area $\ldots \ldots, 15$

2. Diatomite quarry at Christmas Valley $\ldots \ldots \ldots \ldots \ldots \ldots \ldots$

3. Oil Dry Incorporated processing plant $\ldots \ldots \ldots \ldots \ldots \ldots \ldots$

4. Gradation of the manufactured soil with $10 \%$ fines $\ldots \ldots \ldots \ldots 20$

5. Collapse strain of material that consists of 100 percent fines $\ldots \ldots 22$

6. Collapse strain of material that has a uniform gradation with $\mathbf{1 0}$

percent fines $\ldots \ldots \ldots \ldots \ldots \ldots \ldots \ldots \ldots \ldots \ldots \ldots \ldots \ldots \ldots \ldots \ldots$

7. Collapse strain of material retained on the no. 7 sieve $\ldots \ldots \ldots 24$

8. Gradation of mechanically broken down diatomite $\ldots \ldots \ldots \ldots 26$

9. Collapse strain of material retained on the no. 20 sieve $\ldots \ldots \ldots 28$

10. Collapse strain of the material that is a 50/50 mixture of

diatomite retained on the no. 7 and no. 20 sieves $\ldots \ldots \ldots \ldots 29$

11. Gradation of Oil Dry Inc. commercial product, Kitty Diggins . . . . . 30

12. Gradation of diatomite as received from Oil Dry Inc. $\ldots \ldots \ldots 32$

13. Collapse strain of the material that was acquired from Oil Dry

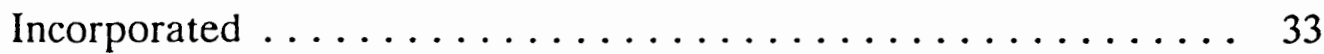

14. Upper and lower compression boundaries for the Double

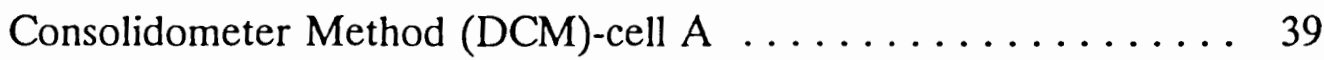


15. Upper and lower compression boundaries for the Double

Consolidometer Method (DCM)-cell B

16. Collapse upon wetting of 5.0 to $320.0 \mathrm{KPa}$ pressure for the Full

Collapse Window (FCW)

17. Superposition of the Full Collapse Window (FCW) upon the

Double Oedometer curve for cell A .............. 44

18. Superposition of the collapse curve of partial saturation over full

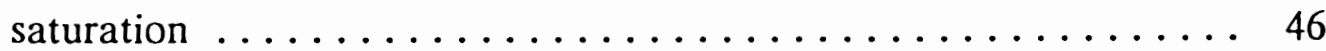

19. Pressuremeter probe with fabric wick $\ldots \ldots \ldots \ldots \ldots \ldots \ldots$

20. Equipment leads and water tube inserted under fabric wick assembly

21. Pressuremeter cell assembly $\ldots \ldots \ldots \ldots \ldots \ldots \ldots \ldots \ldots \ldots \ldots 2$

22. Pressure regulator and leads for the pressuremeter cell $\ldots \ldots \ldots .52$

23. Pressure verses strain curves for Test Series 1, strain controlled

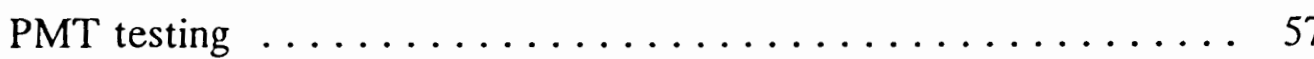

24. Pressure verses radial strain for the PMT series 2 tests $\ldots \ldots \ldots . .59$

25. Comparison of pressure/strain curves for the Series 1 and 2 tests for the 5.0 and 10.0 psi surface pressure $\ldots \ldots \ldots \ldots \ldots 60$

26. Pressure vs. strain curves for Test series 3 tests . . . . . . . . . 62

27. Pressure vs. strain for Series 4 test $\ldots \ldots \ldots \ldots \ldots \ldots \ldots \ldots \ldots$ 
28. Comparison of results of strain and pressure controlled tests for 10.0 psi-dry soil $\ldots \ldots \ldots \ldots \ldots \ldots \ldots \ldots \ldots \ldots \ldots$

29. Pressure vs. strain curves for the pressure controlled dry/sat test with 10.0 and 15.0 psi $\ldots \ldots \ldots \ldots \ldots \ldots \ldots \ldots \ldots \ldots \ldots$

30. Pressure vs. strain curves for saturated pressure controlled test with 10.0 and 15.0 psi $\ldots \ldots \ldots \ldots \ldots \ldots \ldots \ldots \ldots \ldots \ldots \ldots \ldots$

31. Triaxial assembly with LVDT, load cell, and steel loading rod ..... 74

32. Close-up of triaxial assembly $\ldots \ldots \ldots \ldots \ldots \ldots \ldots \ldots \ldots \ldots$

33. Deviator stress verses vertical strain for the dry soil at $5.0,10.0$ and 15.0 psi confining pressure $\ldots \ldots \ldots \ldots \ldots \ldots \ldots \ldots$

34. Failure surfaces for Mohr Circle with 5, 10 and 15 psi confining stress and $0.33 \%-2.3 \%$ strain $\ldots \ldots \ldots \ldots \ldots \ldots \ldots \ldots \ldots$

35. Triax testing on dry CVD at $5.0,10.0$ and 15.0 confining stress $\ldots \ldots 83$

36. Comparison of stress verses strain for the tests conducted on the dry CVD at 10.0 psi confining stress $\ldots \ldots \ldots \ldots \ldots \ldots \ldots$

37. Comparison of stress verses strain for the tests conducted on dry CVD at 15.0 psi confining stress $\ldots \ldots \ldots \ldots \ldots \ldots \ldots \ldots \ldots$

38. Deviator stress verses vertical strain for the saturated soil at 5.0, 10.0 and 15.0 psi confining pressures $\ldots \ldots \ldots \ldots \ldots \ldots \ldots .87$

39. Failure surfaces for Mohr Circle with 5, 10 and 15 psi confining stress and $.33 \%-2.3 \%$ strain on saturated material $\ldots \ldots \ldots \ldots 88$ 
40. Triaxial testing on saturated CVD at 5.0, 10.0, and $15.0 \mathrm{psi}$ confining stress

41. Comparison of results from the Dry, Saturated, and Dry/Saturated tests conducted on CVD at 5.0 psi confining stress .......... 91

42. Comparison of results for the Dry, Saturated, and Dry/Saturated tests conducted on CVD at 10.0 psi confining stress . . . . . . . 92

43. Comparison of results for the Dry, Saturated, and Dry/Saturated tests conducted on CVD at 15.0 psi confining stress . . . . . . . 93

44. Q-p space stress path for 2.33 percent strain ............... 94

45. Q-p space stress path for 4.0 percent strain $\ldots \ldots \ldots \ldots \ldots \ldots$

46. Q-p space stress path for 6.67 percent strain . . . . . . . . . . 96

47. Vertical stress verses strain for dry to saturated, strain controlled triaxial test with 10.0 psi confining stress $\ldots \ldots \ldots \ldots$. . . . . . 99

48. Theoretical isotropic compression curve for the dry material . . . . . 104

49. Theoretical isotropic compression curve for the saturated material . . 105

50. Parameters Lamda ( $\lambda$ ) and (M) for the Elastic Function for the dry CVD .......................... 107

51. Parameters Lamda ( $\lambda$ ) and (M) for the Elastic Function for the saturated CVD 108

52. Parameters $(C)$ and $(p)$ for the Hardening Function for the dry CVD 
53. Parameters (C) and (p) for the Hardening Function for the saturated CVD $\ldots \ldots \ldots \ldots \ldots \ldots \ldots \ldots \ldots \ldots \ldots \ldots \ldots \ldots$

54. Parameter alpha $(\alpha)$ for the dry CVD $\ldots \ldots \ldots \ldots \ldots \ldots \ldots \ldots$

55. Parameter alpha $(\alpha)$ for the saturated CVD ........... 117

56. Parameters $(\eta)$ and $(m)$ for the Failure Criterion for the dry CVD $\ldots 119$

57. Parameters $(\eta)$ and $(m)$ for the Failure Criterion for the saturated

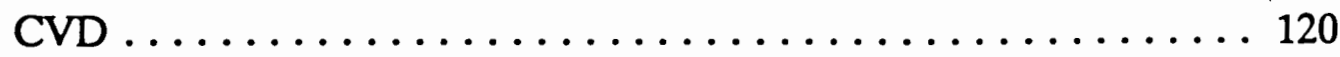

58. Parameters $\left(\psi_{2}\right)$ and $(\mu)$ for the Plastic Potential for the dry CVD . . 124

59. Parameters $\left(\phi_{2}\right)$ and $(\mu)$ for the Plastic Potential for the saturated

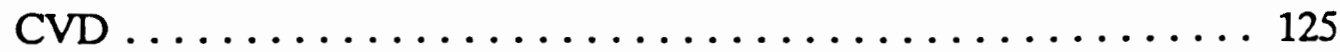

60. Plastic Work Contours for the dry and saturated CVD ....... 126

61. Plastic Potential contours for dry and saturated CVD . . . . . . 127 


\section{CHAPTER I}

\section{INTRODUCTION}

\section{COLLAPSIBLE SOILS}

Collapsible soils are a metastable soil that have strength at the natural water content, but will experience large decreases in volume and surface settlement upon wetting.

The structure of a collapsible soil is similar to concrete in that the soil consists of a granular material such as gravel, sand, or in the case of Sand $\mathrm{H}$ Debris Basin, cobbles and boulders, that is surrounded and held together by soils that have the same effect as cement. Soils such as flocculated clay or chemical bonds such as salt fall into the category of a "soil cement". In a dry state, the bonds that hold the cement together have much higher shear strengths than the applied stresses. Upon wetting, the bonds start dissolving and the strength is reduced. Applied stress becomes greater than the shear capacity of the bonds causing failure in the material which is manifested by a condensing of the soil matrix, or collapse of the soil.

Another cause of soil collapse is that some soils have a composition of minerals and salts. Their structure is not like the concrete matrix, but is homogeneous. In the dry state, these materials are strong, but upon the addition 
of water, the soil particle softens and intergranular crushing takes place which densifies the soil, with sudden settlement as the result.

Soils that experience collapse are typically found in the arid regions of the Western and Southwestern United States in alluvial fans, and in loess or wind blown deposits. Due to the method of deposition, and being in areas of little rainfall, these soils remain unconsolidated and only partially saturated. They are characterized by low densities.

\section{SOIL CONSERVATION SERVICE DEBRIS FAN SOILS}

The threat of flash floods and the debris that accompanies the water are common in areas of little rainfall. The United States Department of Agriculture, Soil Conservation Service has many debris basin flood control dams built on alluvial fans which are subject to collapse. The structures range in size from 20.0 to 50.0 feet (6.1 to 15.2 meters) in height and from several thousand feet to as much as five miles in length ( $1 \mathrm{~km}$ to $8.1 \mathrm{~km})$.

Some of the debris dams have exhibited longitudinal and transverse cracking. Additionally, there is evidence to suggest the presence of hidden transverse cracks. At some sites, sinkholes adjacent to the structure have also appeared. It is thought that there may be as many as fifty debris dams affected by collapsible foundation soils (Talbot, 1985). 


\section{INVESTIGATION AND SOLUTIONS TO CRACKED DAMS}

At the present time, in order to identify the existence of a collapsible soil or to determine the degree of collapse, SCS uses oedometer testing to determine collapse potential.

To design for, or investigate the effect of collapse on a structure the SCS uses a finite element program called FEADAM (Finite Element Analysis of Dams). This program was written by Jim Duncan and analyzes settlement in dams during and after construction. In the collapse of soil, along with the settlement is a change in the soil structure and properties. The soil parameters remain constant in FEADAM which does not model collapse; therefore does not give accurate results.

Based on the above history, the study in this report was designed to provide the information necessary to gain an understanding of collapse behavior. It was hypothesized that information obtained through laboratory testing could be used to derive a constitutive model. This tool then could be used in the field to more accurately predict soil responses.

\section{LABORATORY TESTING}

The laboratory testing program consisted of Oedometer, Triaxial and Pressuremeter tests conducted on a generic "collapsible" soil that was manufactured specifically for this research. 
The oedometer testing was used primarily as a means to observe collapse and determine collapse potential. The work of Lutenegger (Lutenegger, 1989) Houston and Houston (Houston and Houston, 1988), and SCS laboratory procedures were the sources for the methods and testing philosophies.

The triaxial testing was used to gain an understanding on how the strength of the soil changes with stress and moisture state. The results from this testing were also used to determine the elastic and plastic parameters to be used in a constitutive model. The stress paths from all three types of testing were then analyzed in order to gain an understanding of how the stress changes in relation to failure.

Pressuremeter testing was used as an aid in developing field testing procedures to be used for insitu testing. The strength before and after wetting were also sought to better understand the collapse phenomena. 


\section{CHAPTER II}

\section{BACKGROUND}

\section{MANUFACTURED MATERIAL}

Brigham Young University has had some success with manufacturing collapsible soils (Rollins, 1990). Their attempts began in 1981 under the direction of Professor Ralph L. Rollins. The objective of manufacturing the laboratory soil was to better understand how the formation and material properties affect the potential of a soil to collapse.

The process used to create the soil was to mix a slurry of clay and sand, with an amount of water that would duplicate natural void ratios. The mixture was blended, poured into a small dish with drainage holes, and when solid enough to hold its form, was allowed to air dry. The collapsible soil made in this fashion had void ratios of 0.9 to 1.1 for the high natural void ratios and 0.6 to 0.8 for low natural void ratios. The corresponding collapse strains ranged from 8.0 to 19.0 percent for the soils with the high void ratios and no collapse for the soil with low void ratios.

Other studies investigated the influence of plasticity, clay content, and water content on collapse potential. Results showed that there appeared to be optimum amounts of each of these components in collapsible soils. There needed 
to be enough clay to make the granular material bond. But, too much clay would interfere with collapse. In addition, if the clay was not very plastic more was required to hold the soil mixture together, and the collapse potential would decrease. There needed to be enough water to moisten and mix the components together into a slurry. But, too much would allow the granular particles to settle out.

Even though these experimental soils may have collapsed, their structures did not truly represent what was found in the field. Naturally deposited collapsible soils have numerous pinholes and fissures. In order to duplicate the depositional environment and create pinholes in the soil, changes in the process and slurry mixture were made. Instead of allowing the slurry simply to drain and dry out, it was poured into a sedimentation tube. After the settling out of solids, any water on the surface was siphoned off and the sample allowed to dry. This procedure was used for two variations in the slurry. One mixture contained salt to create a flocculated structure; the other contained air entraining agents which formed air bubbles. Another procedure used to create pinholes was to keep rinsing the soil with fresh water allowing it to dry between rinses.

Results of these tests showed that even though the addition of salts or air entraining agents produced soils with structures similar to those found in natural deposits, the collapse strain upon wetting was inconsequential. The samples that were put through the drying and wetting cycles yielded the same results. 
In the latest attempt at creating a laboratory specimen, a different approach was used. It was realized that the previous procedures were more similar to deposition of soil in a lake bed. The new method to form a sample was to use a sand collar which allowed drainage in all directions eliminating sedimentation. The collar was formed in a gallon can and was moist enough to support a circular vertical face in the center. The slurry was poured into the "form" and when enough water drained so that the soil column was stable, it was oven dried. This process produced a soil with the required structure and acceptable collapse strain in a matter of a few days.

\section{LABORATORY TESTING}

Up to the present, the most often used testing method to study collapsible soils is the oedometer. The testing is used mostly as a tool for prediction of collapse settlement, or better known as collapse potential.

One of the first methods developed was called the Double Oedometer test. In this test, a void ratio vs. log pressure curve is developed for a soil at its natural water content and while in a saturated state. The collapse potential is defined as the strain resulting from the height of the sample at the two different void ratios for a given stress level (Jennings and Knight, 1956, 1957).

Sandra L. Houston and William N. Houston (1988) modified the Jennings and Knight test by developing a test method that would accurately predict the collapse that might actually occur in the field. To conduct this study, a footing 
was set up in the field and was loaded by placing concrete cylinders on a steel plate on top of the footing. With the footing in place, water was added and the resulting settlement monitored and was used as a comparison to the laboratory tests.

Using a modified version of Jennings and Knight test, representative samples from the soil profile of the footing zone were trimmed and placed into the consolidometer rings. They were seated at $5.0 \mathrm{kPa}$ and the dial gauge zeroed. It was assumed that any compression due to this stress level was from softening and not collapse. Once seated, the stress was increased in increments up to an anticipated infield stress level with dial gauge readings taken every half hour until compression was less then 1.0 percent. At that time, the sample was inundated so that collapse would be initiated. When the settlement appeared to cease, the stress level on the sample was increased in order to establish the compression curve of the saturated sample. To predict collapse at any stress level, a line was extended from the point of collapse back to the initial starting point of the curve. Collapse potential as defined by this method is the difference between the strain of the two curves.

Alan J. Lutenegger (1988) conducted a study using oedometer testing to establish a method that could be used for identifying collapse potential to be adopted by American Society of Testing and Materials (ASTM). He pointed out that most of the criteria for identifying collapsible soils was based on correlation of water content, density of combination to the two. He felt that these parameters 
could only give indications of collapse, were site specific and based on disturbed samples. The best method for identifying collapse was a direct measurement using the oedometer.

Lutenegger's study two methods of oedometer testing were investigated. The first one developed by Abelev (1948) is referred to as the Single Oedometer test method. In this method, the stress level on the sample was increased to a desired level and the sample flooded. The collapse potential is the change in strain upon wetting. The second method investigated was the Double Oedometer as developed by Jennings and Knight (1957).

The result of Lutenegger's study was to use the single oedometer method as the standard. He felt that there were two different mechanisms between the two tests. The double oedometer test mainly reflected how the compression in a dry and saturated curve behaved. In the single oedometer test the change in void ratio upon wetting was descriptive of the collapse mechanism.

The test method that resulted from this study involved preparing a sample as prescribed by ASTM Test Method for One-Dimensional Consolidation Properties of Soils (D2435). Once set up, the stress level would be increased to $300.0 \mathrm{kPa}$ in increments. The addition of each load increment followed dial gauge readings less then $0.05 \mathrm{~mm} / \mathrm{hr}$. Once the maximum stress level and resulting compression were complete the sample would be inundated and dial gauge readings taken. Collapse potential would by defined by equation 2.1 . 


$$
I=\frac{(\text { del e })}{(1+e i)} \times 100 \%
$$

In this equation, (del $e)$ is the change in void ratio upon wetting and $\left(e_{i}\right)$ is the void ratio prior to wetting.

Finally using the collapse potential, a guideline to it's severity was given. The degrees of collapse susceptibility were Slight for $I=2$, Moderate for $I=6$, and Severe for $I=10$.

\section{TRIAXIAL TESTING}

Evert C. Lawton (1991) did tests on a slightly expansive, clayey sand using standard triaxial equipment. The objective in the testing was to see how anisotropic stresses of a general stress state effected the volumetric collapse strains.

The tests conducted were similar to the Double Oedometer test in that one test sample was at a dry state and another was saturated before loading. The results of the test were in terms of axial or radial strain verses principal stress ratios, sigma axial over sigma radial, and in strains verses mean normal stress.

Lawton concluded that even though the amount of strain depends more on normal mean stress then the stress ratio, axial strain increases and radial strain decreases with an increase in the stress ratio. He also superimposed the results of oedometer testing over the triaxial results and found that the coefficient of lateral earth pressure varies from an active condition at small stresses and positive 
strains, and becomes passive at higher stresses and negative or collapse strains. With these results, a better understanding of the effect of multidimensional stresses on compacted fills could be made.

Extensive use of triaxial testing on stable soils has been done by Lade (1977, 1988, 1990). Using the results from conventional triaxial testing on frictional soils and employing a elasto-plastic stress-strain relationship, he developed constitutive models to describe yielding, and plastic work. Evaluation of the models shows that the functions describe three dimensional surfaces which are a series of contours.

\section{PRESSUREMETER TESTING}

At the present, the majority of pressuremeter testing on collapsible soils has been done under the direction of Trevor Smith of Portland State University. The testing has involved testing of soils in collapse deposits as well as local testing used to develop equipment.

The procedures used for the field tests involve a series of tests that examine the soil strength at its natural moisture content and in a saturated state. Tests conducted on the dry soil are the standard pressuremeter test, ASTM 4719.87, which includes expanding the cavity of a bore hole with a probe. The fluid pressure required to expand the probe is compared to volume expansion. Results reflect the soil resistance, or stiffness, as well as a limit pressure (strength). 
For the tests conducted on the saturated soil, the procedure is the same as for the dry test except once the probe is in place, water is poured into the hole. The test proceeds as in the dry test. 


\section{CHAPTER III}

\section{MANUFACTURED COLLAPSIBLE SOIL}

\section{INTRODUCTION}

\section{Objectives}

In order to do laboratory testing on collapsible soils, field samples would have to be taken from wherever a deposit of collapsible soil existed. In addition, the means to obtain a sample would be the Shelby tube which would most likely create sample disturbance that would make repeatable test results impossible (Day, 1990). Therefore the decision was made to manufacture a soil which would behave as a collapsing soil.

\section{Soil Requirements}

The requirements for the laboratory soil was that it should collapse, and that the vertical strains upon collapse be similar in magnitude to that in the field, about $10 \%$. The tests to be conducted using the material were: the Pressuremeter, Oedometer and Triaxial tests. In order to do all of these tests enough material for numerous tests, as well as those using large amounts of material $(7.5 \mathrm{cft})$, was needed. This required the soil to be made with as little manpower and time as possible. The components needed to be readily available, 
and the materials and procedures used in making the soil need to give repeatable results.

\section{Christmas Valley Diatomite}

A Central-Eastern Oregon quarry was located containing a diatomite deposit in Christmas Valley, Oregon. Its location is shown in Figure 1 (Oregon Department of Geology and Mineral Industries, 1982). Diatomite is usually silica rich, except in this formation the diatomite is contaminated with calcareous materials. The quarry is owned and operated by Oil Dry Incorporated who mine the diatomite in its natural state, as a solid material, with a density of $47.5 \mathrm{pcf}$ ( $0.76 \mathrm{gm} / \mathrm{cc})$, a natural water content of 7.22 percent and a specific gravity of 2.2 . The diatomite is then taken to the Oil Dry plant where it is ground up, baked in kilns and used for oil absorbent, or, with deodorant added, used for kitty litter. Figure 2 shows Oil Dry's quarry pit and Figure 3 shows the processing plant.

With an ample source of soil located, the requirement of availability was met. The remaining requirements of collapsibility, repeatability and the ability to manufacture large volumes were still to be met. A series of tests utilizing the oedometer were conducted to verify the suitability of the diatomite. 


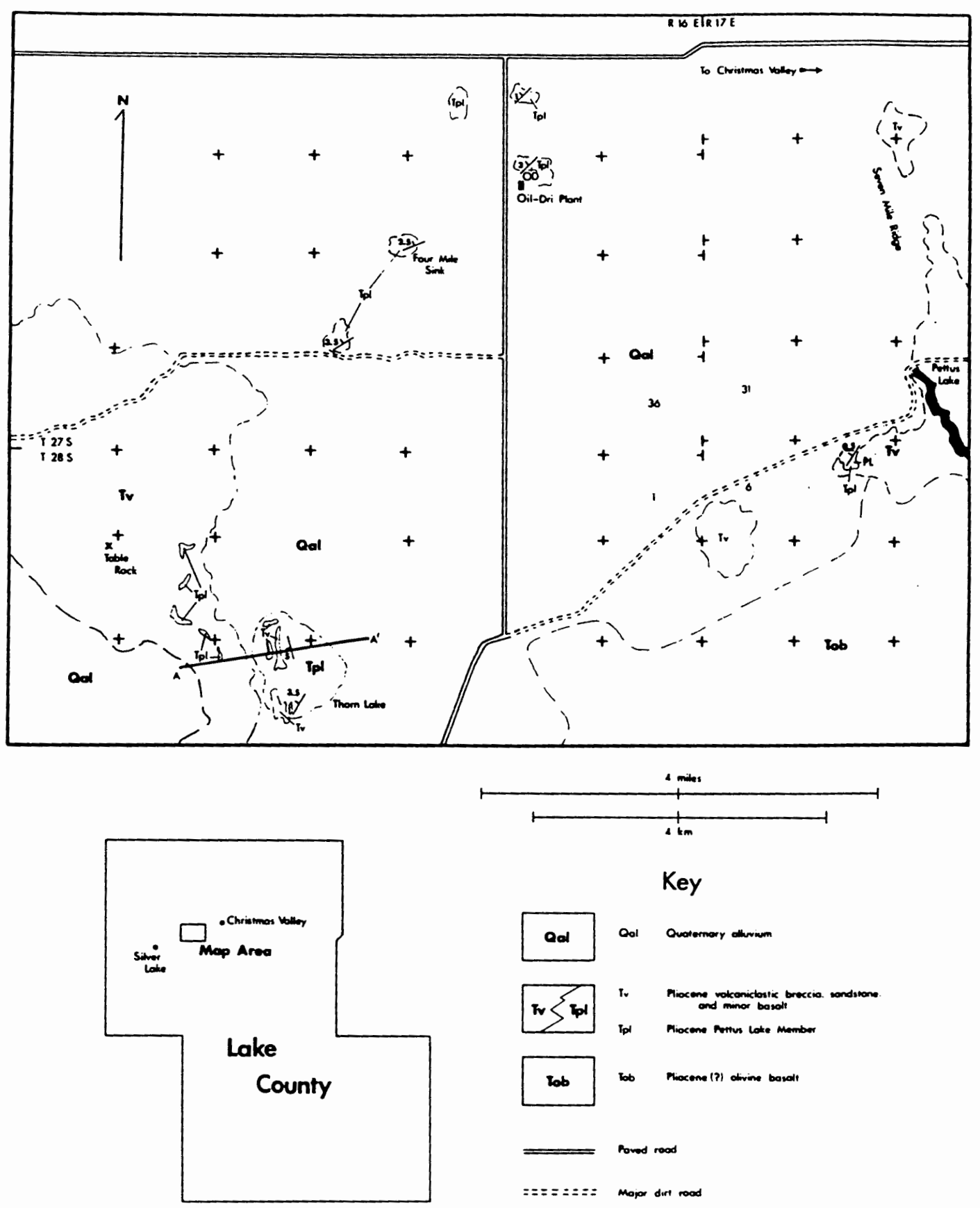

Figure 1. Geologic sketch map of part of southwestern Fort Rock basin. Units TV and Tpl are part of Fort Rock Formation of Hampton (1964). Unit Tob is partial equivalent of Picture Rock Basalt. Unit Tob contact modified after Walker and others (I967). "PL" indicates location of type section of Petrus Lake Member, "OD" indicates location of supplementary section. Two attitudes within Thorn Lake blowout depression were measured on volcaniclastic breccia beds (unit $T v$ ) and are offset slightly to the east for the purpose of clarity. Letters " $A$ " and " $A$ " indicate end points of crass-section presented in Figure 8 . Crasses indicate corners of .jections. Map centered on $44^{\circ} 10^{\circ} \mathrm{N} ., 121^{\circ} 48^{\prime} \mathrm{W}$.

Figure 1. Location of Christmas Valley and geologic formation of area. 


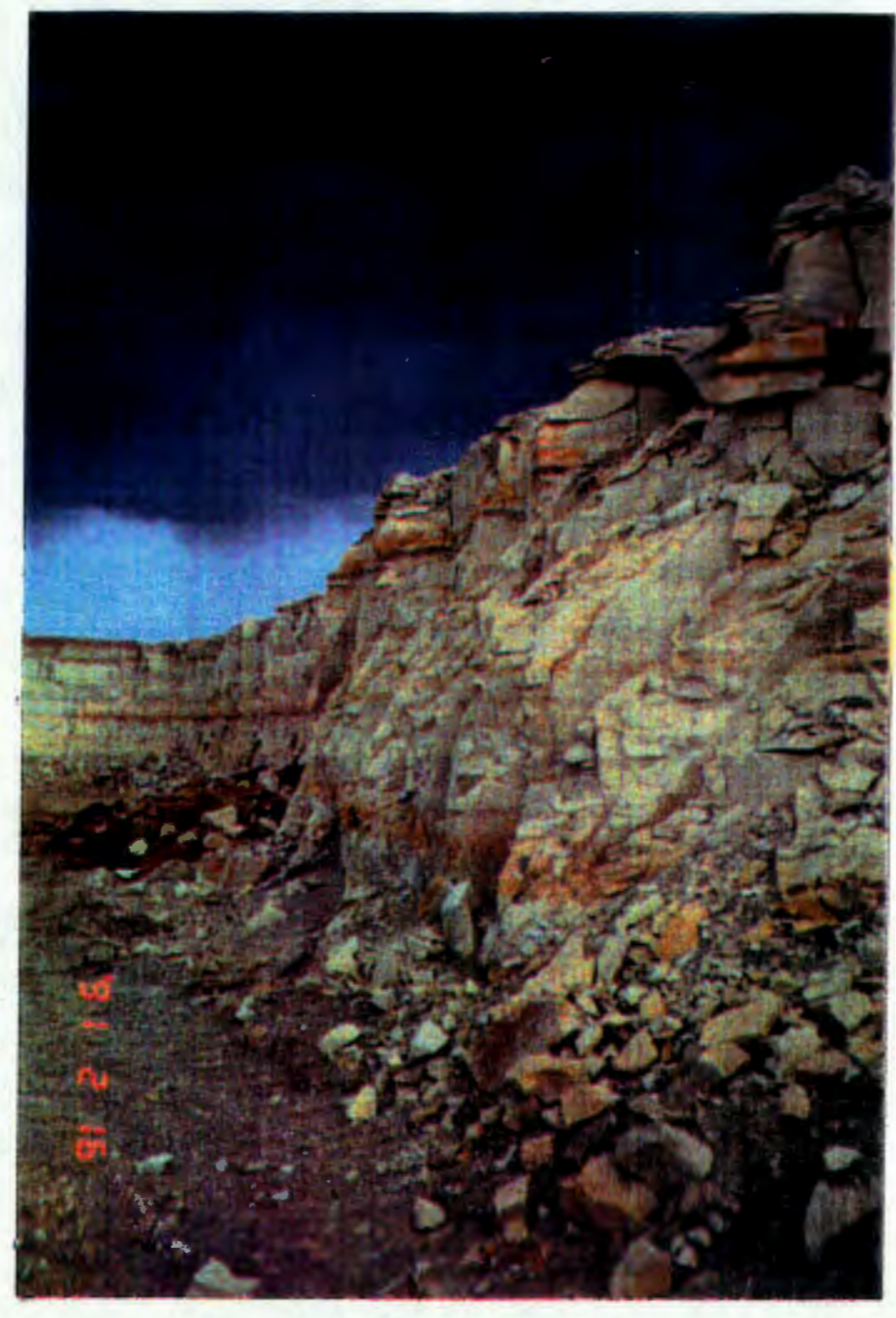

Figure 2. Diatomite quarry at Christmas valley.

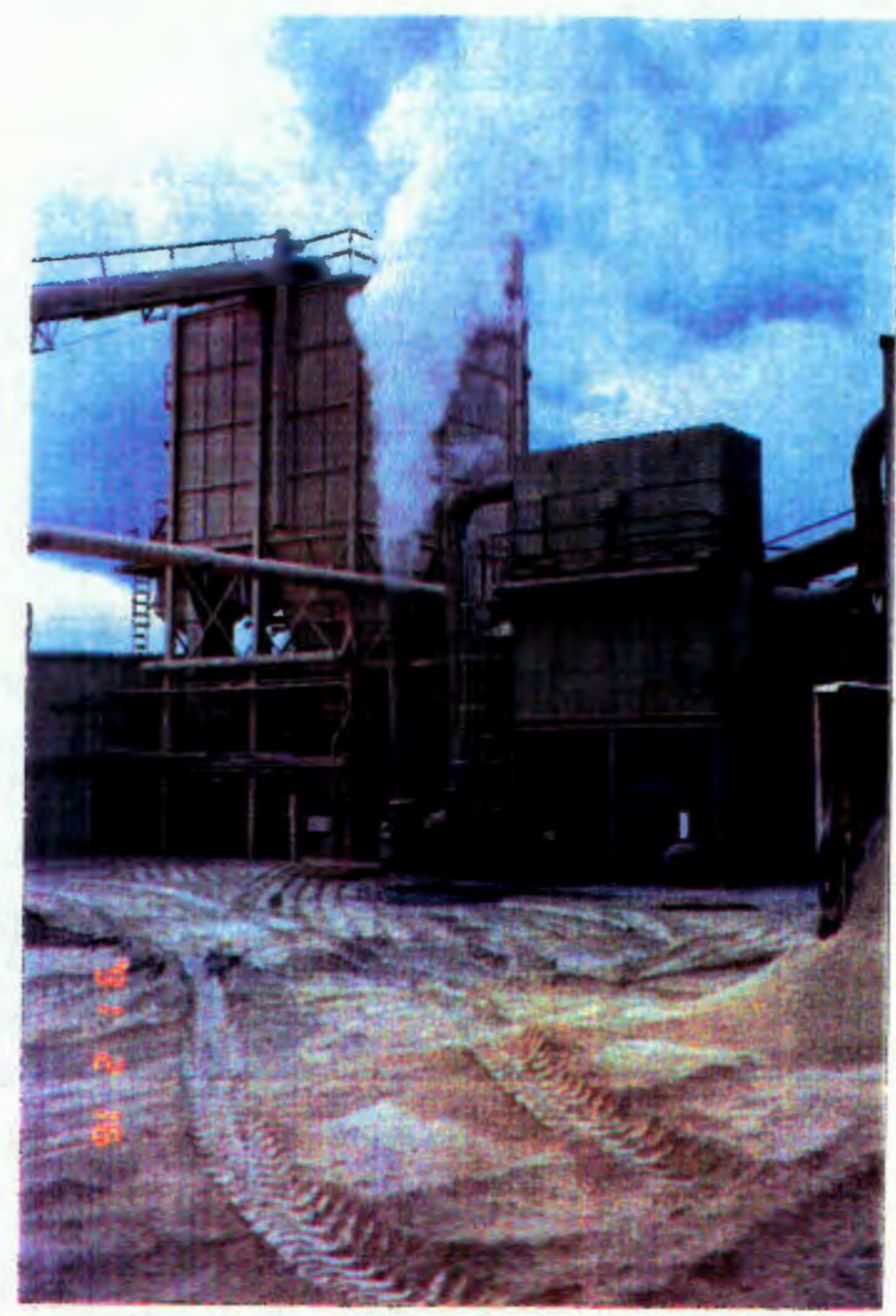

Figure 3. Oil Dry Incorporated processing plant. 


\section{PRELIMINARY COLLAPSE TEST-SOLID FORM}

\section{Objective}

The initial test conducted on the Christmas Valley diatomite was to verify that it would experience collapse upon wetting. In order to expedite this phase of testing, a sample made of the solid diatomite was used.

\section{Preliminary Test For Collapse}

For this test and all subsequent oedometer tests, the sample size used was 1 inch $(2.54 \mathrm{~cm})$ high and 2.5 inches $(6.35 \mathrm{~cm})$ in diameter. The apparatus used was a Soiltest C-252 floating ring consolidometer with a soiltest multi-bay frame (C-240). Bay A of the frame has a 40:1 load ratio, and bay B a 10:1 ratio.

\section{Specimen Preparation}

The diatomite proved to be a brittle material and was prepared by cutting it to fit the dimensions of the consolidometer ring. This was accomplished by using a drill with a 2.625 inch $(6.67 \mathrm{~cm})$ diameter plug attachment. A plug made from the diatomite was then fitted to the ring by using a sanding screen to remove excess material, after which it was placed in the ring.

\section{Test Procedure}

With the sample and apparatus set up, the dial gauge was zeroed and the stress level on the sample was brought up in a single increment to 3.13 TSF (300.0 $\mathrm{kPa}$ ) which would be equivalent to an overburden of $63.0 \mathrm{ft}$ (19.1 meters) using an 
assumed unit weight of $100.0 \mathrm{TSF}(15.72 \mathrm{kPa})$. Dial gauge readings were taken to record any compression of the sample at it's natural water content. The sample being a solid material experienced no significant compression. Water was then added through the bottom intake and was continually added until water appeared through the top porous stone. All the while, dial gauge readings were recorded as the collapse occurred due to wetting.

\section{Test Results}

The results of the test show that this material did experience collapse upon wetting, with the amount of vertical strain being $2 \%$. In it's solid plug form, the material had a low potential to collapse, and was quite strong. Clearly, the material bonds must be mechanically broken to increase the vertical strain to the desired $10 \%$.

\section{COLLAPSE POTENTIAL OF DIFFERENT GRAIN SIZES}

\section{Apparatus}

The next stage in the material investigation was to use different ground down grain sizes and gradations to achieve a more significant amount of collapse. In order to do this, the solid material needed to be broken down, the individual grain sizes separated and desired gradations weighed and mixed.

The apparatus \& equipment used to accomplish this were hammers, chisels and rollers to break the material down, and sieves to separate it. The sieves used were U.S.A. Standard sieves No. 4, 7, 20, 40, 200 and pan. The opening sizes of 
each sieve was 0.187 in $(4.75 \mathrm{~mm}), 0.111$ in $(2.8 \mathrm{~mm}), 0.0331$ in $(0.850 \mathrm{~mm})$, 0.0167 in $(0.425 \mathrm{~mm}), 0.0029$ in $(0.075 \mathrm{~mm})$ and no openings, respectively. A Soiltest Portable Sieve Shaker, model no. RX24 was used to shake the soil from the sieves.

\section{$\underline{\text { Sample Preparation }}$}

The first sample was formed entirely of fines passing the no. 200 sieve. 37.0 grams of fines were weighed and placed in the consolidometer ring in lifts with each lift being compacted with a soft, blunt instrument. Other grain sizes and gradations were also explored. One was a uniformly graded sample weighing 41.7 grams with 10\% fines (Figure 4), and the other sample weighing 34.2 grams, consisted entirely of material retained on the number 7 sieve. The densities for the three samples were $28.7,32.5$, and $26.8 \mathrm{pcf}(0.46,0.52$ and $0.43 \mathrm{~g} / \mathrm{cc})$, respectively.

\section{Test Procedures}

For this series of tests, a maximum stress level of $1.0 \mathrm{TSF}(100 \mathrm{kPa})$ was used. This would represent a more realistic overburden depth of $20.0 \mathrm{ft}$ (6 meters). The standard used to monitor dial gauge readings was after the addition of any stress increment, or when water was added to the sample, the dial gauge dial readings would be taken at $0.25,1.0,3.0,6.0,10.0,15.0,30.0,60.0$ minutes or until movement was less then $0.00003 \mathrm{in} / \mathrm{min}(0.05 \mathrm{~mm} / \mathrm{hr})$. Each sample would be seated at 0.33 TSF ( $31.5 \mathrm{kPa}$ ) with the next stress increment being $0.66 \mathrm{TSF}$ 


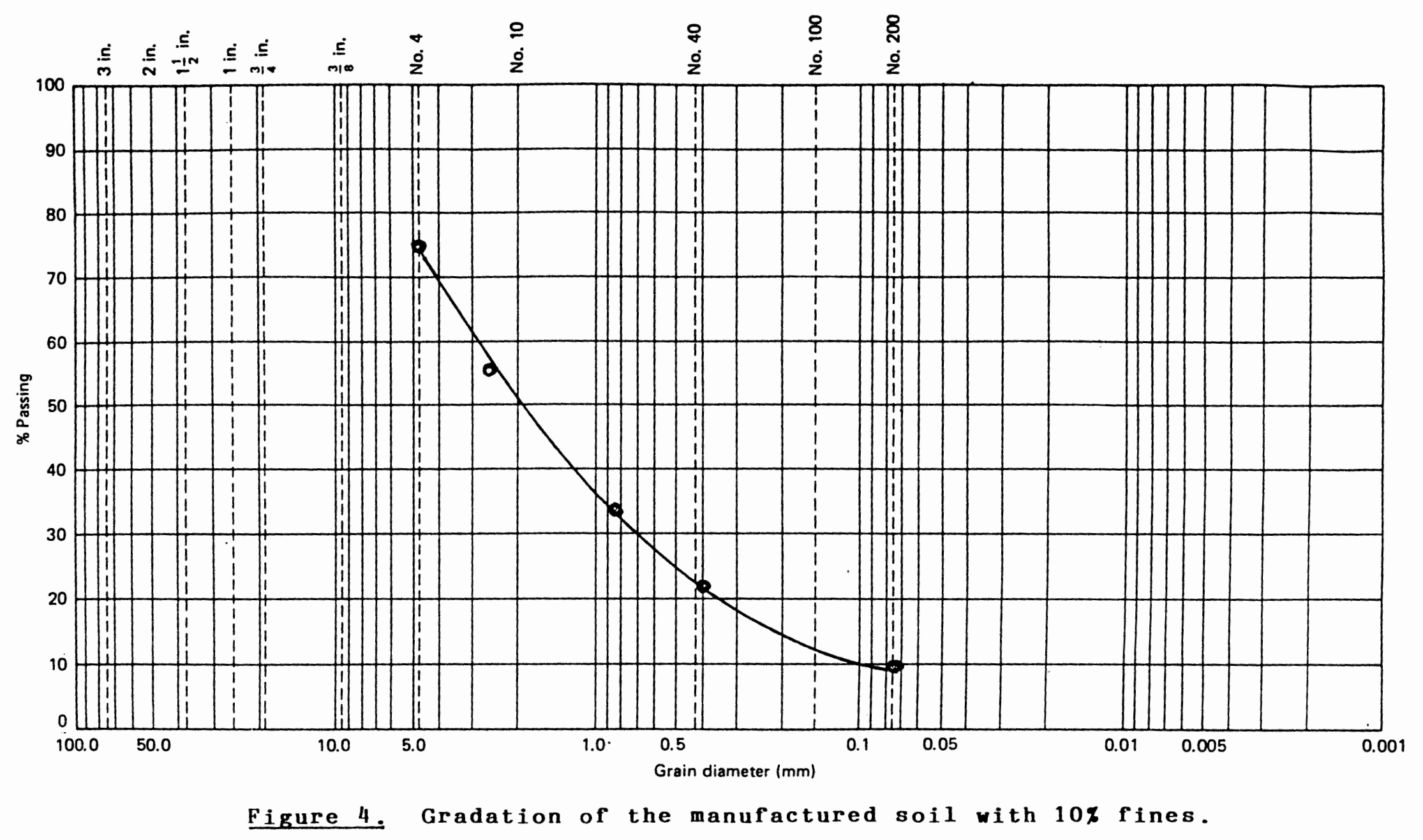


$(63.0 \mathrm{kPa})$, bringing the stress level up to the maximum amount. The sample was then inundated by adding water under the bottom porous stone until the top porous stone and gutter was saturated. Dial gauge readings were taken as specified. The sample was left for twenty four hours with a final reading taken to observe creep in the material.

\section{Test Results}

To compute the collapse strain upon wetting, the compressive vertical strain vs. pressure $(\mathrm{kPa})$ was plotted for each sample. The collapse strain is the difference between the strain the sample experienced due to dry elastic compression and the strain of the material upon addition of water. As can be seen in Figures 5 through 7, the results of these tests indicate the sample made of 100 percent fines showed $6.16 \%$ strain, the uniformly graded sample with $10 \%$ fines had $4.50 \%$ strain and the sample made with the material retained on the no. 7 sieve gave $8.00 \%$ strain. The amount of creep proved to be insignificant.

Thus, the samples made from the fines and grain sizes retained on the no. 7 sieve seemed likely candidates for the laboratory soil. Tests were conducted to confirm if the results could be repeated.

\section{COLLAPSE POTENTIAL REPEATABILITY}

The tests were conducted in the same way as before. The results showed that the collapse for the fines showed repeatability with $2-3 \%$ collapse strain and the collapse for the larger grain sample varying from 8-13\%. Even though the 


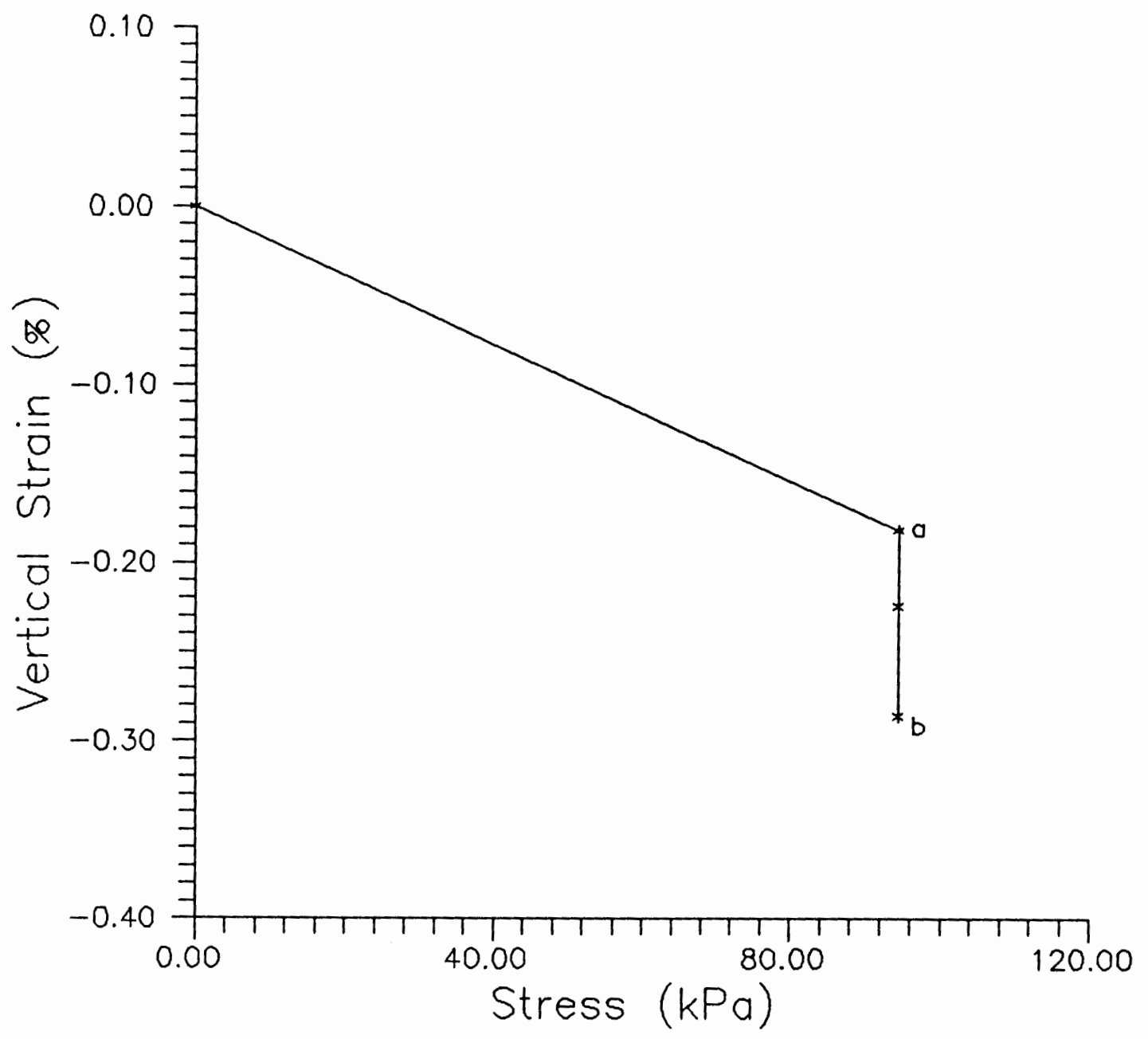

Eigure 5. Collapse strain of material that consists of 100 percent fines. At point (a) water is added. Point (b) is the amount of collapse induced strain. For this material, the strain is 6.16 percent. 


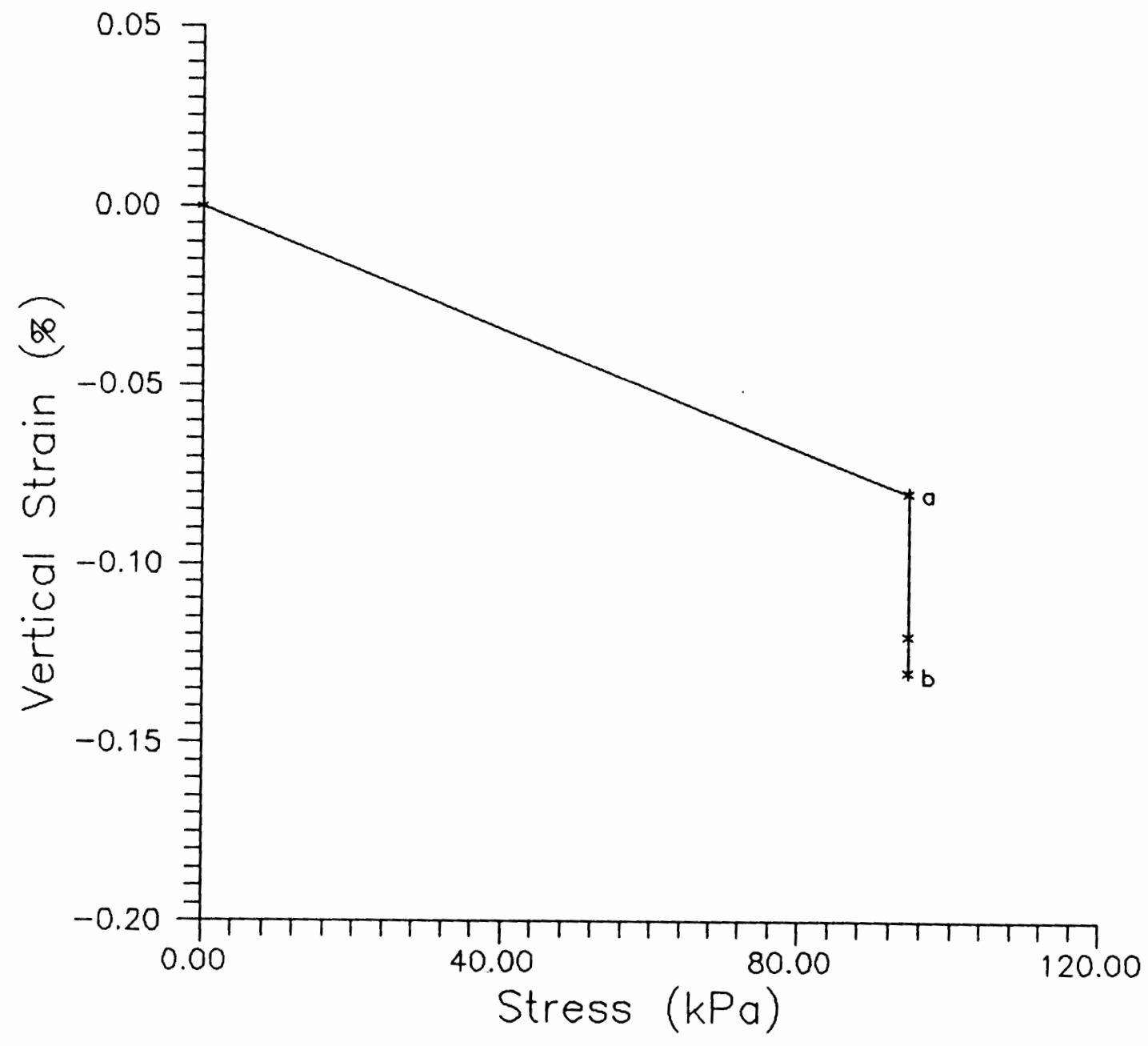

Eiqure 6 . Collapse strain of material that has a uniform gradation with 10 percent fines. At point (a) water is added. Point (b) is the amount of collapse induced strain, of $4.5 \%$ 


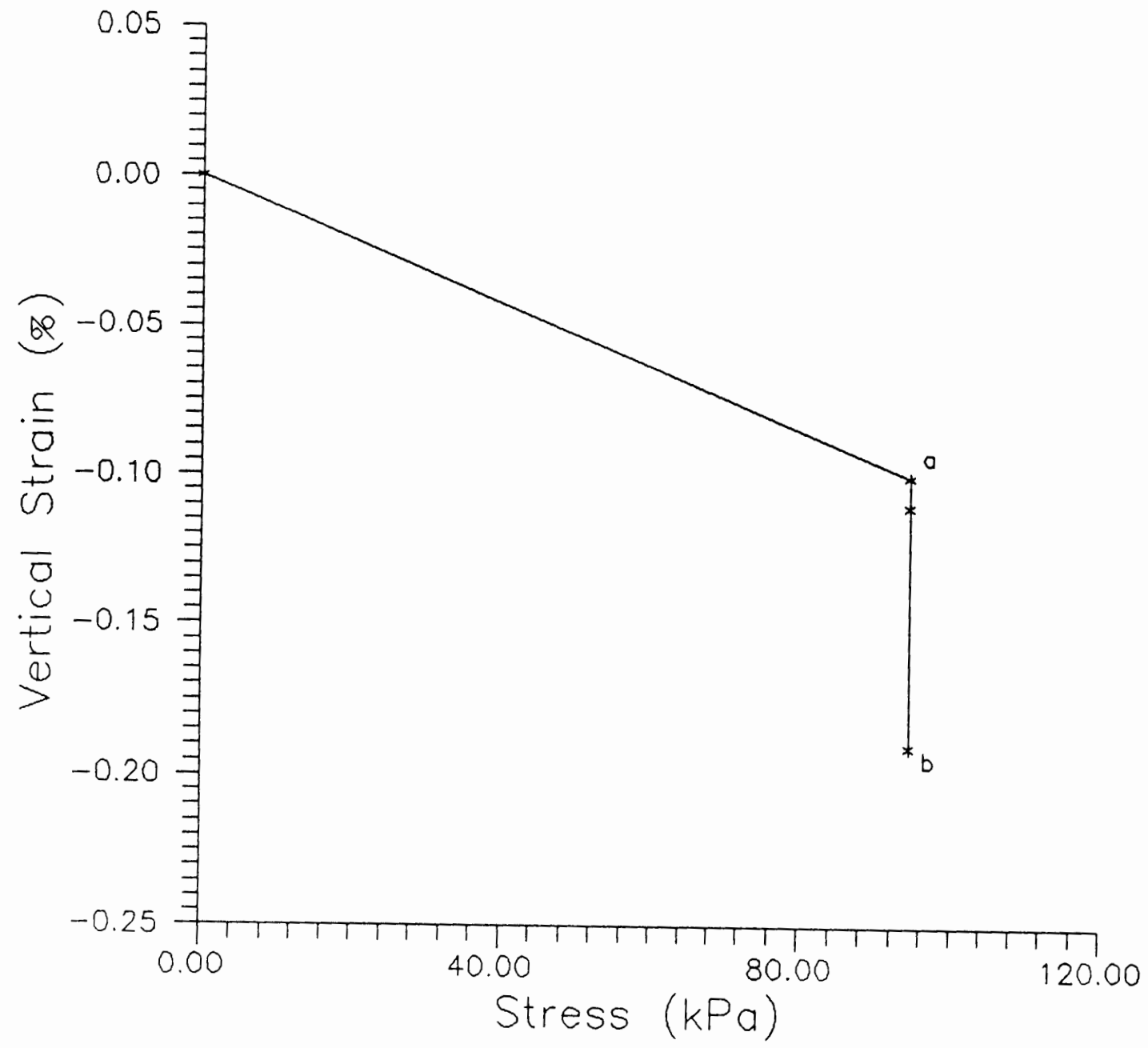

Eigure 2. Callapse strain of material retained on the no. 7 sieve. At point (a) water added. Point (b) is the extent of collapse strain. For this material the strain is $8.0 \%$. 
range of collapse varied more for the larger grained material, the magnitudes of strain reflected the values of strain encountered in the field and was repeatable to an acceptable degree. Using this particular grain size for a laboratory soil would meet most of the requirements.

The next problem to solve was the ability to manufacture large quantities, in a timely and safe manner and have enough of the parent material available.

\section{SOIL MANUFACTURING}

\section{Introduction}

The method employed to produce granular material from the solid material involved breaking it apart into 1 inch plus pieces with a chisel and hammer. Smaller grain sizes were achieved by crushing the larger pieces with a mallet and a roller. The resulting gradation shows a uniform mixture and is shown in Figure 8.

This method of material preparation created large amounts of fines and less amounts of materials larger then the no. 4 sieve. From a large piece of diatomite the most prominent resulting grain size was less then the no. 4 sieve. This would require a considerable amount of diatomite in order to produce enough material with larger grain sizes. Thus, using one grain size only became an impractical alternative. 


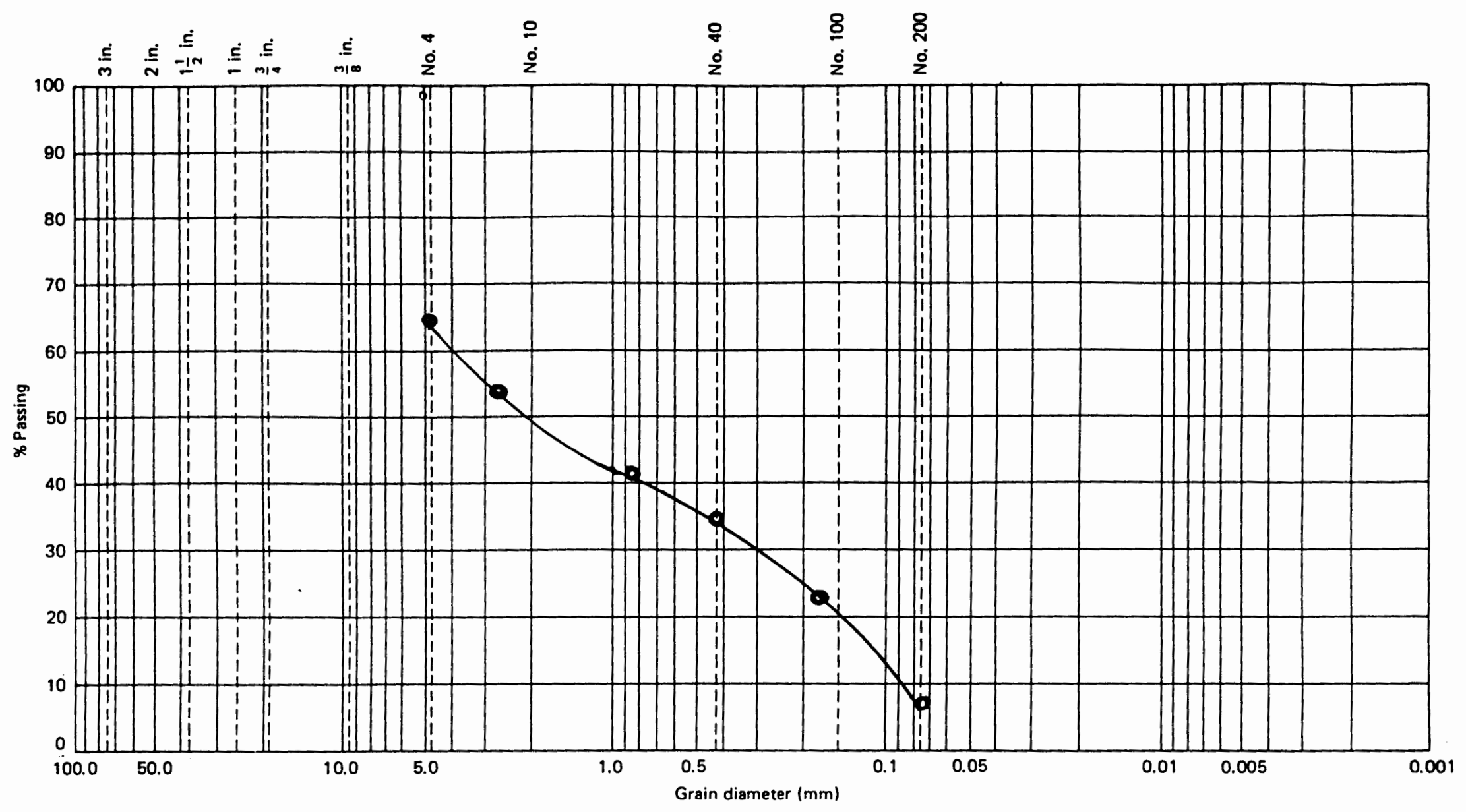

Figure 8. Gradation of the mechanically broken down diatomite. 


\section{Gradation Alternative}

A successful solution to this problem was a mixture of two or more grain sizes. In addition to material retained on the no. 7 sieve, was a good supply of material retained on the no. 20 sieve.

Test samples consisting entirely of the no. 20 material and samples with half no. 20 and half no. 7 were tested for collapse and repeatability. The results given in Figure 9 show that the soil retained on the no. 20 sieve was collapsible and had a collapse strain of $10.38 \%$. Figure 10 shows the results of the strain for the mixture that contained $50.0 \%$ no. 7 and $50.0 \%$ no. 20 . For this mixture, the strain was $7.01 \%$ which was judged acceptable.

The problem of manufacturing enough material was solved when it was noticed that the grain sizes in Oil Dry's commercial product, Kitty Diggins, appeared the same as that tested. A grain size distribution was conducted to verify this. The results as shown on Figure 11 show a gradation consisting of about $35.0 \%$ retained on the no. $7 \%$ sieve, $57.3 \%$ on the no. 20 sieve and $2.5 \%$ fines.

\section{$\underline{\text { Suitability Tests }}$}

The difference between the commercial product and the material tested was that the litter had been baked in a kiln and was deodorized and the raw material had no pretreatment. Two samples of raw material were dried in a microwave and tested for collapse. Upon addition of water no collapse occurred. Therefore, it was critical that the material remain in it's natural state. 


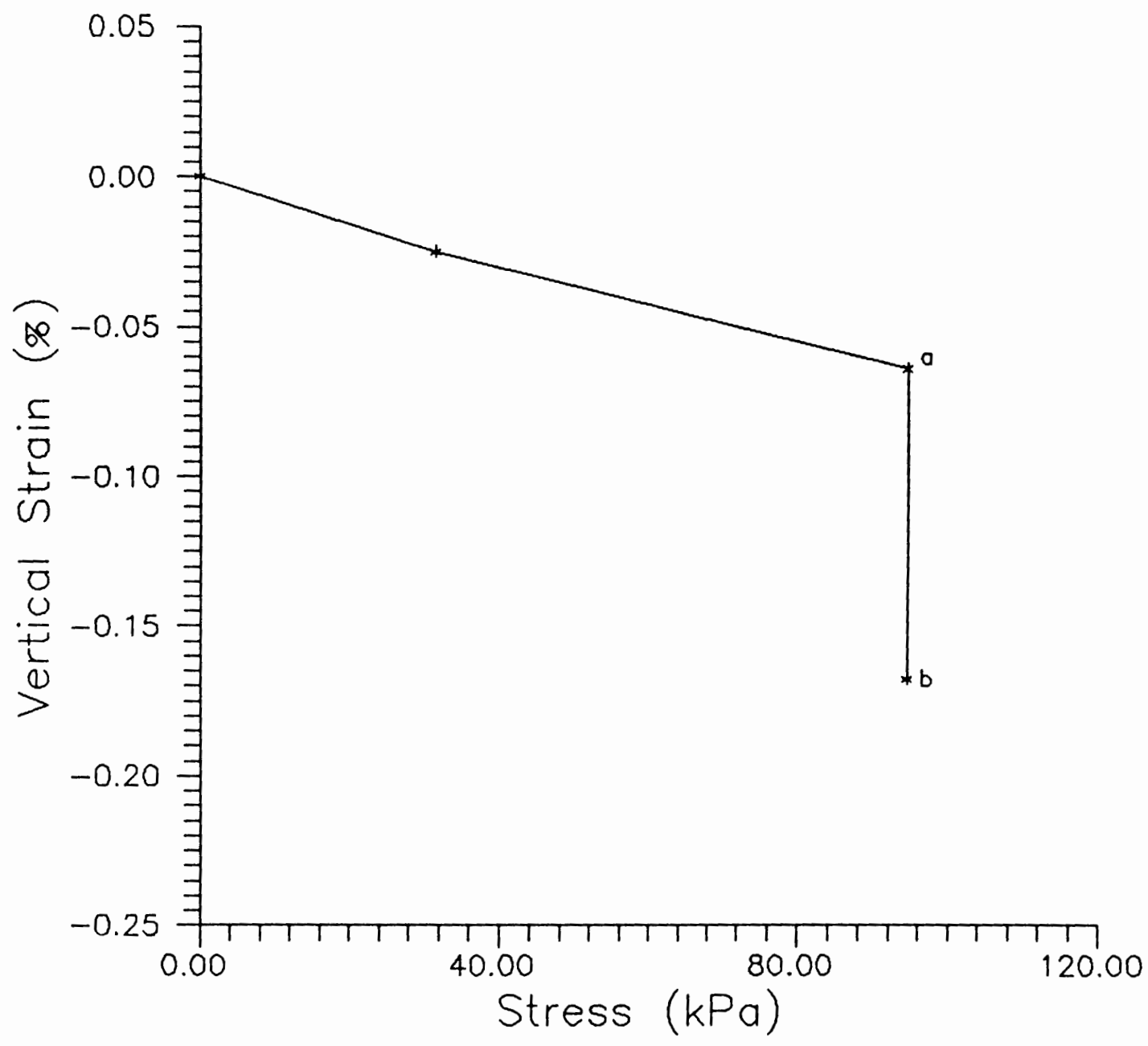

Figure 9. Collapse strain of material retained on the no. 20 sieve. At point (a) water is added.

Point (b) is the extent of collapse strain. For

this material the strain is $10.4 \%$. 


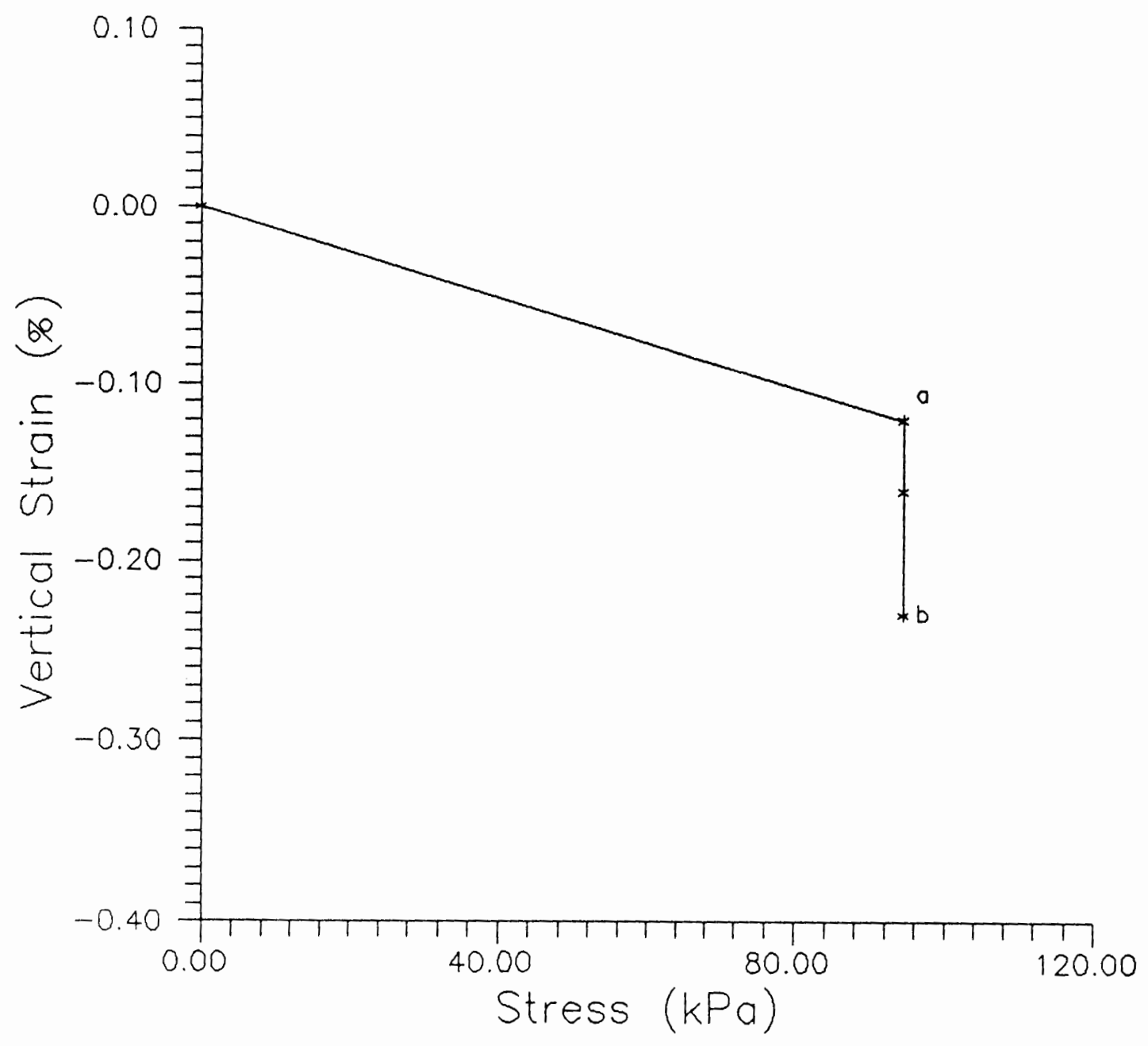

Figure 10. Collapse strain of the material that is a $50 / 50$ mixture of diatomite retained on the no. 7 and no. 20 sieves. Water is added point (a). Point (b) is the extent of collapse strain which is $7.0 \%$. 


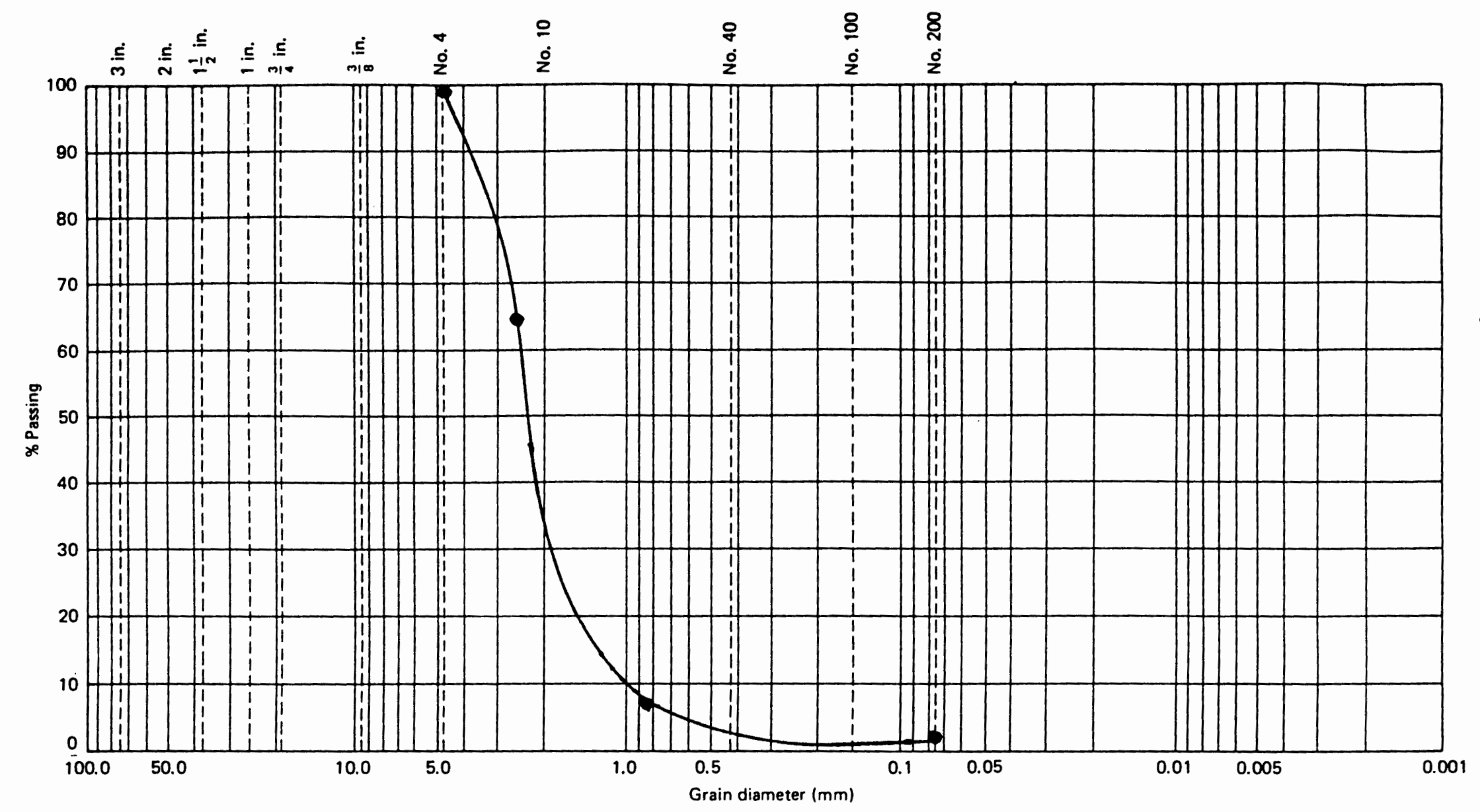

Figure 11. Gradation of Oil Dry Inc. commercial product, Kitty Diggins, 


\section{Acquisition of Material}

Arrangements were then made with Oil Dry Incorporated to obtain a large quantity, $500 \mathrm{lb}(227 \mathrm{~kg})$, of the diatomite as it came from the grinders and before the kilns. The gradation of the material as received from Oil Dry is given in Figure 12. The collapse potential as determined for this material was $9.72 \%$ as shown in Figure 13. This gave us enough of the material required for the full suite of laboratory testing. The laboratory material is here after referred to as CVD. Table I gives a summary of the tests conducted in developing CVD and the results of the tests. 


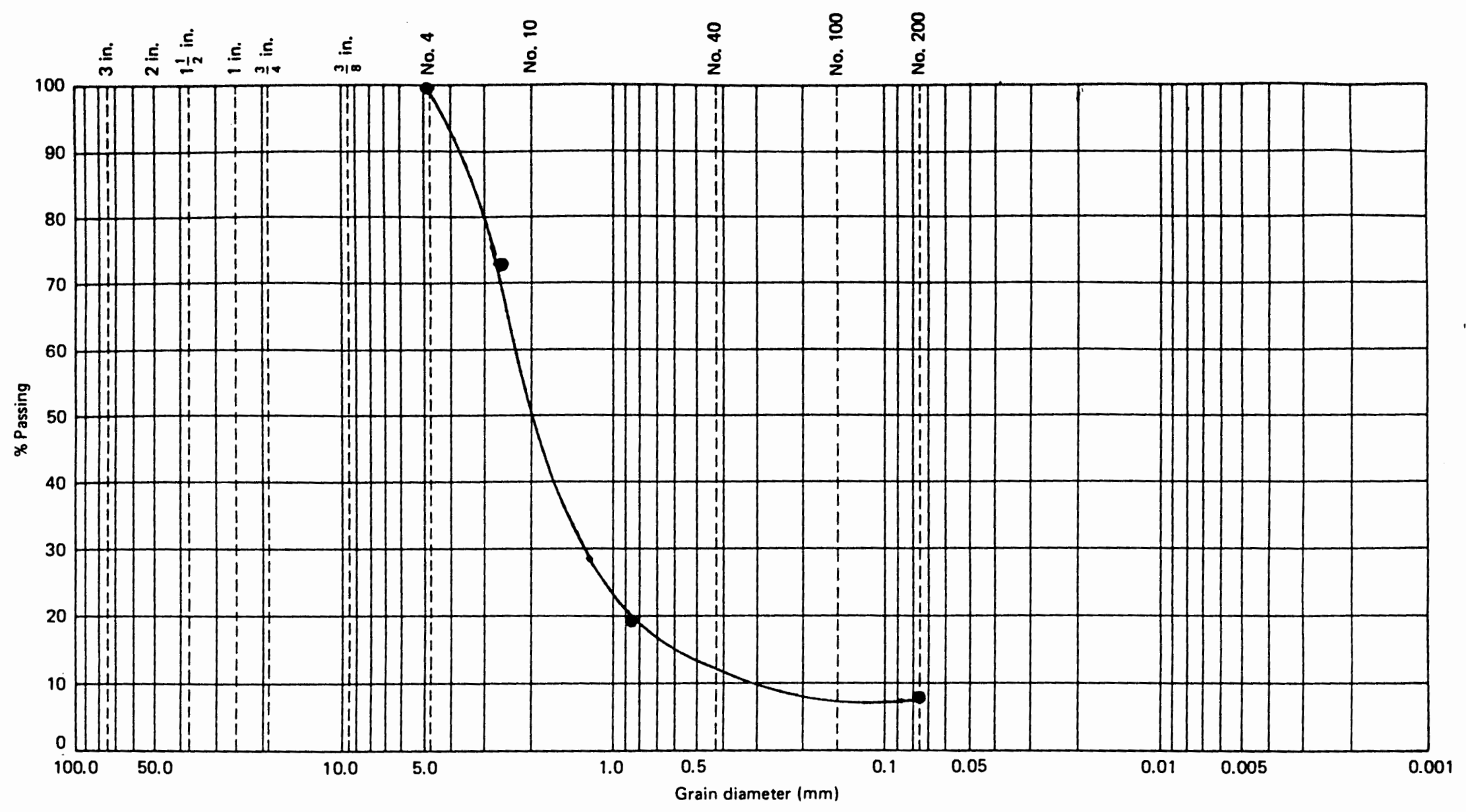

Figure 12, Gradation of diatomite as received from 0il Dry Inc. 


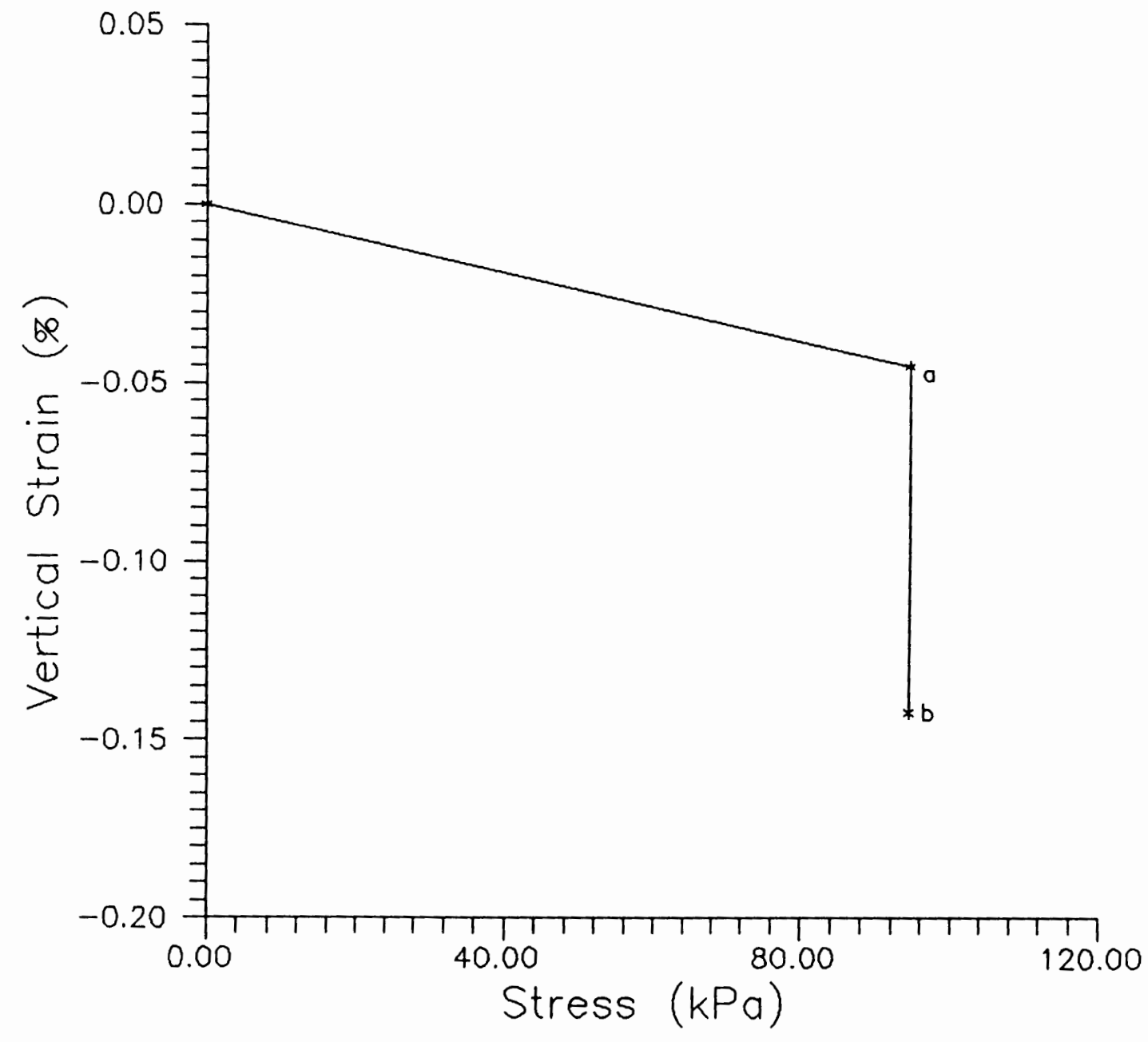

Eigure 13 Collapse strain of the material that was acquired from Oil Dry incorporated. Water is added at point (a). Point (b) is the extent of the collapse strain which is $9.7 \%$. 
TABLE I

COLLAPSE POTENTIAL OF THE VARIOUS GRAIN SIZES AND GRADATIONS OF DIATOMITE

\begin{tabular}{||l|l|r||}
\hline Test Type & Material Description & $\begin{array}{l}\text { Percent } \\
\text { Vertical } \\
\text { Strain }\end{array}$ \\
\hline \hline Preliminary Collapse Test & Solid Plug & 2.00 \\
\hline $\begin{array}{l}\text { Collapse Potential of Different } \\
\text { Grain Sizes/Mixtures }\end{array}$ & $100 \%$ fines & 6.16 \\
\hline & Uniform Gradation 10\% fines & 4.50 \\
\hline & $\begin{array}{l}100 \% \text { Material Retained on No. } 7 \\
\text { Sieve }\end{array}$ & 8.00 \\
\hline & $\begin{array}{l}100 \% \text { Material Retained on No. 20 } \\
\text { Sieve }\end{array}$ & 10.38 \\
\hline & $50 \%$ No. 7 / 50\% No. 20 & 7.01 \\
\hline & Material as Received from Oil Dry & 9.72 \\
\hline
\end{tabular}

Moisture induced vertical strains, in percent, of the various gradations and grain sizes of diatomite. 


\section{CHAPTER IV}

\section{OEDOMETER TESTING}

\section{OBJECTIVES}

\section{Establishment of Upper/Lower Boundaries}

There were three principal objectives in the oedometer testing series. The first was to define the range of void ratios at any given stress level and at any degree of saturation for the soil to collapse. The upper boundary of this zone is the elastic compression curve of the soil in a dry state and the lower boundary is the compression curve of the soil in a saturated state. These boundaries were established using the double oedometer method as described by Lutenegger and Saber (1988) and Knights and Jennings (1956, 1957). Test Series \#1 was designed to meet this objective.

\section{Verification of the Lower Boundary}

The second objective was to verify that the lower boundary was indeed a true lower limit. An observation made by the Soil Conservation Service Laboratories in Lincoln, Nebraska (SCS, 1991) found that in several instances when using the single oedometer test method, the vertical strains would exceed those as predicted by the lower boundary. This method is also preferred by Lutenegger (1988) on the basis that there are two different mechanisms occurring 
between the single and double oedometer test methods. The void ratio vs. log pressure curves of the double oedometer test are simply a representation of the compression of the soil in different states of moisture content and the single oedometer test is a true representation of collapse. These tests are containcd in Test Series \#2.

\section{Influence of Moisture Content on Collapse Strain}

The third objective was to gain a better understanding of just how water influences collapse. Is collapse brought on by full saturation? Or, would a percentage of total possible water volume cause a corresponding amount of collapse? Could the amount of collapse be predicted if the volume of water added was known? These are similar questions that Houston and Houston attempted to answer in their research. In their study they added water to the dry sample in increments of ten grams and measured corresponding collapse. They concluded that generally, the amount of collapse increased with increased amounts of water. At about 80-100 percent saturation, full collapse occurred (Houston and Houston, 1989). This represented Test Series \#3.

For the oedometer testing, the methods as described by Alan J. Lutenegger and Robert T. Saber (1988) and Houston and Houston (1989) were followed with some modifications. Sample preparation and setup, as well as stress increments were those as recommended by American Society for Testing and Materials (ASTM) test for One-Dimensional Consolidation Properties of Soils, D2435. 


\section{TEST PREPARATION}

\section{$\underline{\text { Material }}$}

The material used for the oedometer tests was the manufactured soil,

CVD. To prepare the soil for the tests, 16 grams each of the material retained on the no. 7 and no. 20 sieves was weighed and mixed. The mixture was then placed into the consolidometer in three lifts of about 10.6 grams per lift. To insure the mixture remained uniform, it was gently stirred and once placed, was packed with a soft blunt instrument. The stones and filter paper used were as recommended by ASTM Standard D 2435. The total unit weight of the sample was $24.8 \mathrm{pcf}$ (.40 gram/cc) with an approximate void ratio of 0.93 .

\section{TEST SERIES 1 - UPPER/LOWER COMPRESSION BOUNDARIES}

\section{Test Procedures}

The first test series ran was the double oedometer test. This was to establish the upper and lower bound void ratio curves. Following Lutenegger's (1988) recommendation, the consolidometer was seated with a $5.0 \mathrm{kPa}$ load and after initial settlement had taken place, the dial gauge reading was taken as the initial height. The pressure increments added were 10.0, 20.0, 40.0, 80.0, 160.0, and $320.0 \mathrm{kPa}$. This gave a delta $\mathrm{p} / \mathrm{p}$ ratio equal to 1 . For each pressure increment, dial gauge readings were taken as recommended by ASTM procedures at intervals of $0.25,0.50,1.0,2.0,4.0,8.0,16.0,30.0,60.0$ minutes and so on up to 
24 hours, or, until the dial gauge reading was less then $0.00001 \mathrm{in} / \mathrm{min}(0.05$ $\mathrm{mm} / \mathrm{hr})$.

To establish the dry, upper bound curve, the sample was loaded in the increments up to the $320.0 \mathrm{kPa}$ load limit with the dial gauge readings recorded. In the test to establish the lower bound, saturated curve, the soil was inundated after being seated. The procedure for increasing the stress level and data monitoring was the same as for the dry curve.

\section{Test Results}

The results of this testing series is plotted as Vertical Strain vs. Log Pressure $(\mathrm{kPa})$ and is given on Figures 14 and 15. The collapse strain which is the difference between the strains of the upper and lower bound curves at any given pressure ranges from 0.01 at $5.0 \mathrm{kPa}$ to 0.156 at $320.0 \mathrm{kPa}$ for test cell $\mathrm{A}$ and for test cell $\mathrm{B}$, the range is 0.01 at $5.0 \mathrm{kPa}$ and 0.115 at $320.0 \mathrm{kPa}$. A comparison of the curves for the different test cells show that even though the compression of the dry curves are different, the values of collapse strain are similar. This similarity shows repeatability of the tests. The curves also show the void ratio in the saturated state is less then the void ratio in the dry state. In going from one state to the other, compression must occur. 


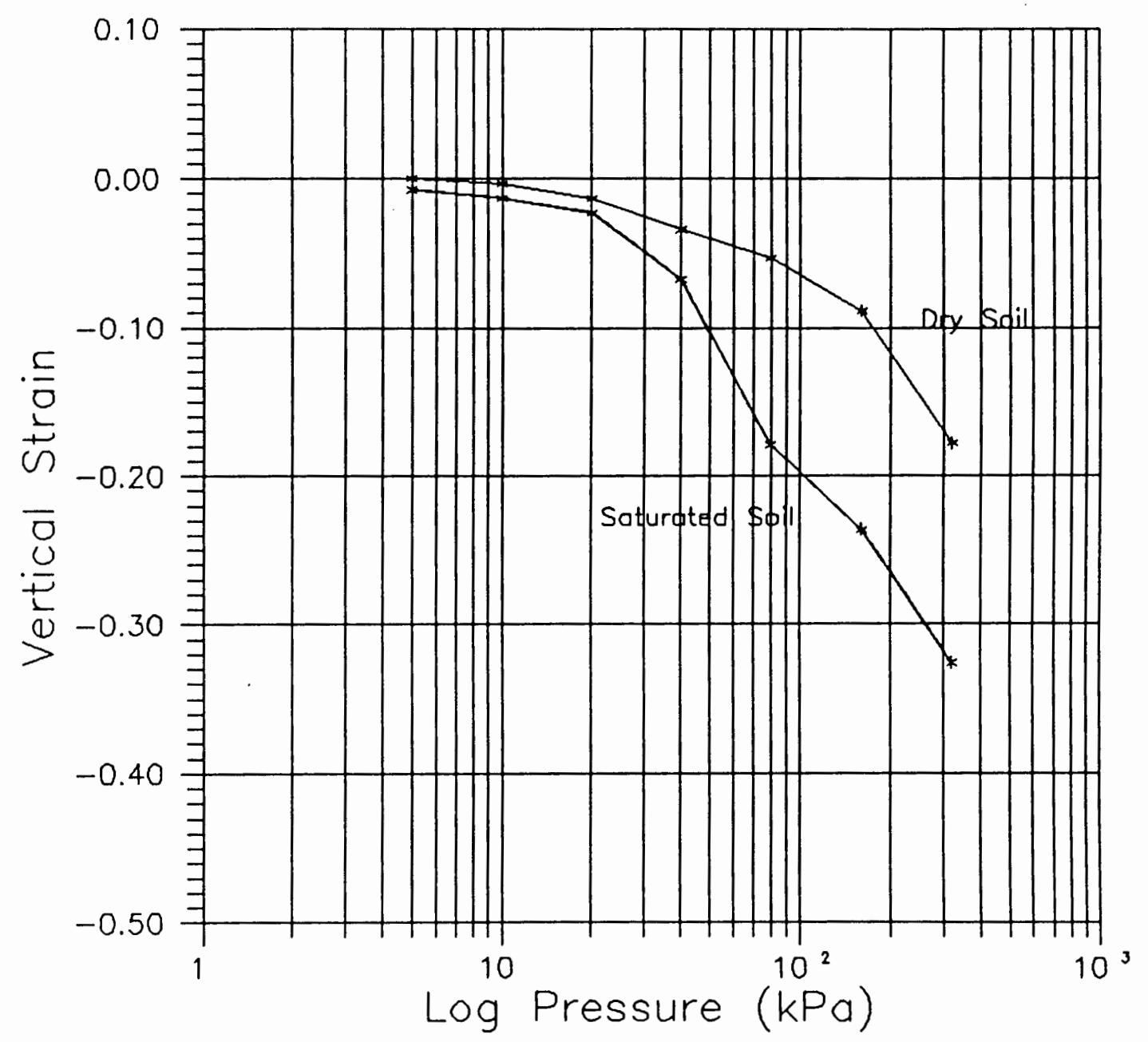

Figure 14. Upper and lower compression boundaries for the Double Consolidometer Method (DCM)-cell A.

Collapse potential is the area in between the curves. 


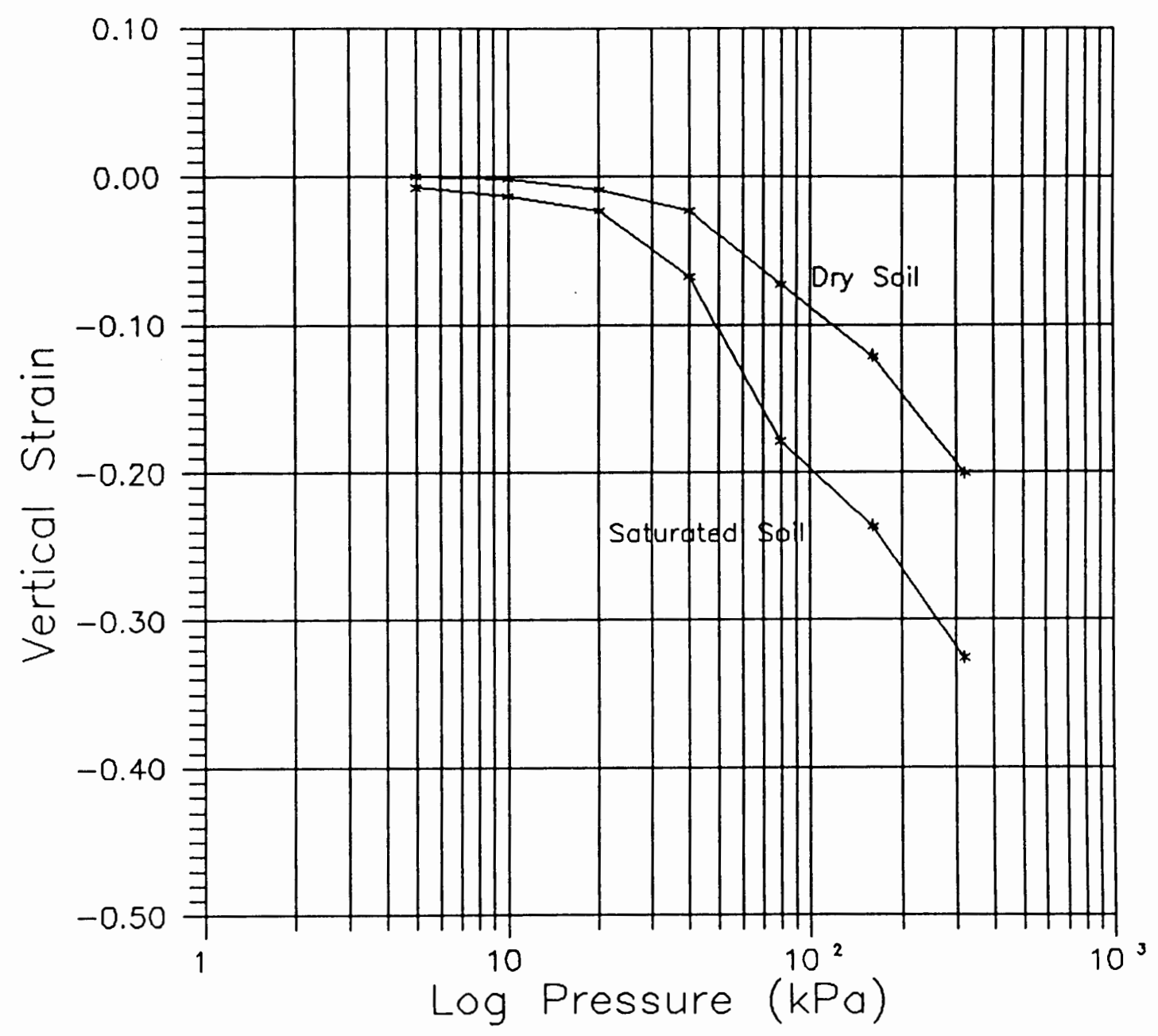

Eigure 15. Upper and lower compression boundaries for the Double Consolidometer Method (DCM) - cell $B$. Collapse potential is the area in between the curves. 


\section{TEST SERIES 2 - SINGLE OEDOMETER COLLAPSE STRAIN}

\section{Test Procedures}

The second series of tests utilize the single oedometer method. After seating the consolidometer and taking all initial readings, the sample is loaded as before in incremental loads. All loads are added after the settlement has apparently ceased. The sample being at its natural water content, is loaded to the desired stress level with water being added through the bottom porous stone. The water is continually added until water appears through the top porous stone. The gutters of the consolidometer are then flooded to insure the soil will become saturated. For this test, the dial gauge reading was taken before the water was added. After the addition of water, the dial gauge readings were taken at 15.0, $30.0,45.0$, and 60.0 seconds; $1.5,2.0,2.5,3.0,5.0,10,15,30$, and 60 minutes; 2.0 , 4.0, 8.0 and up to 24.0 hours.

\section{Test Results}

The results of the single oedometer test are shown in Figure 16. For each stress level, the upper bound dry curve shows the increase in vertical strain as the stress level is increased, with $1.0 \%$ strain at $5.0 \mathrm{kPa}$ and $18.0 \%$ at $320.0 \mathrm{kPa}$. Upon the addition of water, there is a sudden increase in strain with no corresponding change in the stress level. 


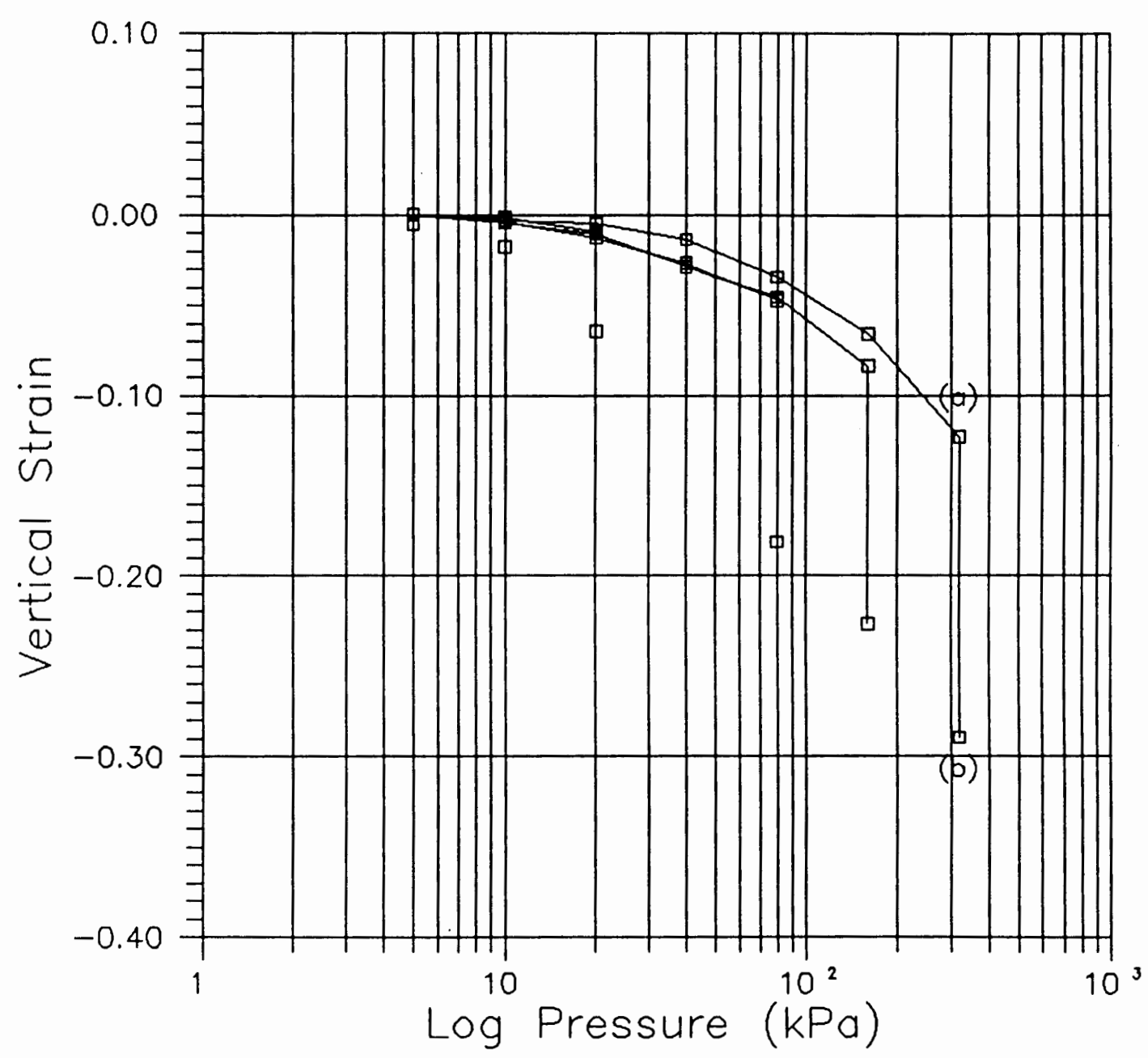

Figure 16. Collapse upon wetting of 5.0 to 320.0 $\mathrm{kPa}$ pressure for the Full Collapse Window (FCW). The soil is loaded and compressed dry to point (a), water is added and collapse strain occurs, (b). 
When the results of the single oedometer test are superimposed upon the results of the double oedometer test, Figure 17, it becomes apparent that at lower stress levels the vertical strain from the single oedometer test exceeded those of the double oedometer test by $2.0 \%$ at $10.0 \mathrm{kPa}$ to $4.0 \%$ at $20.0 \mathrm{kPa}$. The difference in the amount of strains can be due to sample variability. Or, for this manufactured soil, the lower bound void ratio curve may not be the lower limit.

\section{OEDOMETER TEST SERIES 3 - COLLAPSE STRAIN VS. WATER CONTENT}

\section{Test Procedures}

The final series of oedometer tests explored how the volume of water would influence the amount of vertical collapse strain.

The volume of water in a saturated sample, the consolidometer bottom gutters, and the volume of water required to saturate a stone, was determined in order to prepare for these tests. Each of these components were summed giving the total volume of water required for a test with full saturation. Next a squirt bottle was marked and calibrated in volume increments equal to $10.0 \%$ of total water volume.

As in the single oedometer test, the sample was prepared, seated and loaded to the desired stress level. When settlement ceased, water was added to the sample by injecting it under the top porous stone. The first volume of water 


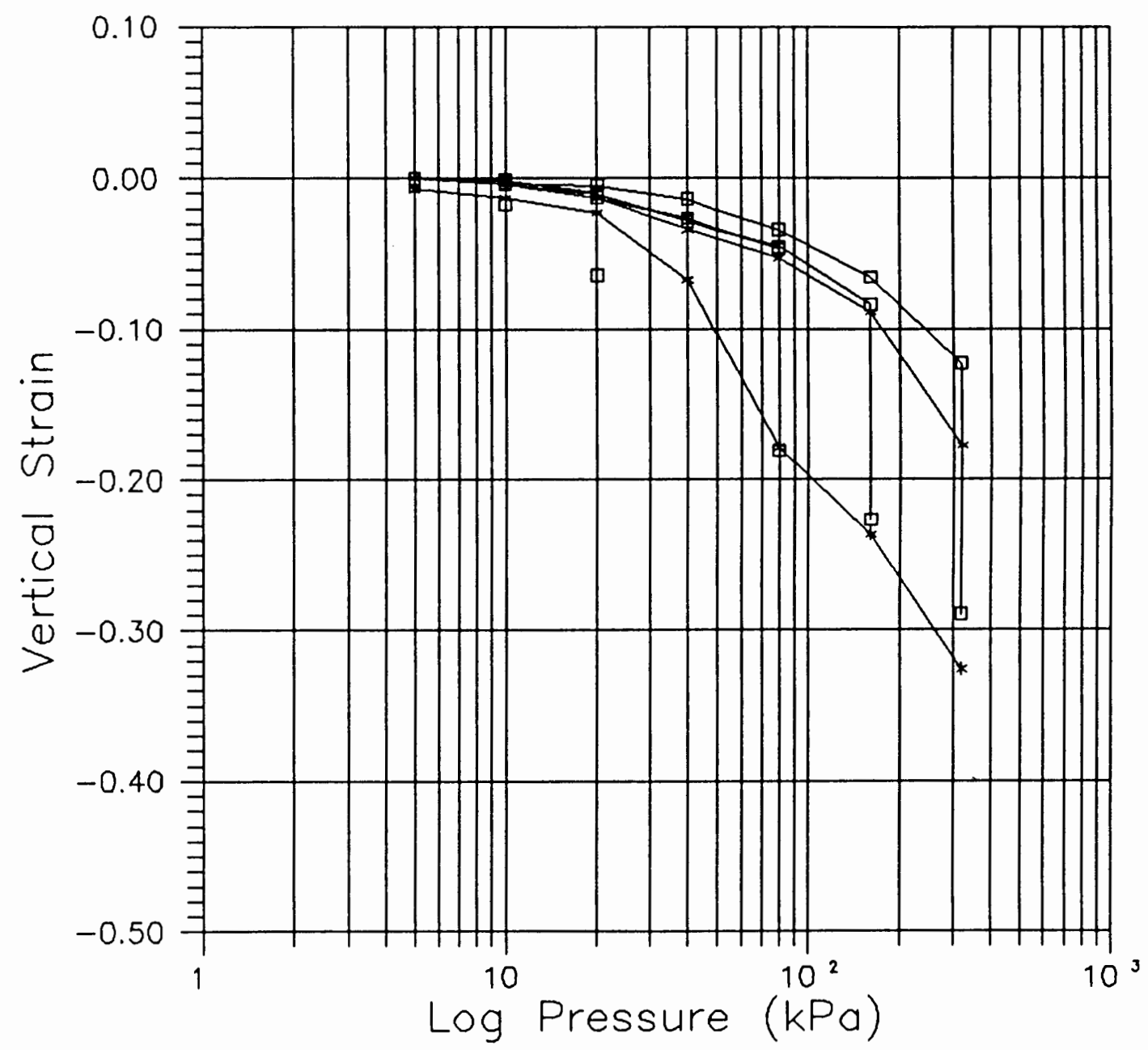

Eigure 17. Superposition of the Full Callapse Window (FCW) upon the Double Oedometer curve for cell A. 
added was $20.0 \%$ of total computed volume. Dial gauge readings were taken as before, and when appropriate, another $20.0 \%$ of water volume was added.

\section{Test Results}

The results of this test as given in Figure 18 show that under some stress levels, the portion of water added created a collapse greater then if it would have been flooded. At stress levels of $10.0 \mathrm{kPa}$ and $20.0 \mathrm{kPa}$ the collapse brought on by $40 \%$ saturation caused strains that were over $100 \%$ greater then that caused by full saturation.

There was much inconsistency in the results which might be attributed to two factors. One is the top stone partially binding on the consolidometer ring. Because the water couldn't be added uniformly, one side of the sample in the consolidometer ring collapsed before the other. This caused a differential settlement which caused the binding. Further, to dislodge the stone created disturbance in the readings. The other factor contributing to inconsistencies was that the squeeze bottle was hard to control in distributing a given amount of water, plus there was no means available to verify amount of saturation. The moisture content of the tests averaged about $65.0 \%$ for full saturation, $55.0 \%$ for $40.0 \%$ saturation at the 10.0 and $20.0 \mathrm{kPa}$ stress levels, and about $20.0 \%$ for the higher levels of stress. 


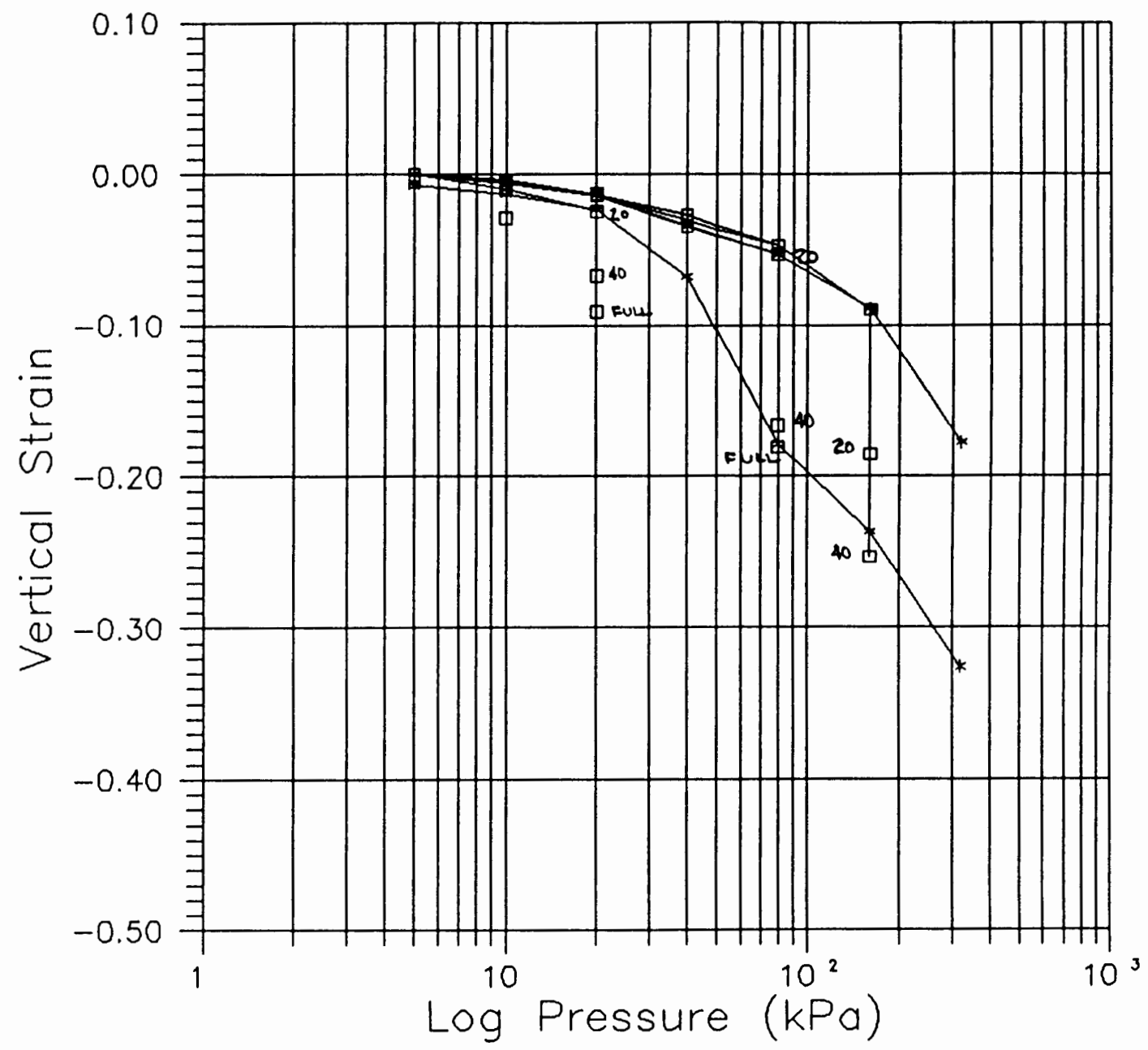

Eiqure 18. Superposition of the collapse curve of partial saturation over full satuaration. 


\section{CHAPTER V}

\section{PRESSUREMETER TESTING}

\section{OBJECTIVES}

\section{Strength Characteristics}

The objectives in pressuremeter testing was to determine the traditional parameters of Pressuremeter modulus and limit pressure of the laboratory material while at its natural moisture content and saturated. How these parameters changed in going from a dry to saturated state were also studied. Further, does the material in a dry and saturated state define two strength boundaries? The results from the Pressuremeter testing would also be used to define stress paths and failure surfaces to be used later for the constitutive model. Finally, the laboratory testing was also an aid in testing equipment and procedures to be used in field work.

\section{APPARATUS}

\section{$\underline{\text { Pressuremeter }}$}

One of the apparatus used for the laboratory pressuremeter testing was a modified Portland State $\underline{\text { University }}$ Pressuremeter (PUP). 
The PUP pressuremeter, as described by Smith and Denham (1991), was modified to complete "pressure controlled testing". The modification made was to build a base onto the RC108 cylinder so that a container could be placed tikete. As deadweights were placed into the container, the system pressure would increase by a constant amount. The appropriate volume of fluid controlled by soil behavior entered the probe to maintain static equilibrium in the cylinder.

A second modification made to the PUP unit was the fitting of a probe sheath without the metal protective fins. Due to the light unit weight of the material and the shallow depth, the pressure required to overcome the metal fin stiffness would be close to the capacity of the soil. Removing the metal fins left only a latex rubber membrane which would take very little pressure to inflate and improve the sensitivity of the soil pressure recording.

Another change made to the probe was the addition of a fabric wick to be used to distribute the moisture around the probe when the soil was wetted. As can be seen in Figure 19, the latex section of the probe is wrapped in the fabric. Adjacent to either end of the fabric are the metal sections of the probe which are wrapped in duct tape. Figure 20 shows the equipment leads and a water tube inserted down alongside and under the fabric. This allows the fabric to absorb the water and the water to migrate down the latex section of the probe. The water is added manually through a funnel. Figure 20 also shows a "wetting front" indicated by the darker colored material. 


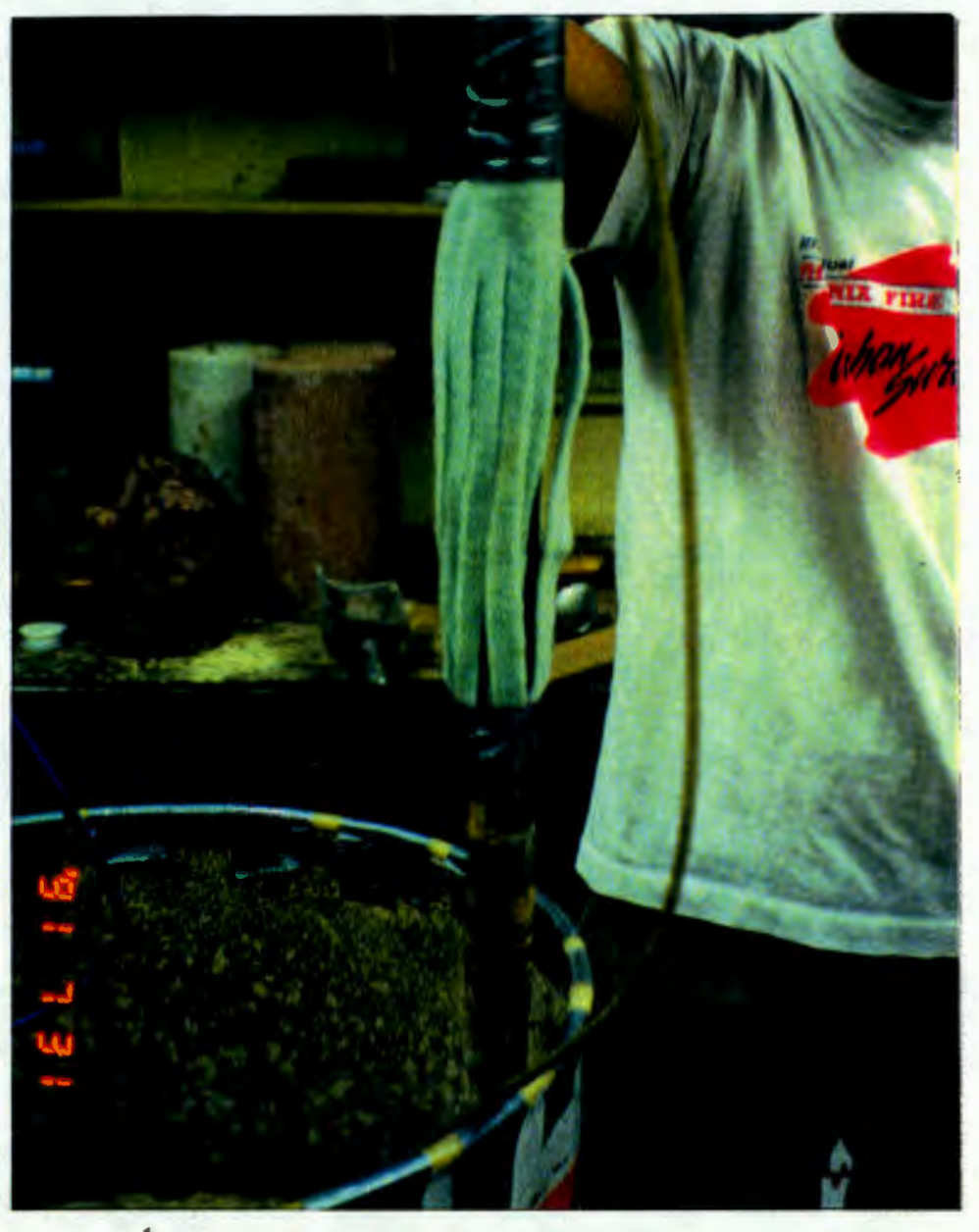

Figure 19. Pressuremeter probe with fabric wick.

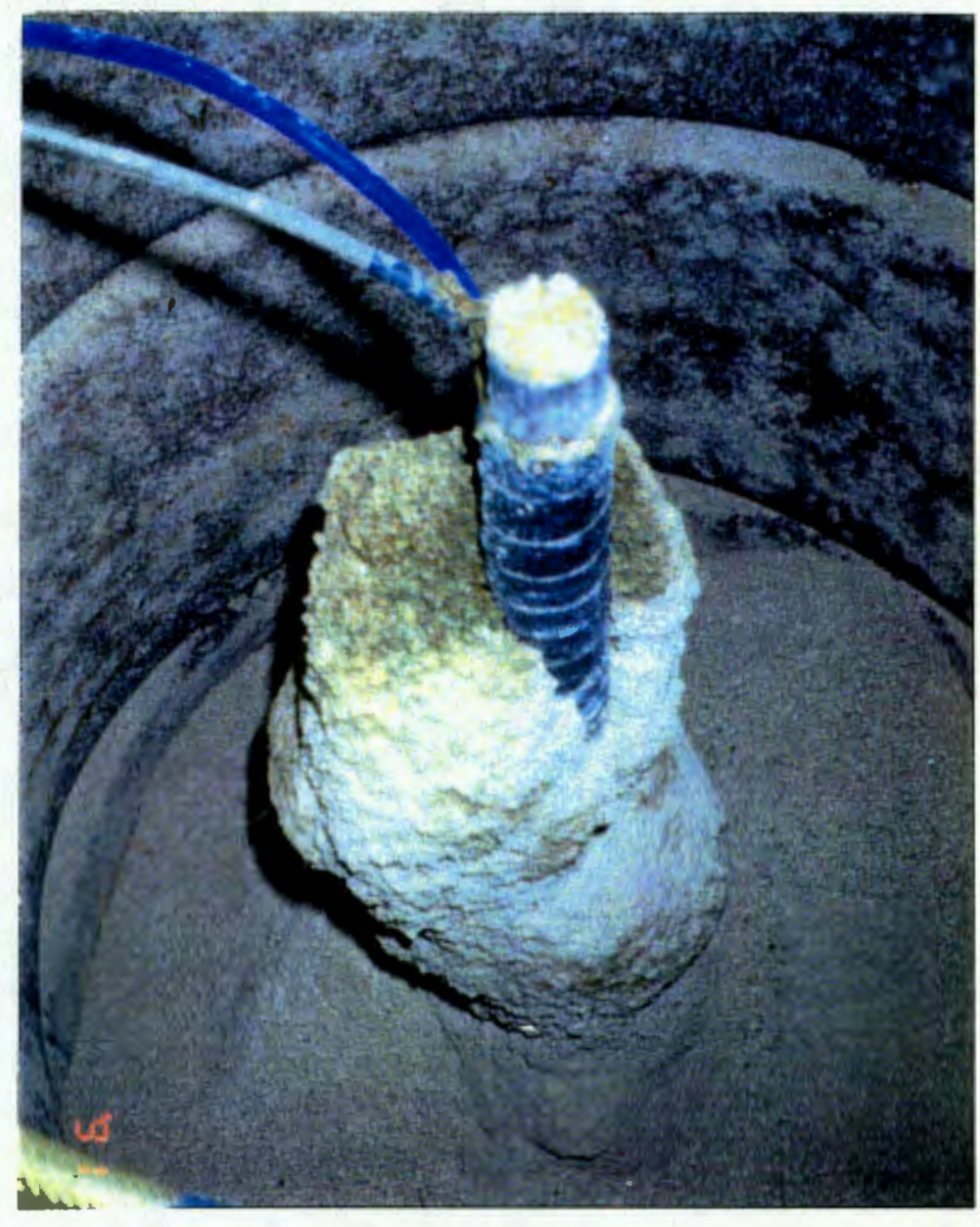

Figure 20. Equipment leads and water tube inserted under fabric wick assembly. 


\section{Confinement Pressure Cell-Design Criteria}

To achieve known boundary conditions in the laboratory testing a confinement pressure cell was designed and built at Portland State University. Boundary effects of the cell sides, depth effects and the logistics of setting up and taking down each test as well as the handling of large volumes of material were considered in the cell design.

To insure that the boundaries of the cell would not influence the test results, the size of the cell would have to be such to simulate an insitu condition. Using a radius of cell to radius of probe ratio of ten, required the radius of the cell be at least 10.0 inches $(25.4 \mathrm{~cm})$.

Any boundary or depth effect due to the bottom of the cell would be insignificant since the base was similar to the stiffness of the bottom of a borehole. This made the requirement for cell depth be that the probe could be securely embedded at the bottom and have enough cover at the top. Thus a minimum depth of 26.0 inches $(66.0 \mathrm{~cm})$ was required. Top depth effects would be simulated by applying a normal pressure to the soil surface.

A third requirement that dictated the size of the cell was the volume of soil to be used as well as the labor, time and safety involved in the setup of each test. It was estimated that each test would require about $7.0 \mathrm{cft}\left(0.2 \mathrm{~m}^{3}\right)$ of material. The cell had to have overall dimensions that allowed easy and safe deposition and removal of material. 


\section{Testing Cell}

The cell as shown in Figures 21 and 22, consisted of a $7.5 \mathrm{cft}$ ( 0.2 cubic meters) metal drum placed between two steel plates. A rubber diaphragm between the material and top plate was used to apply a normal pressure to the surface. The air pressure was applied through an inlet valve in the top plate that was controlled by a pressure regulator. The whole assembly was held together by 4-six ft. $(1.82 \mathrm{~m})$ long threaded steel rods which were placed at the corners of the plates and were tighten with bolts at the top and bottom. The cell was prevented from buckling by a steel belt around the middle. This belt also allowed the cell to be picked up by a fork lift. Additional support included steel plates and a fitted plywood section to keep the bottom of the cell flat. The top of the cell was reinforced by the top steel plate.

\section{TEST PREPARATION}

\section{Material}

The material used for the Pressuremeter testing was the granular diatomite as received from Oil Dry Inc. and described earlier in chapter 3. In this diatomite mixture, $35 \%$ consisted of material retained on the no. 7 sieve, $58 \%$ of the no. 20 sieve and $7 \%$ fines, with a collapse potential of $9.2 \%$. This was a difference of $2 \%$ between the collapse potentials of the $50 / 50$ and the $35 / 65$ mixture. It was decided to use this material as the similarities in collapse behavior and collapse strain magnitude would still give comparable results to the Oedometer and 


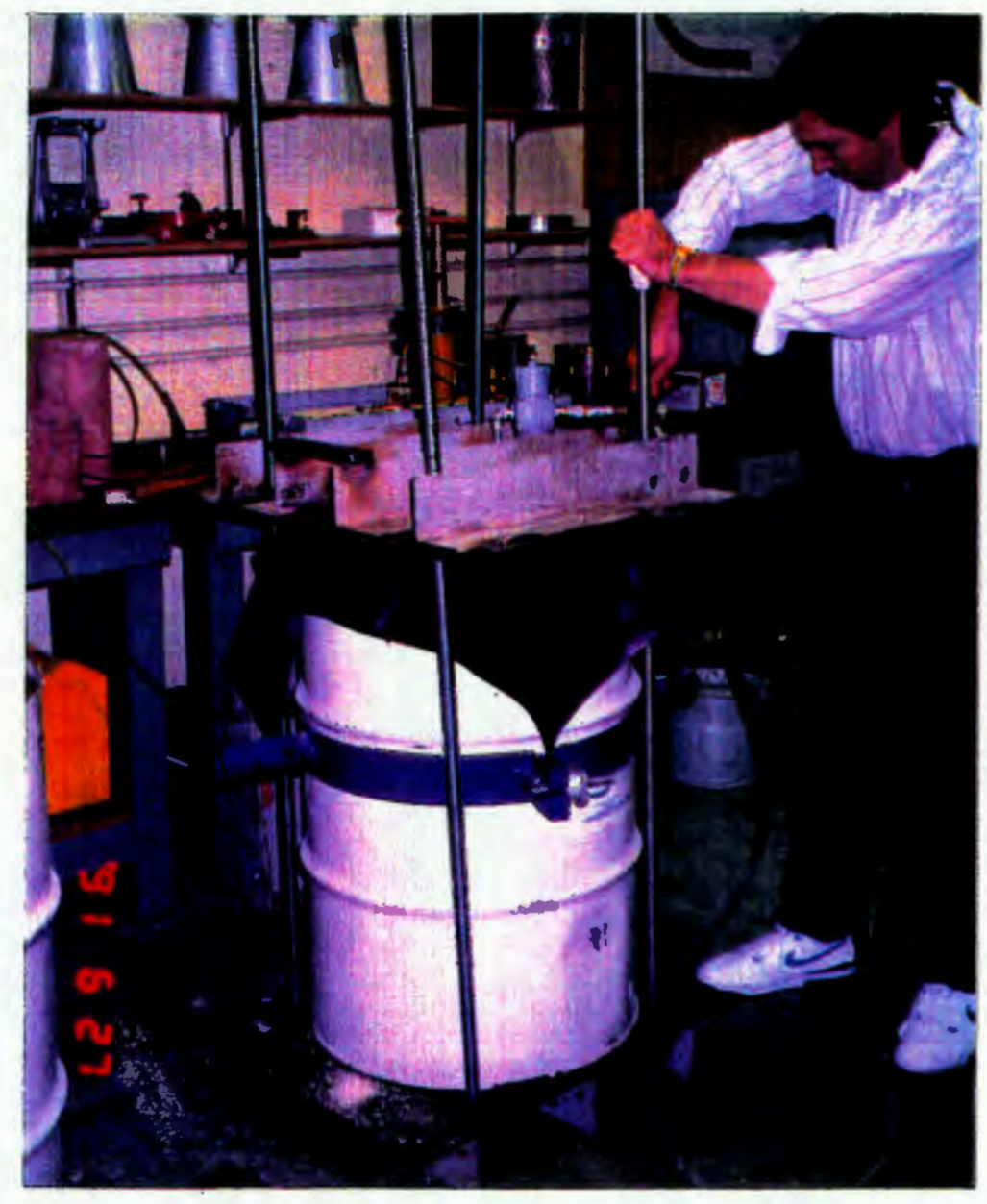

Figure 21. Pressuremeter cell as sembly.

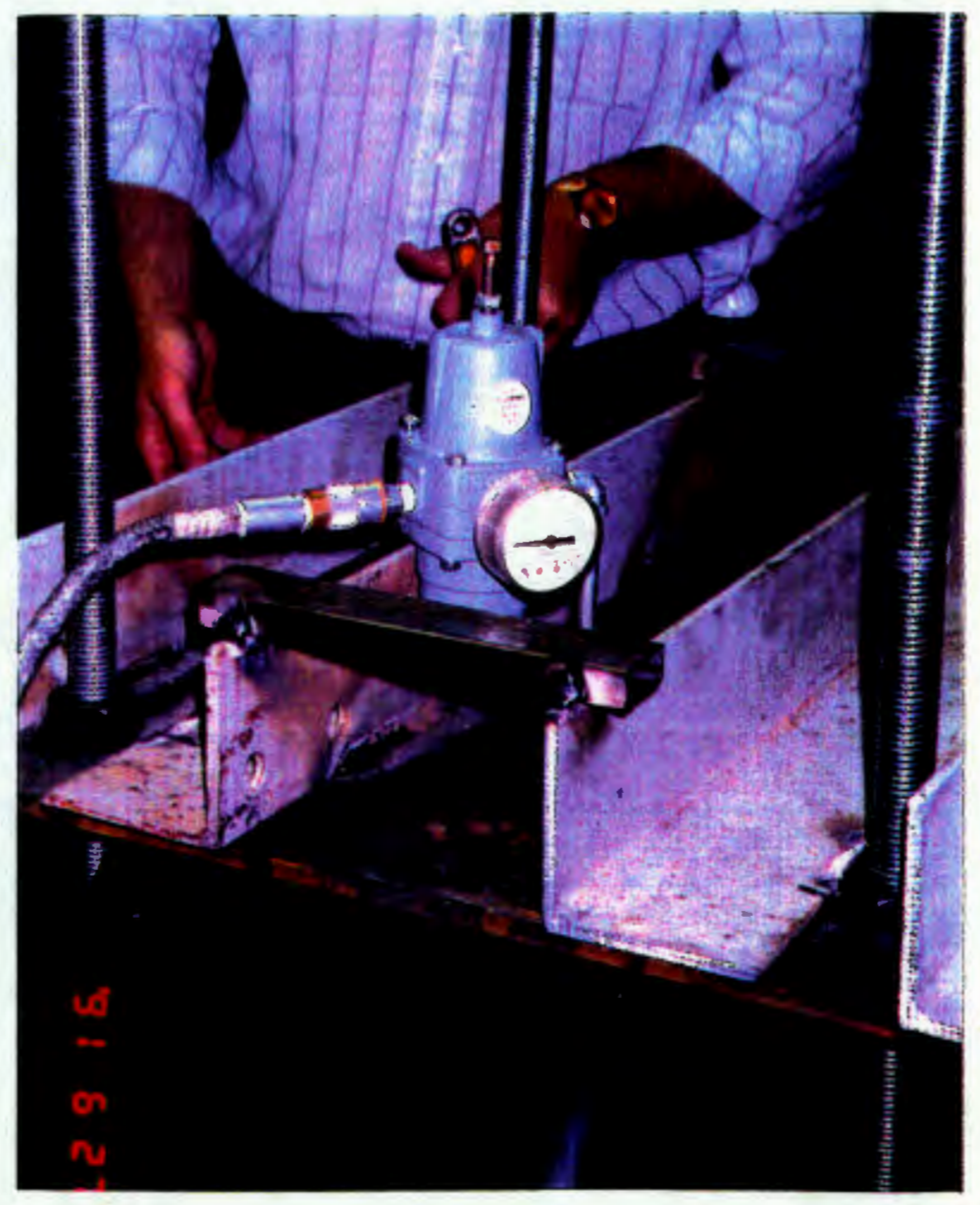

Figure 22. Pressure regulator and leads for the Pressuremeter cell. 
Triaxial result. Further, it would have taken several hours to separate out the gradations in five hundred pounds of material with only standard sieves being available.

\section{Test Set-Up}

To prepare for a test, the top 26.0 inches $(66.0 \mathrm{~cm})$ of material was removed from the cell. The pressuremeter probe was placed into the remaining material such that the bottom end of the inflatable portion was even with the soil surface. Keeping the probe vertical, $211.0 \mathrm{lbs}$. $(4.220 \mathrm{Kg})$ of material was weighed and evenly rained around the probe. This gave a consistent unit weight of 35.6 pcf $\left(5.6 \mathrm{KN} / \mathrm{m}^{3}\right)$ with the maximum height of fall of $2.0 \mathrm{ft}$. (0.6096 meter). With the probe and soil in place, the rubber diaphragm was placed over the surface, the lid was put on, the bolts tightened, and the surface pressure applied.

\section{Test Procedures}

In all the tests, after the initial pressure and cylinder displacement readings were taken, the test proceeded as given in ASTM test for Pressuremeter Testing in Soils, D4719-87.

The surface pressures used were 5.0, 10.0, and $15.0 \mathrm{psi}(34.5,68.9$ and $103.4 \mathrm{kN} / \mathrm{m}^{2}$ ). This would simulate approximate overburden depths of 20.0, 40.5 and 60.7 feet $(6.1,12.3,18.5 \mathrm{~m})$ given the unit weight of $35.6 \mathrm{pcf}\left(5.6 \mathrm{kN} / \mathrm{m}^{3}\right)$ for the material in the drum. 


\section{Data Reduction}

The data from all the tests were reduced using the software program PRESSED. This program was written by Larry M. Tucker and Jean-Louis Briaud (1986) of Texas A\&M University. The program is intended for use on PC's and is written in BASIC. It can be used to reduce the data taken from any pressuremeter that measures volume increase. The input is the pressures and corresponding volume changes from the test data. This is also done in calibrating the cylinder pressure and system volume. Other required input is probe dimensions, set-up dimensions, soil unit weight, depth of probe, etc., the output is the pressuremeter modulus and limit pressure. Some modifications on input prompts were made at Portland State University. A full catalog of the test series details are shown in Table 2.

\section{TEST SERIES 1 - DRY SOIL/STRAIN CONTROLLED}

\section{Test Objectives}

The first series of tests examined the behavior of the material in a dry state at the three selected surface pressures. The modulus and the limit pressures of the material at the three different pressures was sought. This test series as well as all the others was also intended to test the pressuremeter equipment, test cell and refine testing procedures. 
TABLE II

SUMMARY OF PRESSUREMETER TESTING RESULTS

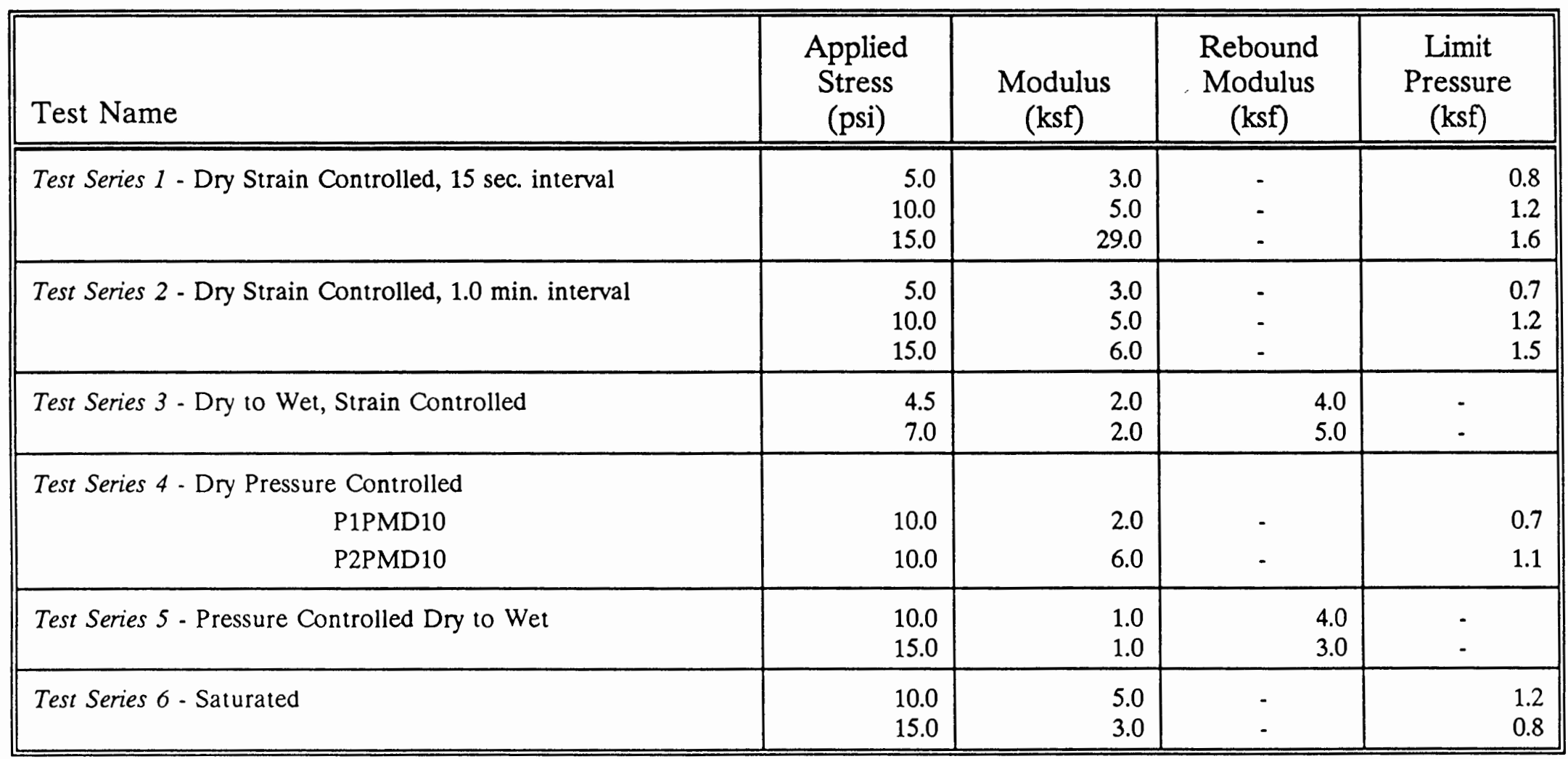




\section{Test Procedures}

For these tests, the ASTM standard was modified by changing the amount of time the pressure gauge was read from when the volume of fluid was injected to fifteen seconds. This test series used a strain controlled method, where strain was the independent variable and pressure the dependent variable. The PUP unit was used as designed where the ENERPACE RC 59 cylinder is used.

\section{$\underline{\text { Test Results }}$}

The results of series 1 tests are given in Figure 23. The moduli for the 5.0, 10.0, and 15.0 psi surface pressures are 3.0, 5.0 and $29.0 \mathrm{ksf}(143.6,239.4$ and $\left.1388.52 \mathrm{kN} / \mathrm{m}^{2}\right)$, with corresponding pressure limits of $0.8,1.2$, and $1.6 \mathrm{ksf}(38.3$, 57.5 and $76.6 \mathrm{kN} / \mathrm{m}^{2}$ ), respectively. The values for the increasing moduli and limit pressure with increasing surface pressure corresponds to increasing depths of 22.5, 33.7 and 45.0 feet $(6.85,10.27,13.7 \mathrm{~m})$. This is reasonable considering that with a granular material, the strength increases with depth. Examination of the three curves in Figure 23 shows as surface pressure increases, the stress for each strain also increases, with each of these curves eventually reaching a maximum stress/strain value.

A further useful indication from the test is on test equipment performance and procedures. In Figure 23 the curves for the tests conducted at 5 and 10 psi are similar in shape which is almost linear, and reflects the increase in the applied pressure. These curves show a material that does not behave elastically. The curve for the test conducted at 15 psi shows a curve which has a non-linear shape 


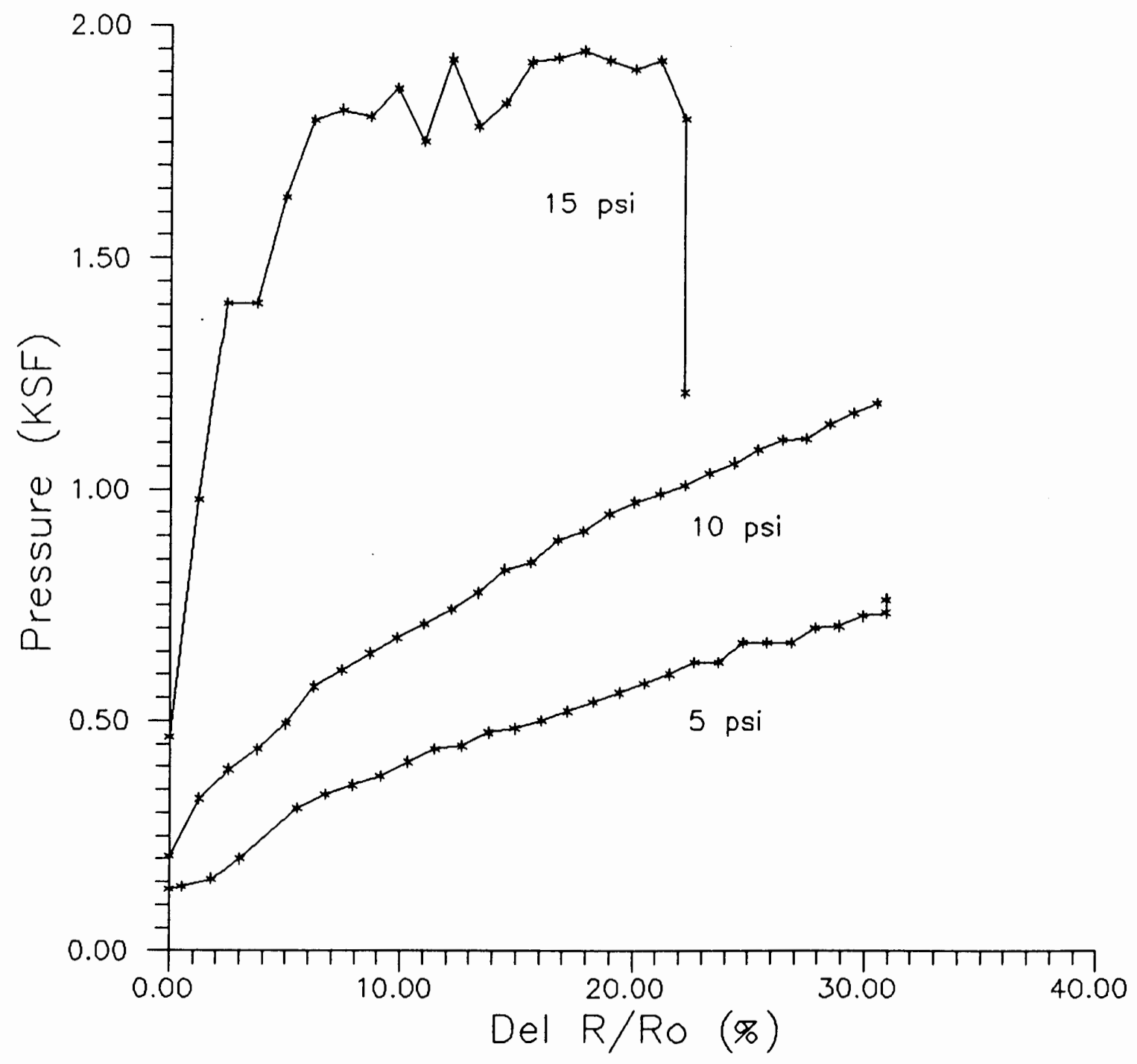

Eigure 23. Pressure verses strain curves for Test Series 1. strain controlled PMT testing. 
and resembles the curve of an elastic material. The differences in these results may be due to an increase in material creep at $15 \mathrm{psi}$ and not enough time in between reading intervals for the creep to dissipate.

\section{TEST SERIES 2 - DRY/STRAIN CONTROLLED}

\section{Test Procedures}

The second series test were conducted using the 5,10 and 15 psi surface loads. The objectives and procedures were the same as the first test series, except the ASTM standard was followed as specified. The time before reading the gauge was one minute. This was completed to study how the time differences affected the creep in the material.

\section{$\underline{\text { Test Results }}$}

The results for series 2 tests are given in Figure 24. For this series the moduli for the 5.0, 10.0, and 15.0 psi tests are 3.0, 5.0, and $6.0 \mathrm{ksf}(143.6,239.4$, $\left.287.3 \mathrm{kN} / \mathrm{m}^{2}\right)$; with limit pressures at $0.7,1.2$ and $1.5 \mathrm{ksf}\left(33.5,57.5,71.8 \mathrm{kN} / \mathrm{m}^{2}\right)$ respectively. These results are better as compared to the series 1 tests. For this material, it is essential to allow one minute to elapse between increasing the membrane volume and taking pressure readings so the creep that is inherent in the material can dissipate.

Comparing the results of series 1 and 2 tests for the 5.0 and 10.0 psi pressures, shows the similarities in the results. As shown in Figure 25, even though the pressure vs. strain in the 5.0 psi test do not begin with the initial 


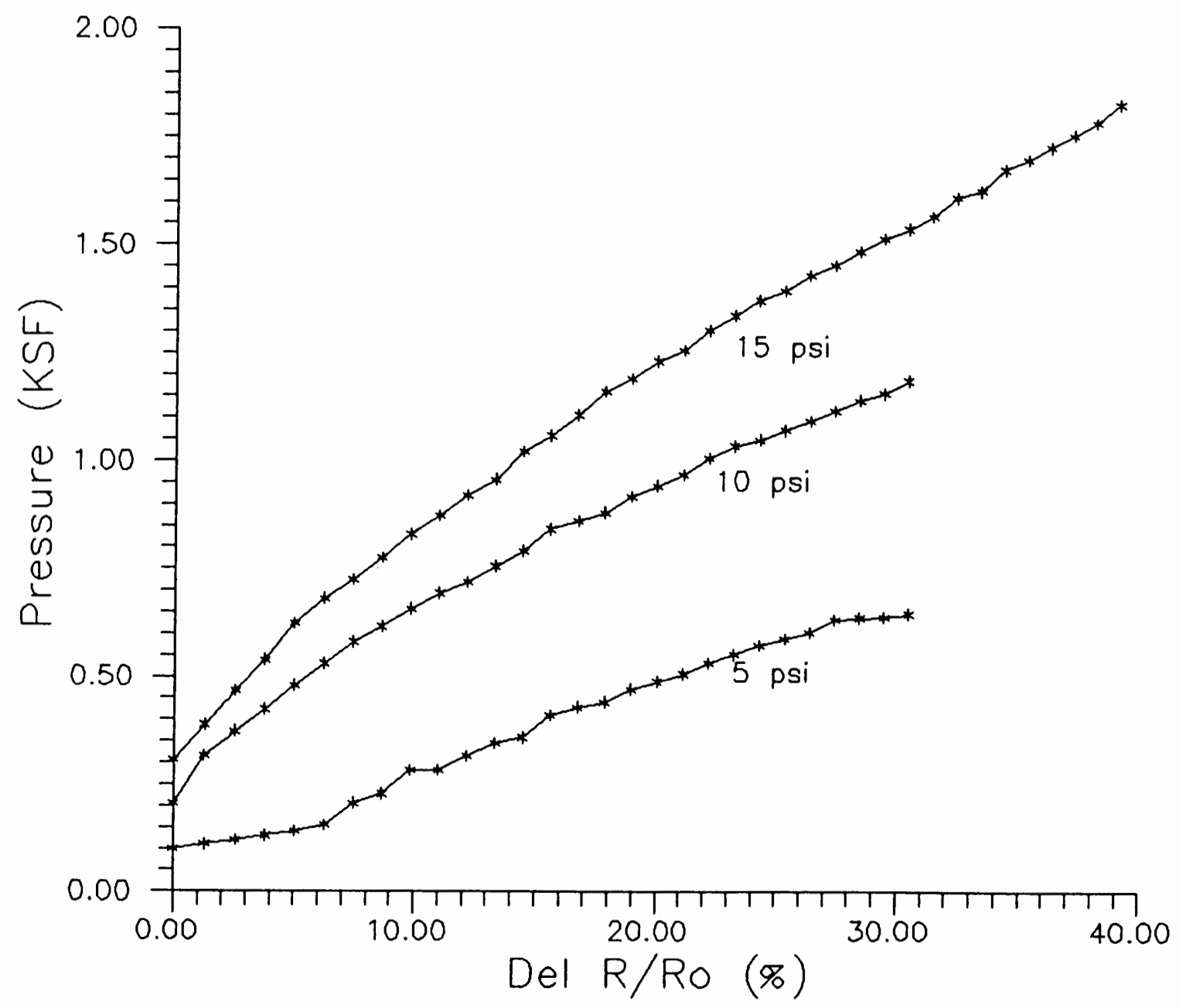

Figure 24. Pressure vs, radial strain for the PMT series 


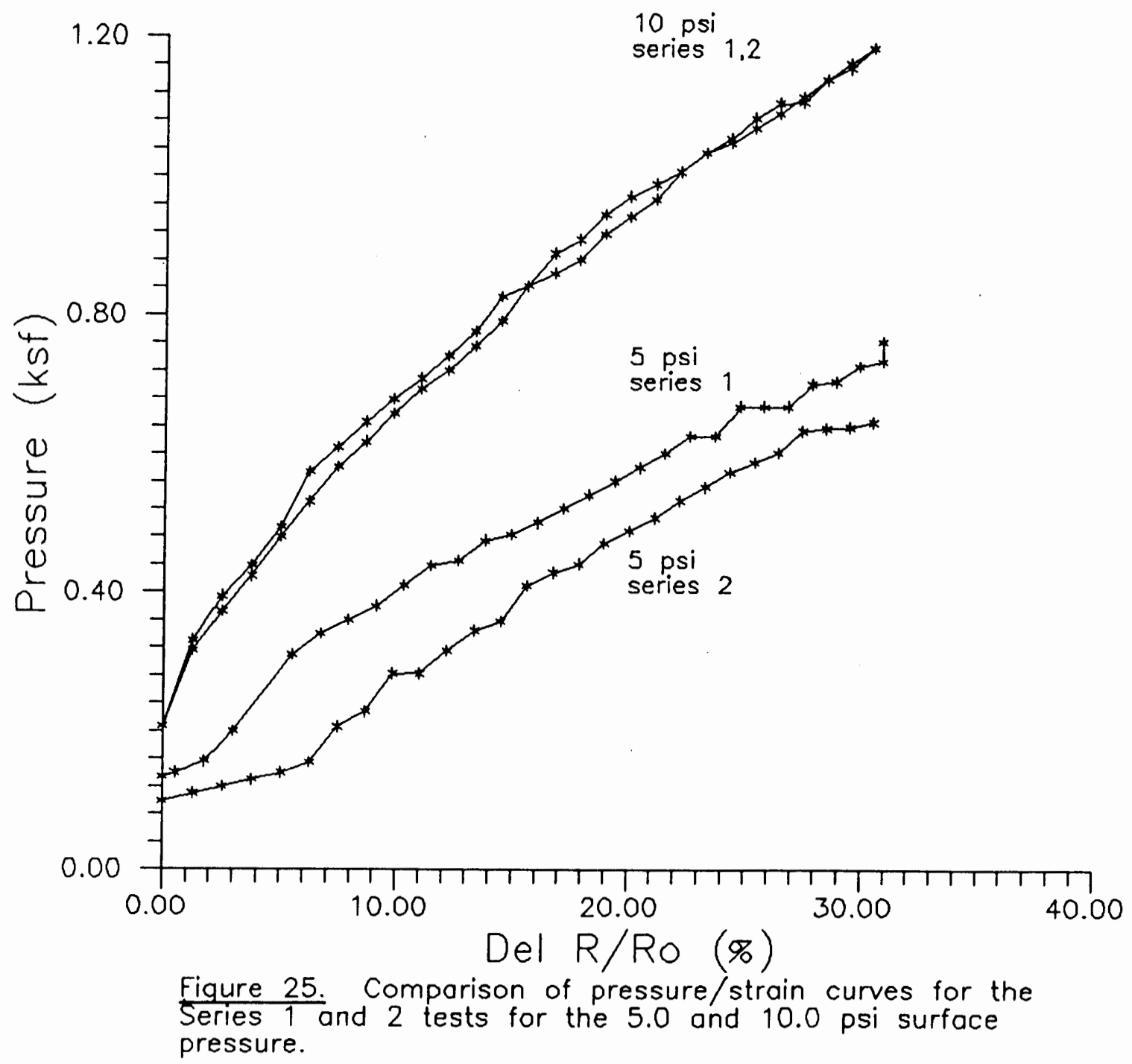


pressure, their slopes are the same. The curves for the tests conducted at $10.0 \mathrm{psi}$ are almost identical. This is in spite of the difference in recording intervals.

\section{TEST SERIES 3 - DRY TO WET/STRAIN CONTROLLED}

\section{Test Objectives}

The next series of tests were also strain controlled. This series of tests explored how the moduli changed in going from a dry state to a wet state.

\section{Test Procedures}

Due to operator error, the surface pressures used for these tests were 4.5 and $7.0 \mathrm{psi}\left(31.0\right.$ and $\left.48.3 \mathrm{kn} / \mathrm{m}^{2}\right)$ instead of 5 and $10 \mathrm{psi}$. In these tests the soil pressure and corresponding volume were taken up to about one third of estimated limit pressure. At this point about one quart of water was added to the soil through the fabric wick. As the moisture moved through the soil and collapse occurred, the pressure gauge was monitored.

\section{$\underline{\text { Test Results }}$}

The results for test series 3 are given Figure 26. The modulus of the dry material for the test ran at $4.5 \mathrm{psi}$, a depth of $18.2 \mathrm{ft}$. $(5.5 \mathrm{~m})$, is $2.0 \mathrm{ksf}(95.8$ $\left.\mathrm{kN} / \mathrm{m}^{2}\right)$, with the rebound modulus of $4.0 \mathrm{ksf}\left(191.5 \mathrm{kN} / \mathrm{m}^{2}\right)$ after wetting. For the test conducted using a 7.0 psi surface pressure, a $28.0 \mathrm{ft}$. $(8.5 \mathrm{~m})$ depth, the modulus at the natural water content is $2.0 \mathrm{ksf}\left(95.8 \mathrm{kN} / \mathrm{m}^{2}\right)$ with the modulus increasing after wetting to $5.0 \mathrm{ksf}\left(239.4 \mathrm{kN} / \mathrm{m}^{2}\right)$. In both instances, the material 


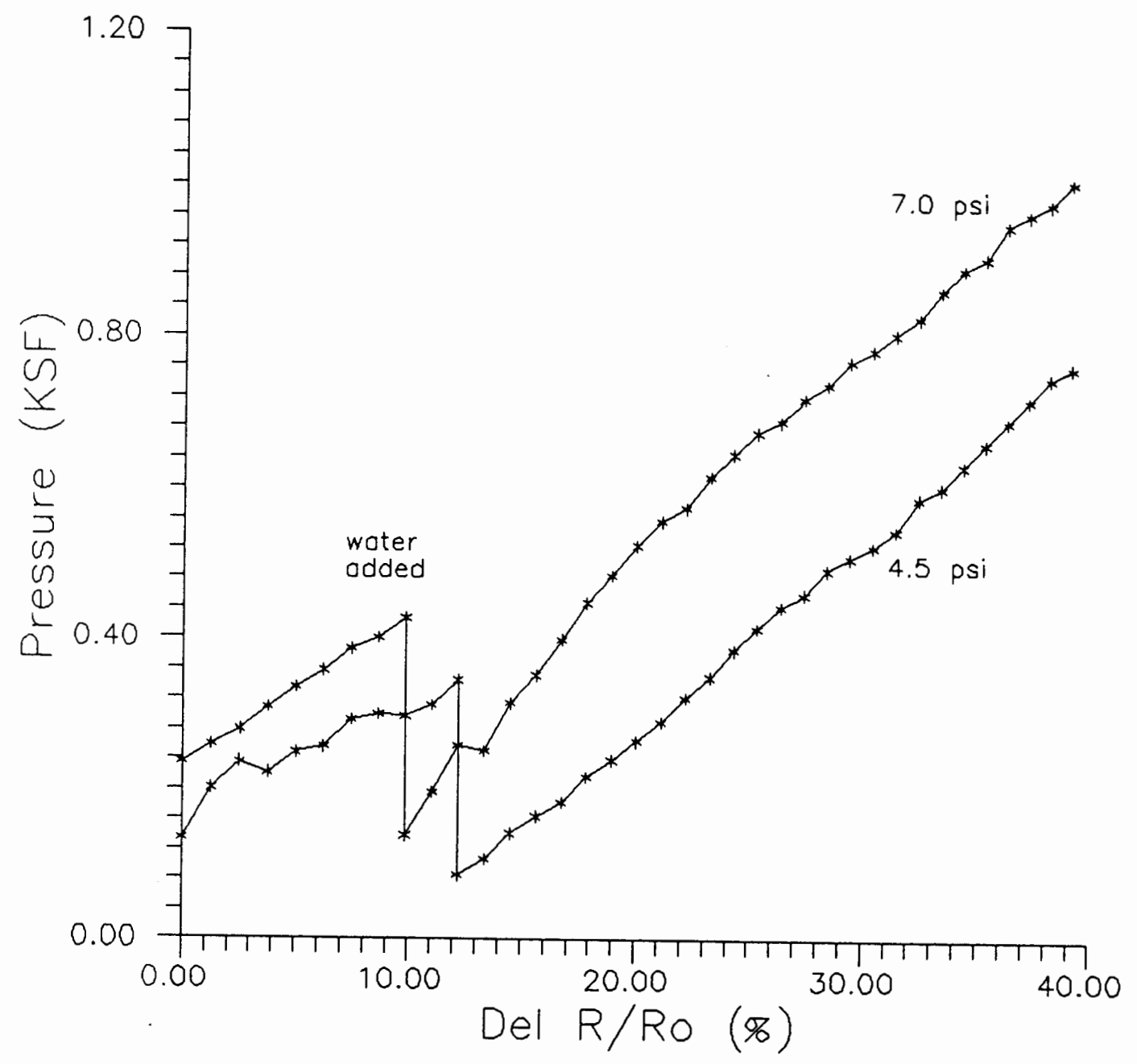

Figure 26. Pressure vs. strain curves for Test series 3 tests. Strain contralled testing with 4.5 and 7.0 psi. 
gained stiffness after collapse. Comparing the modulus of the dry material of these tests to the moduli values of the same material in the 5 and 10 psi tests shows that for this series, the moduli of $2.0 \mathrm{ksf}\left(95.8 \mathrm{kN} / \mathrm{m}^{2}\right)$ were less.

Another result from these tests is that for both tests the pressure decrease upon wetting was about $0.29 \mathrm{psi}\left(2.0 \mathrm{kN} / \mathrm{m}^{2}\right)$. This similarity is due to the surface pressures being close in magnitude and error from the inability to measure small differences in pressure. The drop in pressure arises from soil relaxation and the resulting volume of fluid in the membrane increases. Upon wetting the membrane is still at the same volume, but it is experiencing less resistance from the soil as the soil collapses. Therefore, the pressure decreases.

\section{TEST SERIES 4 - DRY TO WET/PRESSURE CONTROLLED}

\section{Test Objectives}

In the fourth series of tests, the method used was pressure controlled testing where strain became the independent variable and the pressure was the controlling variable. Two tests on dry material at 10.0 psi surface pressure were conducted. The intent in these tests was so a comparison to the strain controlled tests could be made; and so that an upper bound dry curve for this type of testing at 10.0 psi could be established.

\section{Test Procedures}

This series of tests initiated the use of pressure controlled testing. All the procedures used in test set-up, data reading intervals, and recording were the 
same. Stress controlled testing is different from strain controlled methods in that the pressure became the independent variable and the strain the dependent variable. To accomplish this, a RC108 cylinder with a loading pan to hold deadweights was used within the control unit. The test was conducted by placing a deadweight onto the pan then rotating the piston so as to release piston friction. After one minute, the displacement of the cylinder was recorded with the system under constant pressure.

\section{Test Results}

Results for the series 4 tests at 10.0 psi are given in Figure 27. The moduli of the two tests conducted are $2.0 \mathrm{ksf}\left(95.8 \mathrm{kN} / \mathrm{m}^{2}\right)$ and $6.0 \mathrm{ksf}\left(287.2 \mathrm{kN} / \mathrm{m}^{2}\right)$, the limit pressures are 0.7 and $1.1 \mathrm{ksf}\left(33.5\right.$ and $\left.52.7 \mathrm{kN} / \mathrm{m}^{2}\right)$, respectively. A visual inspection of Figure 27 shows significant differences of the two curves. One curve shows a smooth curve which has an increase of strain for every increase of stress. This curve resembles the behavior on a non-elastic material. The other curve has a "stair step" effect. In places there are large increases in strain with almost no increase in stress. This is then followed by almost no strain increases with large changes in stress. The initial stress of this curve is higher then the other curve.

The most likely cause of error is a kink in the tubing that provides the fluid to the membrane. This would increase the initial pressure reading and limit increases after, as the kink creates a pressure limit lower then that of the soil. There had been similar problems with an earlier test which had been discarded. Comparing the moduli and pressure limit of the pressure and strain controlled 


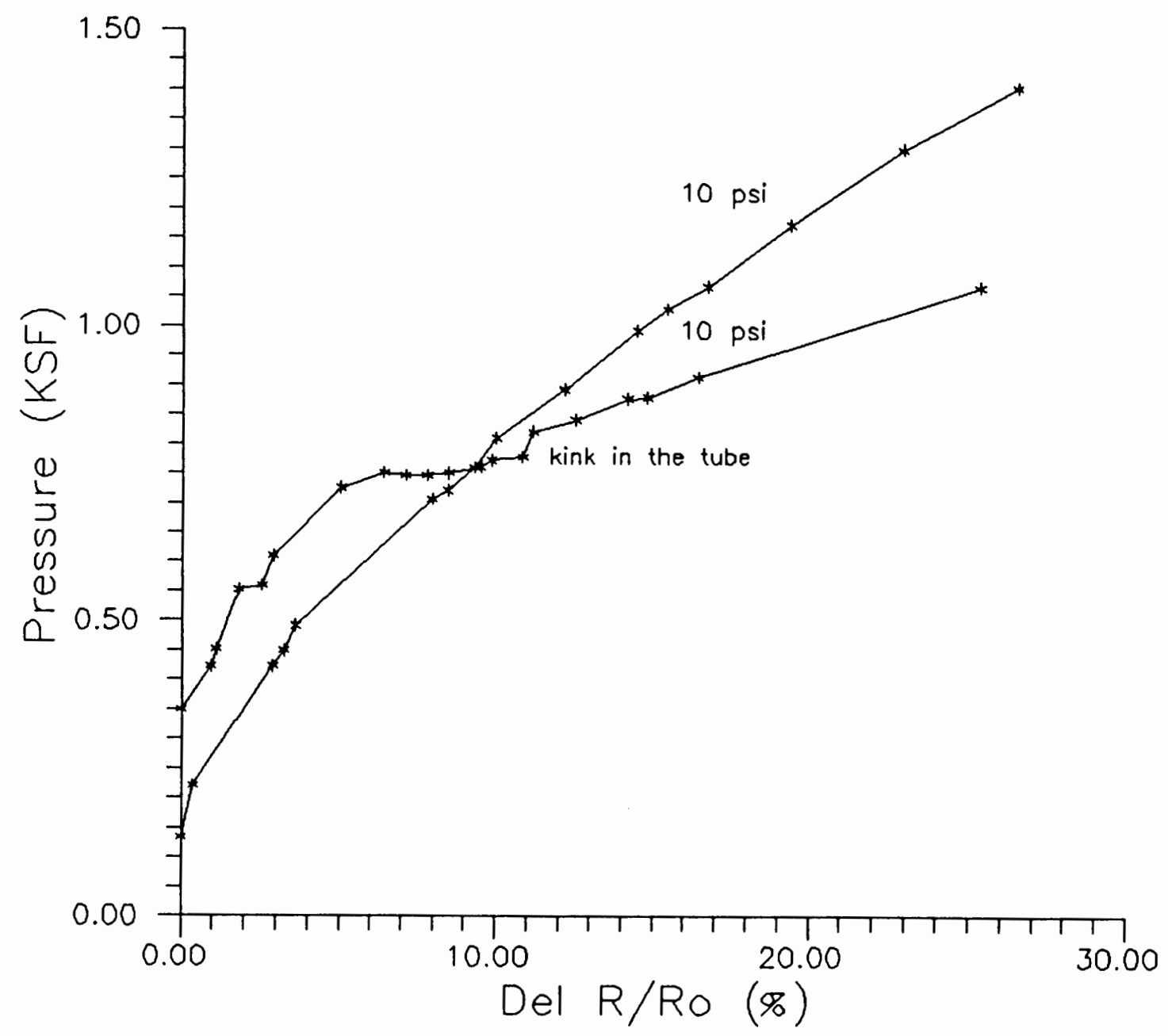

Figure 27. Pressure vs. strain for Series 4 test. A dry, pressure controlled test at 10 psi surface pressure. 
tests for 10 psi stress, Figure 28 shows there are similarities in the two types of testing. The initial pressure values are about equal and the moduli are about the same in the early portion of the curves. The curves for the strain control tests follow each other and the one for pressure control varies slightly. This confirms repeatability and equivalency for the two types of testing. This also substantiates the observation that result of the pressure controlled test with tubing problems was in error as the modulus and pressure limit was vastly different.

\section{TEST SERIES 5 - DRY TO WET}

\section{Test Objectives}

The objective in this series of tests were the same as in the Series 3 Dry to Wet tests. The moduli of the material in a dry state was to be compared to the change that occurred upon wetting.

\section{$\underline{\text { Test Procedures }}$}

The fifth series of tests, which were also pressure controlled, with the 10.0 and 15.0 psi surfaces pressures being used. For this series of tests, the soil was loaded to about one third of estimated limit pressure when water was added.

\section{$\underline{\text { Test Results }}$}

The results for this test series is shown in Figure 29. For both tests, modulus for the dry portion of the curve is $1.0 \mathrm{ksf}\left(47.8 \mathrm{kN} / \mathrm{m}^{2}\right)$. The reload modulus for the 15.0 psi test is $3.0 \mathrm{ksf}\left(143.6 \mathrm{kN} / \mathrm{m}^{2}\right)$ and for the $10.0 \mathrm{psi}$ test, the 


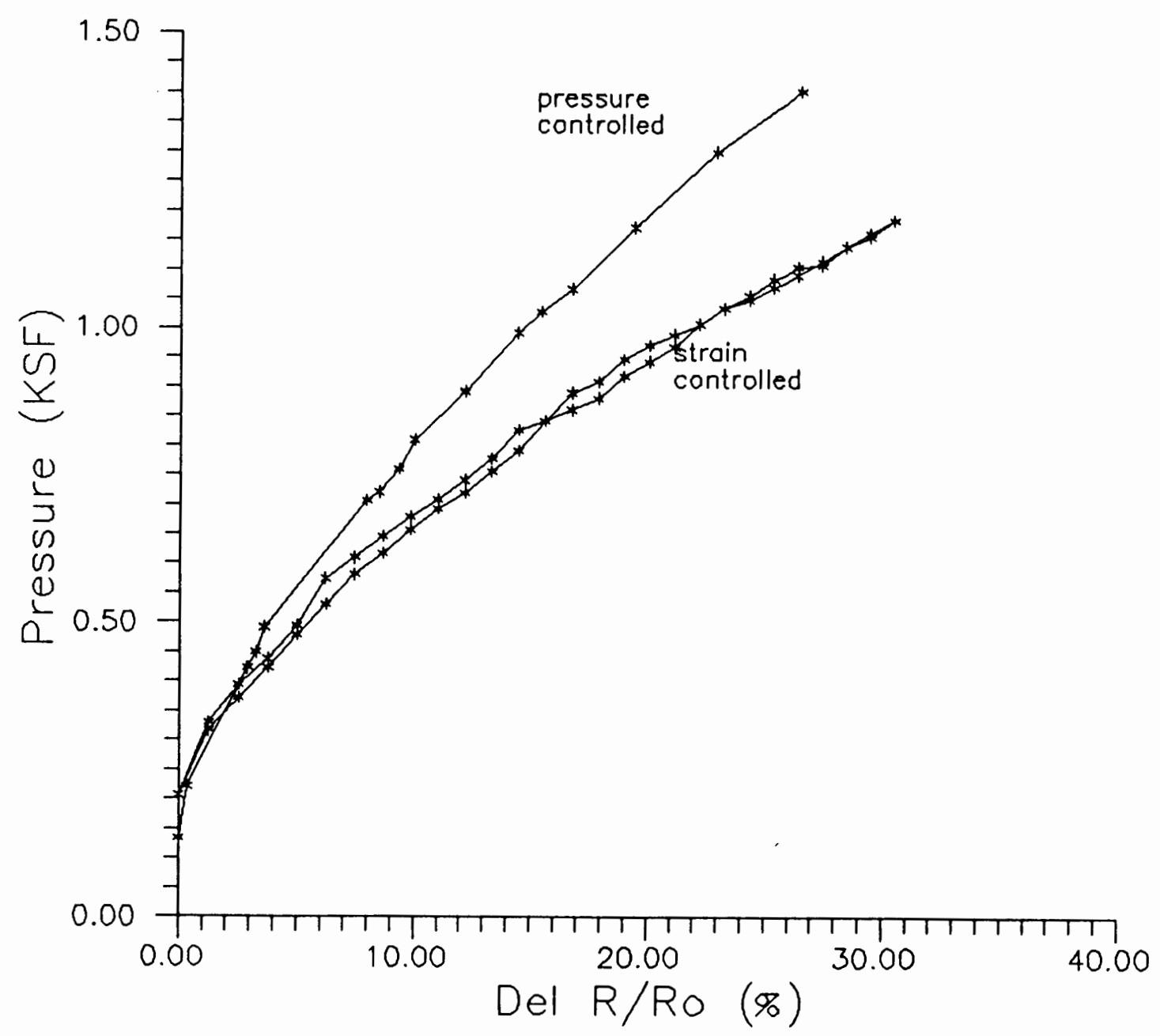

Eigure 28. Comparison of results of strain and pressure controlled tests for 10 psi-dry soil. 


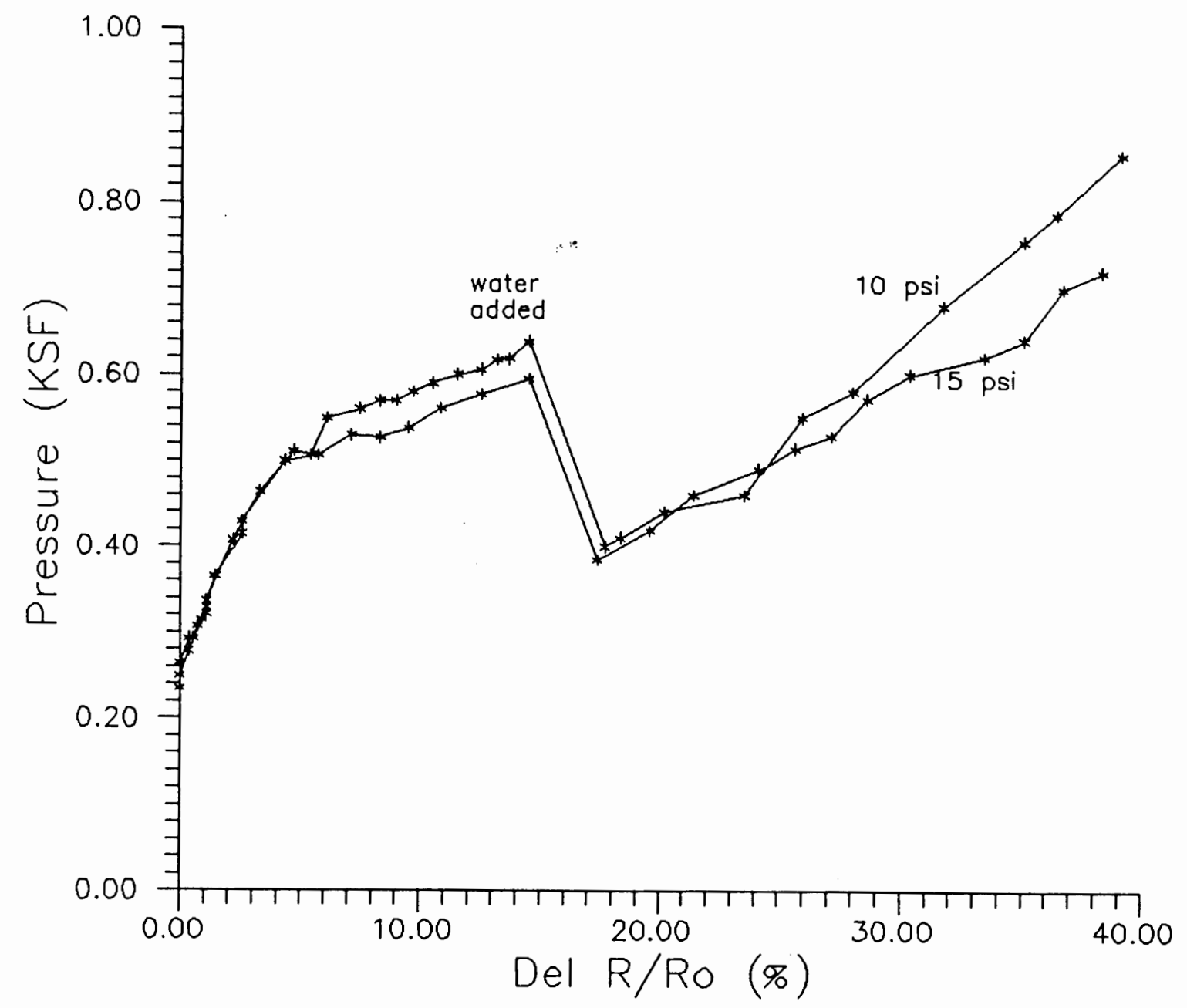

Eigure 22. Pressure vs. strain curves for the pressure controlled dry/sat test with 10.0 and 15.0 psi. 
reload modulus is $4.0 \mathrm{ksf}\left(191.5 \mathrm{kN} / \mathrm{m}^{2}\right)$. The strength of the wet material for the 10.0 psi test is higher than the material for the 15.0 psi test.

The results also show a decrease in pressure of about $0.26 \mathrm{ksf}\left(12.5 \mathrm{kN} / \mathrm{m}^{2}\right)$ with an increase of strain of about $3 \%$ upon the addition of water. Since the applied load is constant, there should be no decrease in pressure. The drop in pressure is most likely due to the friction in the piston seal eventually picking up the applied load and reducing displacement.

An observation made while taking down the test cell was that in the area where the water was added, the material formed a bulbous mass. The mass was uniform in shape with an approximate diameter of 8 inches $(20.3 \mathrm{~cm})$. The bulb maintained its shape and had to be manually broken apart. This is indicative of the strength of the material increasing upon wetting and subsequent consolidation.

\section{TEST SERIES 6 - SATURATED PRESSURE CONTROLLED}

\section{Test Objectives}

The sixth series was pressure controlled and used the 10.0 and $15.0 \mathrm{psi}$ surface pressure. This series involved saturating the material prior to applying the surface pressure. This was to determine if a critical pressure was necessary to induce collapse. Observations of some of the field tests noted that there appeared to be a critical pressure at which point an increase in strain with no corresponding increase in pressure occurred. Two quarts of water were used for these tests to aid the migration of the wetting front. 


\section{Test Results}

The results of this series of tests (Figure 30) show a modulus of $5.0 \mathrm{ksf}$ $\left(239.4 \mathrm{kN} / \mathrm{m}^{2}\right)$ and a limit pressure of $1.2 \mathrm{ksf}\left(57.5 \mathrm{kN} / \mathrm{m}^{2}\right)$ for the test conducted with the 10.0 psi surface pressure. For the test conducted with the $15.0 \mathrm{psi}$ surface pressure the modulus and limit pressure are $3.0 \mathrm{ksf}$ and $0.8 \mathrm{ksf}$ (143.6 and $38.3 \mathrm{kN} / \mathrm{m}^{2}$ ), respectively. The results show that the material tested at 10.0 psi has more strength then the soil tested at $15.0 \mathrm{psi}$.

Visual inspection of the curves do not show a critical pressure with increase in strain, and the results were unexpected. Besides no critical pressure, the results show the material at $10.0 \mathrm{psi}$ being stronger than that at $15.0 \mathrm{psi}$. This is not likely to happen in the field as granular soils gain strength with depth.

A possible cause for the error is that the wetting front did not disperse uniformly. Examination of the bulb of wet material revealed that in the $10.0 \mathrm{psi}$ test, the bulb was symmetrical, and oval shaped with a diameter of approximately 6.0 to 8.0 inches $(15.2$ to $20.32 \mathrm{~cm}$ ). The diameter of the bulb for the 15.0 psi test was about 10.0 inches $(25.4 \mathrm{~cm})$ at the top of the membrane and about 4.0 inches $(10.2 \mathrm{~cm})$ at the bottom. From previous tests results, the material becomes stronger after wetting. In this test only a fraction of the material became wet, therefore it did not achieve the increase in strength. 


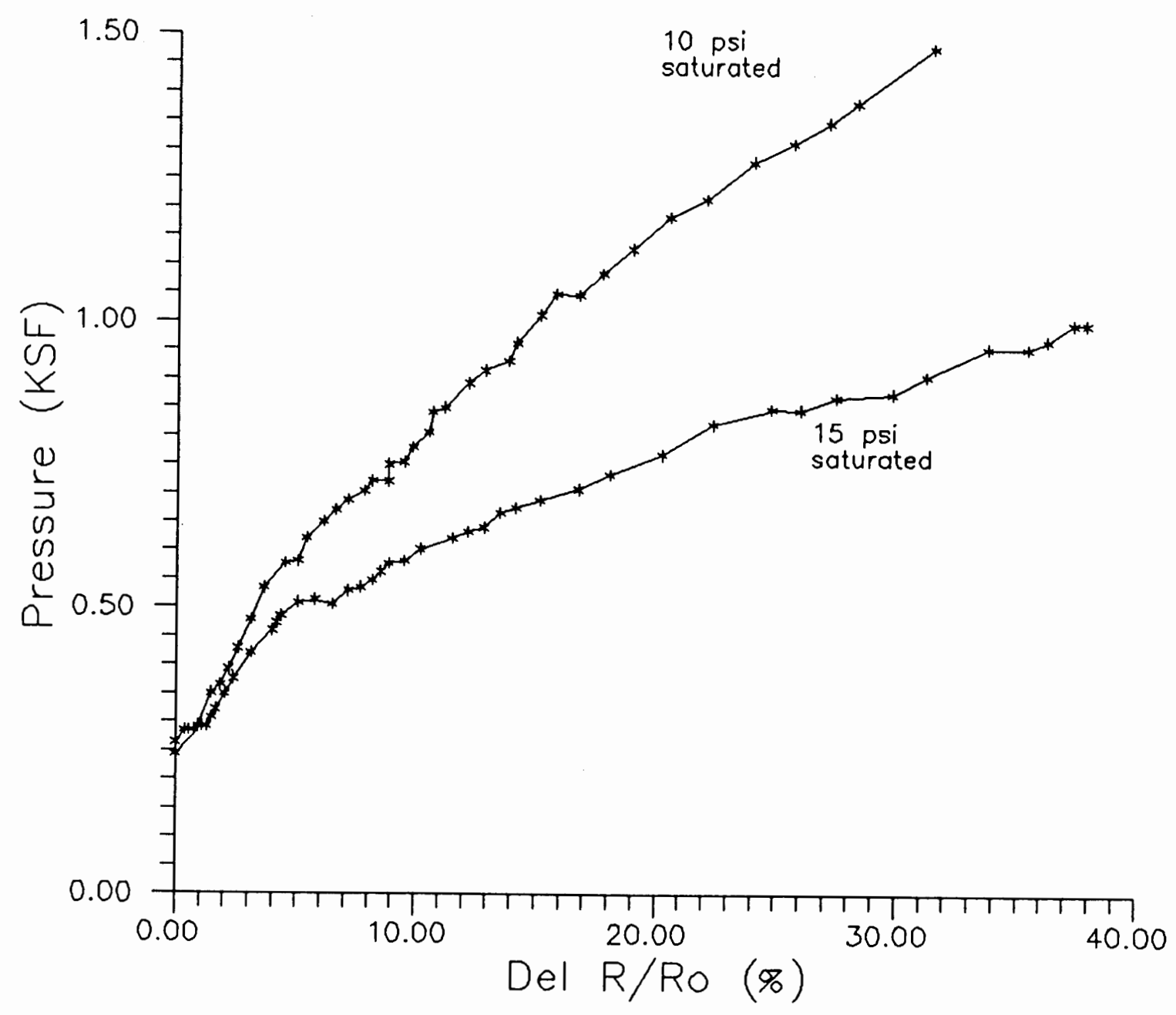

Figure 30. Pressure vs. strain curves for saturated pressure controlled test with 10.0 and 15.0 psi. 


\section{CHAPTER VI}

\section{TRIAXIAL TESTING}

\section{OBJECTIVES}

\section{Stress States}

The triaxial testing was used to gain an understanding of the change in stress states of the soil at its natural water content, and in a saturated state. Further, do these states represent boundaries? In order to address this question, Mohr Coloumb failure criteria was selected to determine the maximum shearing stress and the friction angle, phi. For the soil in a dry and saturated state, it may determine if the soil gains strength or loses strength upon wetting.

\section{Stress Paths}

The same tests were used to determine the stress paths and corresponding failure surfaces in q-p space. If a distinctive failure surface existed for the dry and saturated states, the stress path movement between these stakis could be recorded.

\section{Testing Program}

Triaxial confining pressures of 5.0,10.0, 15.0 psi were employed for stress path correspondence to the pressuremeter tests. Three series of tests were 
conducted to study the soil in the different states of moisture content. The Series 1 tests dealt with the material in a dry state, Series 2 tests in a saturated state, and Series 3 tests examined the change in parameters when going from a dry to a saturated state.

In addition, two other tests were conducted. One of the tests was to determine if there was any inherent significant creep in the soil. The other was a "strain controlled" test that was representative of insitu stress conditions.

\section{APPARATUS AND EQUIPMENT}

\section{Triaxial Assembly}

The apparatus used was the Soiltest Triaxial Assembly model T156 and the T-108 Triaxial Chamber. Modifications to the assembly included removing the proving ring and using a $1.0 \mathrm{in} .(2.54 \mathrm{~cm})$ steel rod to apply the load. The magnitude of load was recorded by a load cell that was placed between the steel rod and a steel base that was built to fit onto the triaxial chamber. Measuring and recording the deflection of the sample was accomplished by the use of a linear voltage differential transducer (LVDT). Figures 31 and 32 show the triaxial assembly with the loading rod, the base for the load cell and LVDT. Another modification made, was to attach a $1000 \mathrm{cc}$ pipette tube with flexible tubing to the frame. The purpose was to introduce water to the sample directly from the tube into the base of the sample. This allowed quick evacuation of water in the system and eliminated the threat of the sample getting wet in dry testing. 


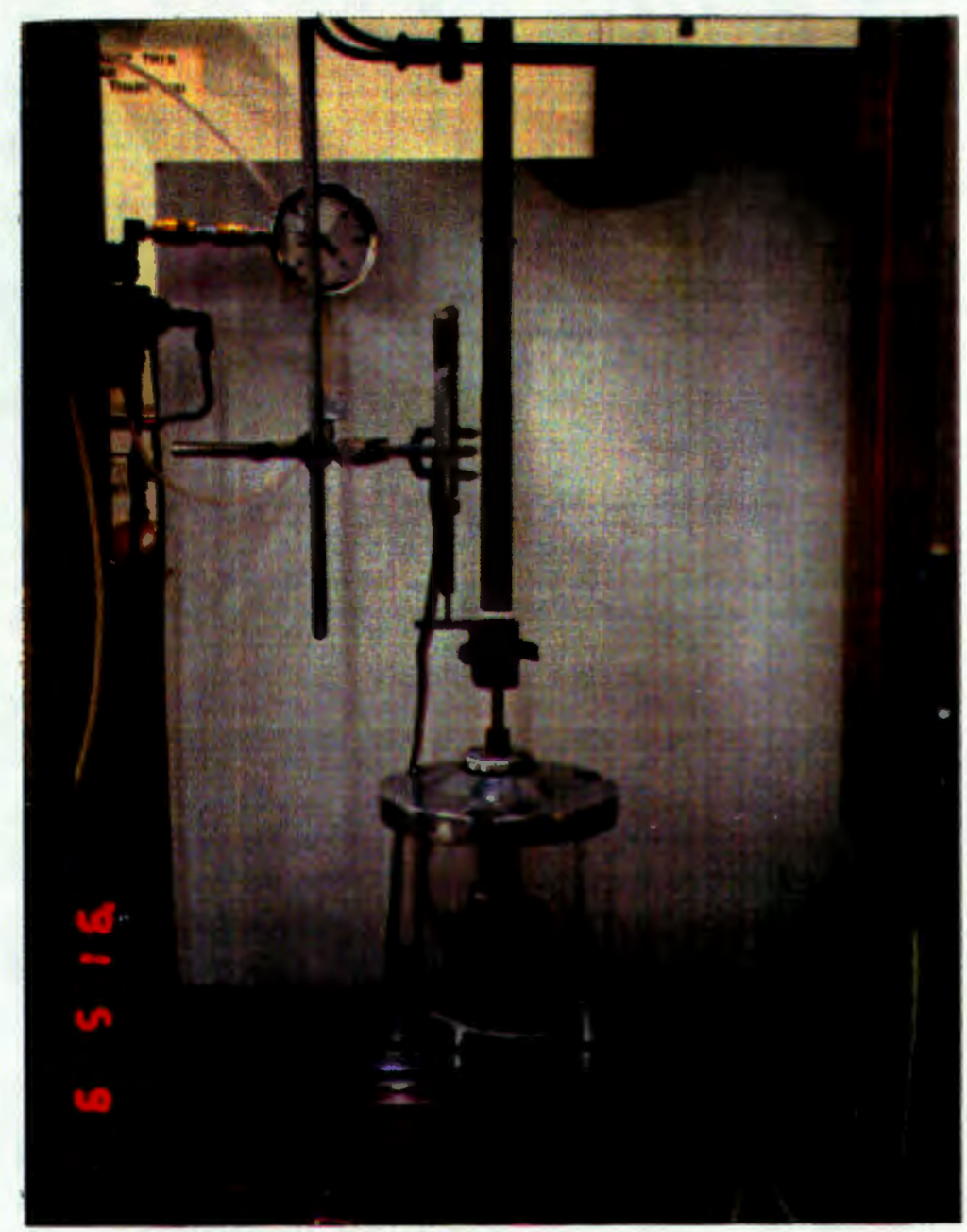

Figure 31. Triaxial assembly with LVDT, load cell, and steel loading. rod.

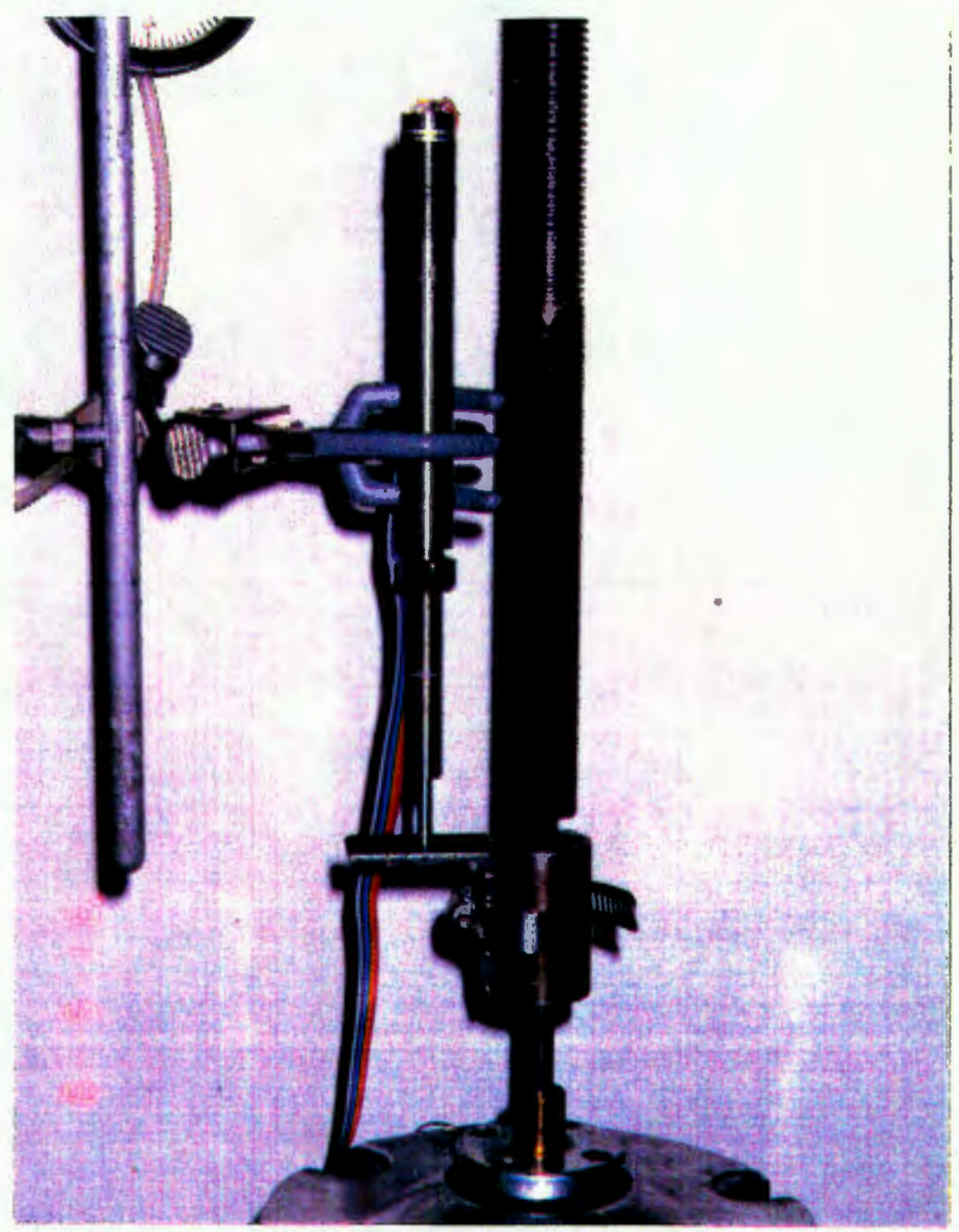

Figure 32. Close-up of triaxial assembly. 


\section{Data Acquisition}

The deflection of the top of a sample together with the load was monitored through a data acquisition unit EDGGE, Electronic ㅁata Gathering System for Geotechnical Engineering (Smith and Boyer, 1990). The EDGGE is a multifunction data acquisition and reduction unit. It uses linear voltage differential transducers (LVDT) to measure displacements and a load cell to measure applied load. These sensors develop an electronic signal which is conditioned, and converted from an analog to digital signal for computer interpretation. The digital signal is transmitted to a Zenith laptop computer by a RS232C serial port interface. The computer then further conditions, stores and reduces the data.

\section{Diameter Collar}

Volume change during a triaxial test is normally measured, for saturated samples, by recording the volume of water flowing into, and out of, the sample. For the testing to be done, the samples would not be saturated so this method of volume measurement could not be used. Additionally, the triaxial equipment being used did not have the devices necessary to measure volume change. In order to measure volume, a small sliding collar that was marked in centimeters was placed around the specimen at the mid section. Before testing an initial reading of the diameter would be made and as the diameter of the sample increased, the collar would expand, thus allowing a measurement of volume change. 


\section{TEST PREPARATION}

\section{$\underline{\text { Material }}$}

The test samples consisted of $1.27 \mathrm{oz}$. (36.0 grams) of the $50 / 50$ mixture of CVD. It was decided to use the 50/50 mixture in this testing because the sample size was small enough that sieving, weighing and mixing the material was not time consuming. Another reason for this choice was the material that had been received by Oil Dry, Inc. (35/56 mixture) had been used in the Pressuremeter testing and was contaminated with collapsed soil. For each sample, $0.63 \mathrm{oz}$. (18.0 grams) of the soil retained on the no. 7 and 20 sieves was used. Once the material was weighed it was then mixed. In order to maintain a uniform mixture the soil was gently stirred as it was placed in the former. Due to the hardness of the soil when dry, no mechanical damage occurred during the mixing. The sample dimensions were 1.4 inches $(3.56 \mathrm{~cm})$ in diameter with a height of about 2.99 inches $(7.6 \mathrm{~cm})$, making a height to diameter ratio of about 2 . The unit weight of the sample was $29.7 \mathrm{pcf}(480.9 \mathrm{Kg} /$ cubic meter $)$.

\section{$\underline{\text { Set Up }}$}

Following the preparation procedures for a dry granular triaxial sample (Bishop \& Henkel, 1962), a metal former was used as a mold. A membrane was placed inside the former and placed on the triaxial pedestal. With the bottom stone and filter paper in place, a vacuum was applied to the former which held the membrane against the walls of the former. The material was placed into the form in lifts of about $0.42 \mathrm{oz}$. $(12.0 \mathrm{gm})$. Each lift was then gently packed with a 
soft, blunt instrument. With the soil in the form and a vacuum applied through the sealed sample the form was removed. Next, the chamber assembly was placed in position and the confining pressure was applied while the vacuum was released. Unlubricated ends were used for all testing. The final step was to place the base for the load cell on the triaxial chamber and attach the load cell. After initial readings and EDGGE set-up, the test proceeded.

\section{DATA REDUCTION}

\section{$\underline{\text { Reduction of Data From EDGGE }}$}

Data reduction required taking the data gathered from EDGGE and importing it into the spreadsheet program Quarto Pro. The data as received from EDGGE contained values for displacement and load prior to the commencement of the test. These values were subtracted in order to obtain zero values for when there had been no displacement or load. When gathering data, EDGGE collects several values for the load per increment of strain. With all acquired data plotted, the resulting graph has a "stair step" curve.

\section{Stress Computation}

To compute stress on the sample, the cross sectional area was required. The only means available to measure the changing area was the collar. This required visual observation and measurement of the collar and sample movement. Because the movement was slight, no measurement was possible. In order to compute stress, an assumption about the stress/strain relationship had to be made. 
Using a model similar to metals, it was assumed that there existed a definable yield point between the elastic and plastic strains. According to visual observation, the sample experienced lateral displacement, or barreling, which occurred at elastic yield.

The assumption used to compute stress was that in the elastic zone the volume change was due to material compression only and the area remained constant. Once the material was stressed beyond the elastic zone, the volume change became constant, therefore the area of the sample changed. To compute the area change, a correction in area obtained from vertical strain was used. The equation used for area in the plastic zone is given in equation 6.1.

$$
A_{c}=\frac{A_{o}}{(1-\text { Vertical Strain })}
$$

In this equation $\boldsymbol{A}_{\boldsymbol{q}}$ is equal to the corrected area and $\boldsymbol{A}_{\boldsymbol{q}}$ is the original cross sectional area of the sample. Since the vertical change was so small, the correction was even smaller; therefore the change in stress showed no drastic increases. This led us to consider the assumption a safe one because the chance of error remaining slight.

\section{TEST SERIES 1 - DRY SOIL}

\section{$\underline{\text { Series Procedure }}$}

The first series of tests were conducted on the dry material. In this series of tests, confining pressures of 5.0, 10.0, and $15.0 \mathrm{psi}\left(34.5,68.9\right.$ and $\left.103.4 \mathrm{kN} / \mathrm{m}^{2}\right)$ 
were used. Once the confining pressure was applied, the deviator load was applied at a constant strain rate until after thirty percent vertical strain occurred. For the tests conducted at 10.0 and 15.0 psi, at least two tests were conducted in order to verify repeatability.

\section{$\underline{\text { Series Results }}$}

The results for the series 1 tests are given in Figures 33 and 34. A visual inspection of Figure 33, deviator stress vs. strain, shows that for increasing confining pressure with a corresponding increase in shear capacity. The computed values for the approximate maximum shear, or deviatory stress before plastic failure are $11.0 \mathrm{psi}\left(75.8 \mathrm{kN} / \mathrm{m}^{2}\right)$ for a 5.0 psi confining pressure; $17.0 \mathrm{psi}(117.2$ $\left.\mathrm{kN} / \mathrm{m}^{2}\right)$ for a 10.0 psi confining pressure; and $30.0 \mathrm{psi}\left(206.8 \mathrm{kN} / \mathrm{m}^{2}\right)$ for $15.0 \mathrm{psi}$ confining pressure.

From Mohr Coloumb criteria the friction angle showed large variations at low strain levels and at about $1.66 \%$ to $2.3 \%$ strain, the friction angle became more consistent. At $0.33 \%$ strain the angle varied from 32.0 to 26.0 to 30.0 degrees for the 5.0, 10.0, and 15.0 psi tests, respectively. At $2.33 \%$ strain, the angle varied linearly, ranging from 63.0 degrees at 5.0 psi confining to 60.0 degrees for 15.0 psi confining pressures. Figure 34 shows a family of curves of the trace of the Mohr Circles failure surfaces for the dry tests at strain levels ranging from $0.33 \%$ to $2.6 \%$. As can be seen in this figure, at about $1.6 \%$ to $2.3 \%$ strain the curve becomes linear. From these curves, it was decided to use $2.3 \%$ strain as the point of failure for the dry material. This resulted in a maximum axial stress 


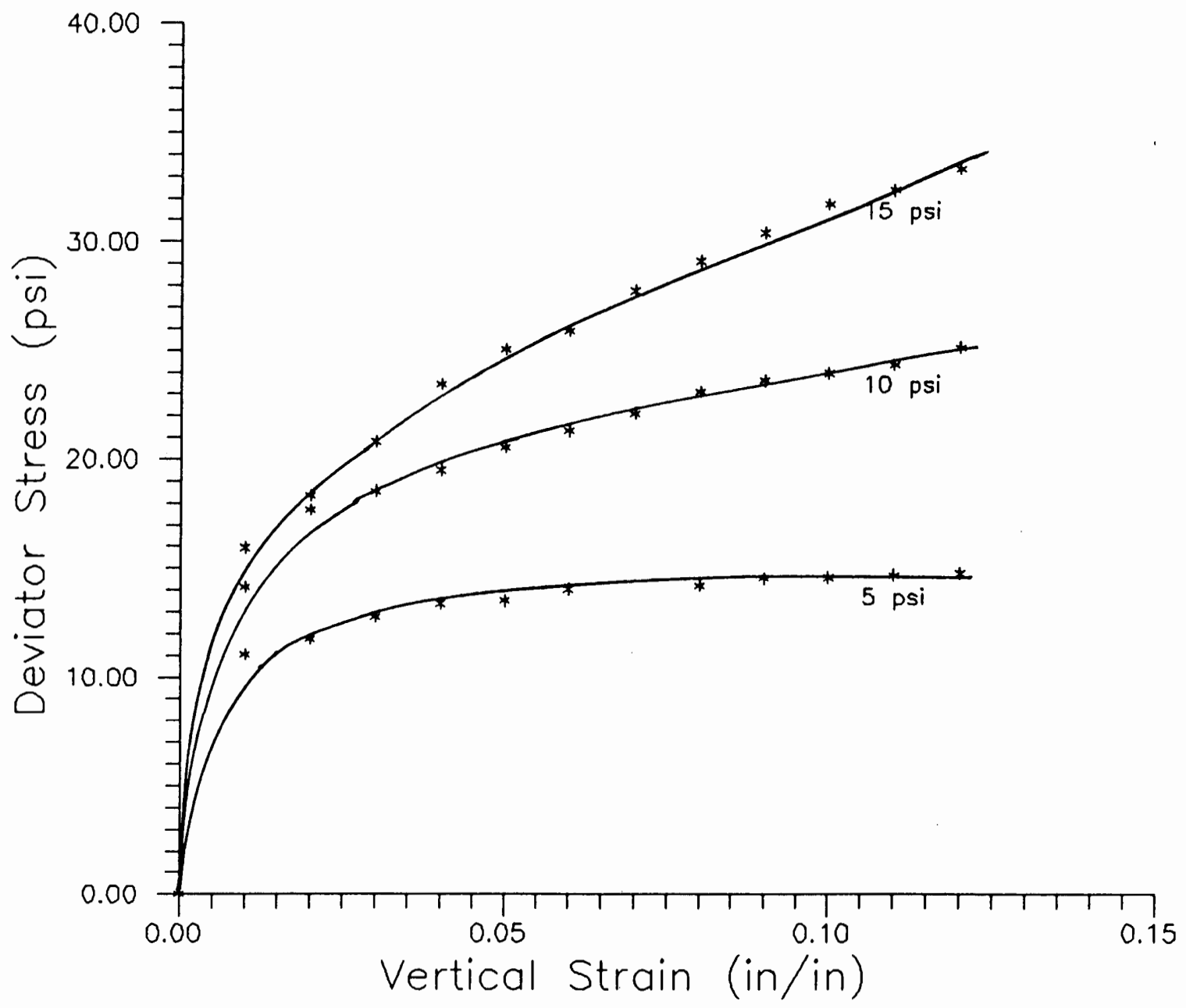

Figure 33. Deviator stress verses vertical strain for the dry soil at 5.0, 10.0 and 15.0 psi confining pressure. 


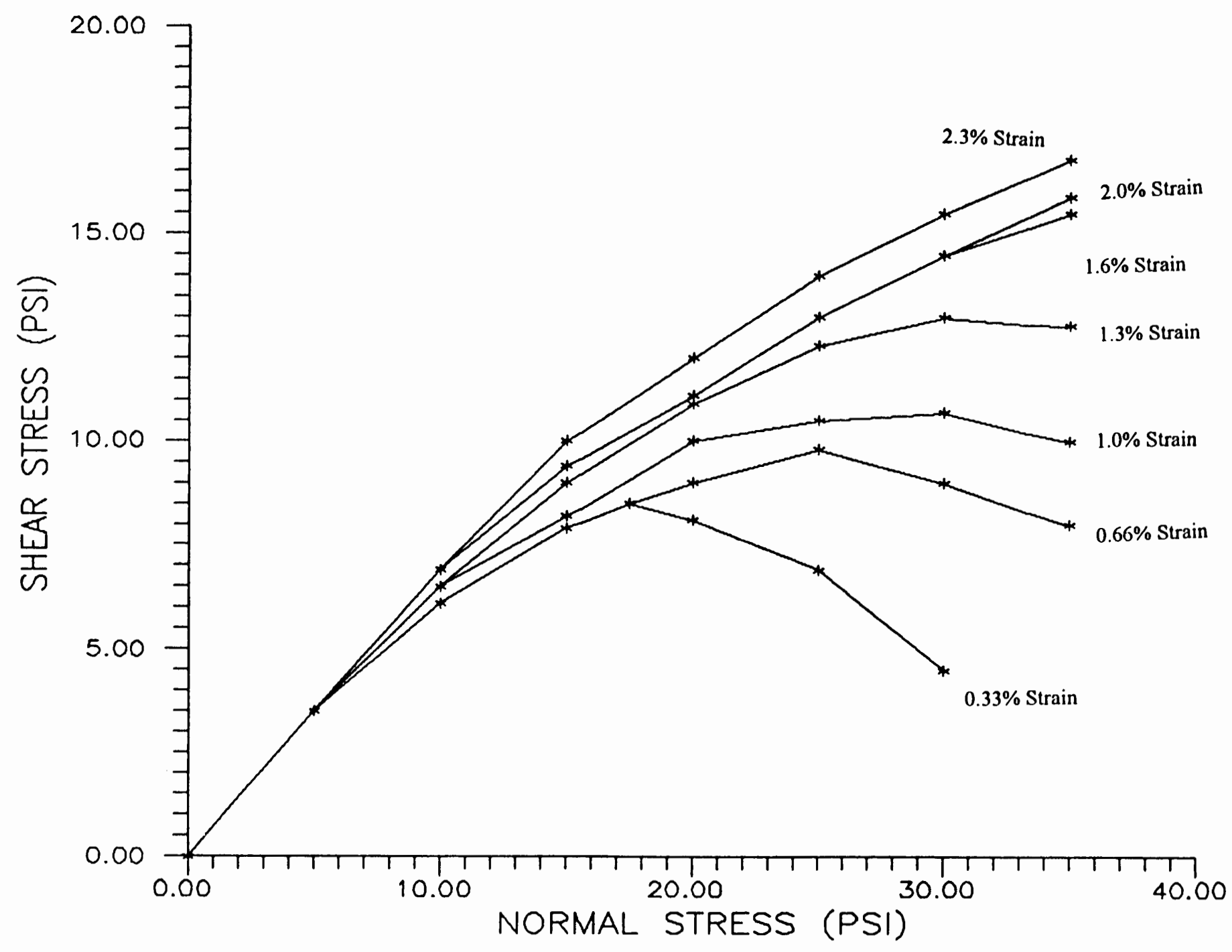

Figure 34. Failure surfaces for Mohr Circle with 5, 10, and 15 psi confining stress and $0.33 \%-2.3 \%$ strain. 
(sigma 1) of $19.2 \mathrm{psi}\left(132.4 \mathrm{kN} / \mathrm{m}^{2}\right)$ for the $5.0 \mathrm{psi}$ confining stress; $32.1 \mathrm{psi}(221.2$ $\left.\mathrm{kN} / \mathrm{m}^{2}\right)$ for the $10.0 \mathrm{psi}$ stress and $42.7 \mathrm{psi}\left(294.4 \mathrm{kN} / \mathrm{m}^{2}\right)$ for the $15.0 \mathrm{psi}$ confining stress. Figure 35 shows sigma 1 verses strain for the dry material.

To verify repeatability, more then one test was ran for the 10.0 and $15.0 \mathrm{psi}$ confining pressures. Figures 36 and 37 shows the deviator stress vs. strain for the 10.0 and 15.0 psi tests. As can be seen, on both figures is one curve (3dry10 and 2dry15) showing a higher shear stress capacity then the other tests with the same confining stress. This is due to the collar offering resistance to expanding and increasing the strength of the sample. Following this observation, the use of the collar was discontinued. Otherwise the results verified repeatability of the tests.

\section{SERIES 2 TESTS - SATURATED SOIL}

\section{Series Procedure}

The second series of tests were similar to the first with the exception that the soil was flooded with deaired water prior to applying the deviator load. After the test the moisture content of the soil was determined.

\section{$\underline{\text { Series Results }}$}

In computing the stresses for the saturated soil, a change in area calculation was made. It was observed that the sample did not barrel. Therefore the assumption of volume change being due to compression with a constant area was used. 


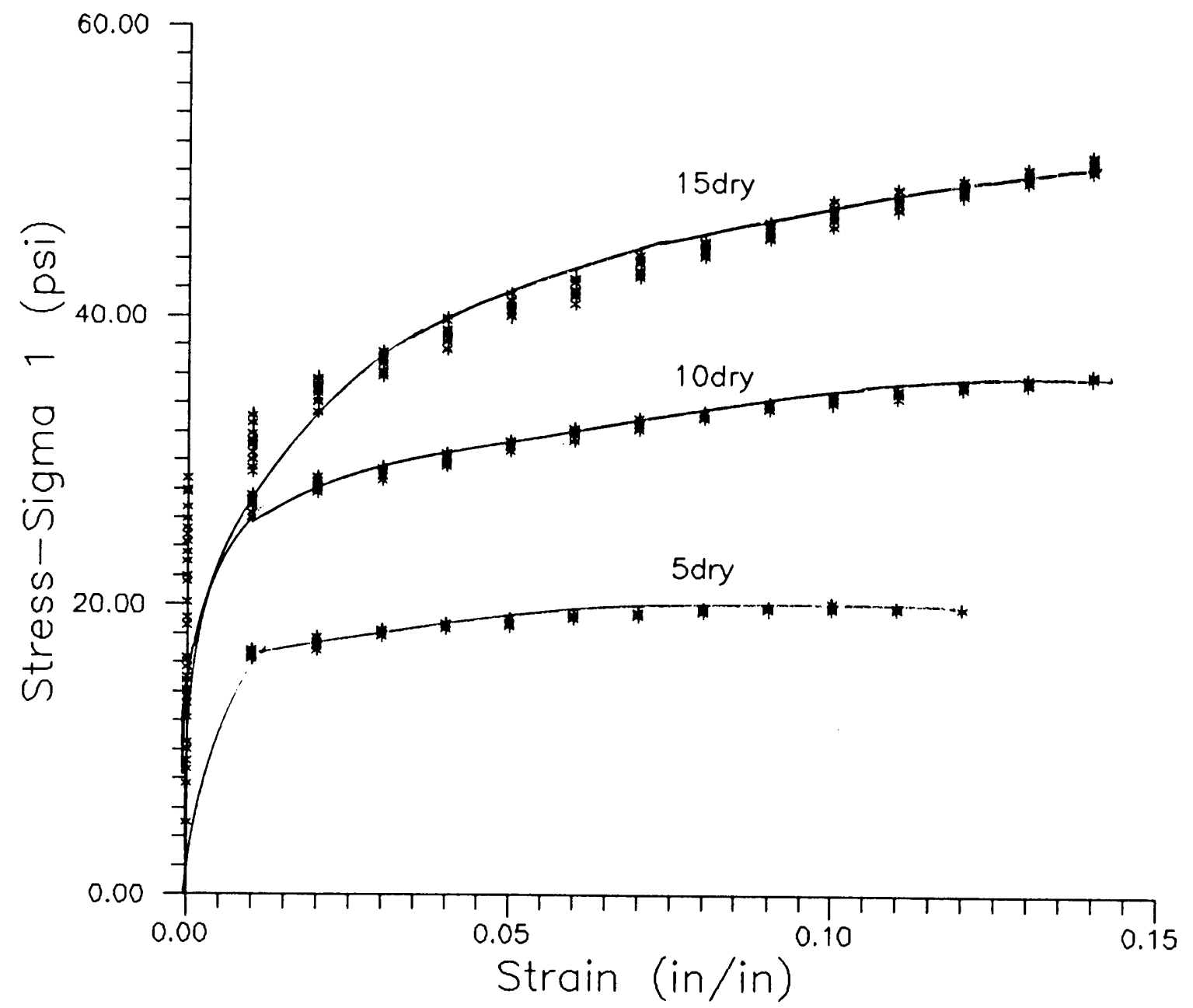

Eiqure 35. Triax testing on dry CVD at 5.0, 10.0, and 15.0 confining stress. 


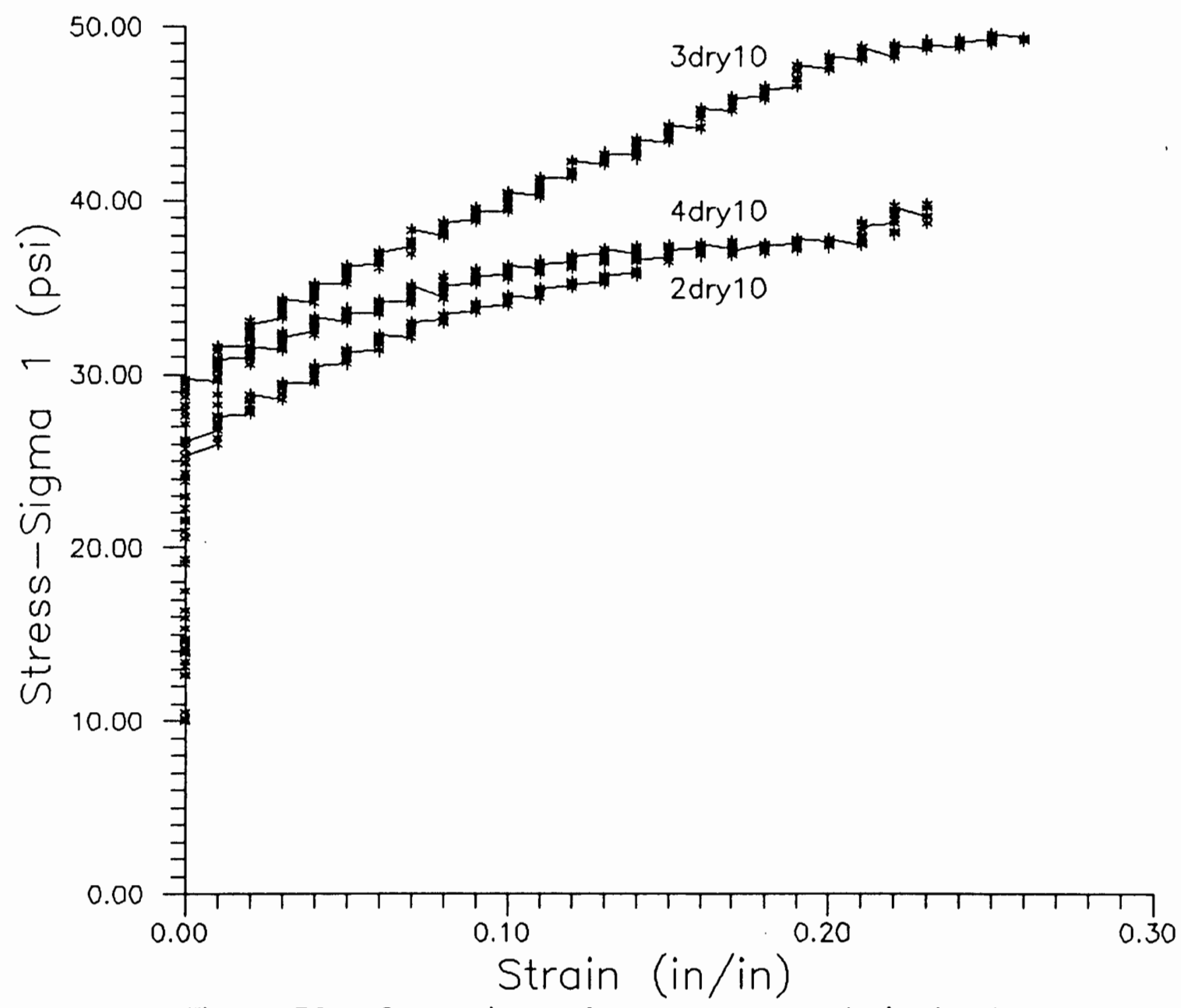

Eigure 36. Comparison of stress verses strain for the tests conducted on the dry CVD at 10.0 psi confining stress. 


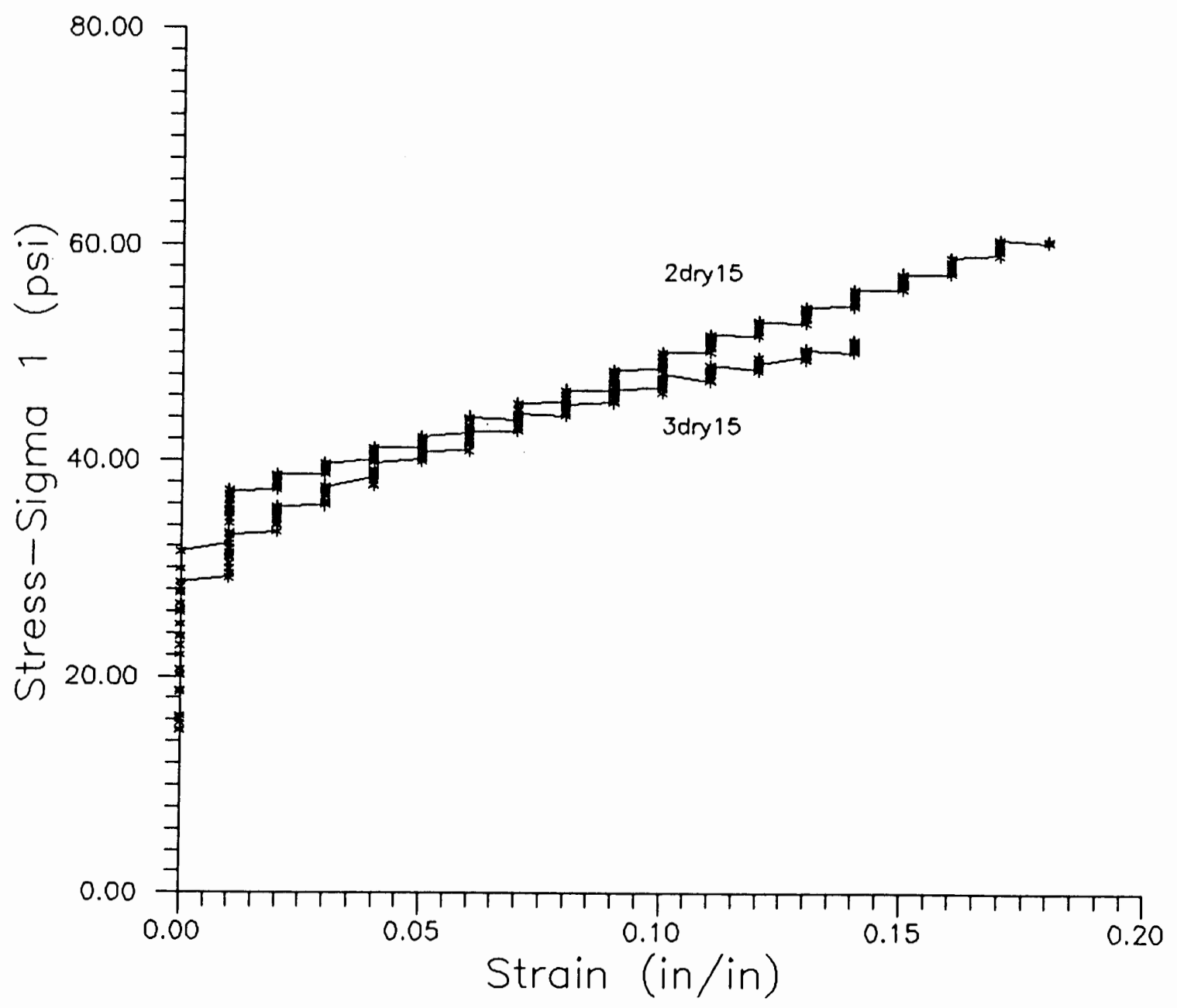

Eigure 37 Comparison of stress verses strain for the tests conducted on dry CVD at 15.0 psi confining stress. 
The shear stress vs. strain is shown in Figure 38. Similar to the dry tests is the increase in shear capacity with confining stress. The maximum stresses appear to be $3.5,9.0$, and $20.0 \mathrm{psi}\left(24.1,62.0,137.9 \mathrm{kN} / \mathrm{m}^{2}\right)$ for $5.0,10.0,15.0 \mathrm{psi}$ confining pressures, respectively.

Plotting the failure surface from Mohr Circle calculations shows the friction angle becoming linear or consistent at $1.6 \%$ to $2.3 \%$ strain. The angle varies from 53.0 to 63.0 to 64.0 degrees at $0.33 \%$ strain and at $2.33 \%$ strain remains at about 58.0 degrees for the different confining pressures. Figure 39 shows the family of curves. As with the dry material, using $2.33 \%$ strain as the yield point gives a maximum sigma 1 of $13.0,26.0$ and $39.2 \mathrm{psi}\left(89.6,179.3,270.3 \mathrm{kN} / \mathrm{m}^{2}\right)$ for the 5.0 , 10.0 and 15.0 psi tests, respectively. This is shown on Figure 40.

\section{SERIES 3 TESTS - DRY THEN SATURATED}

\section{Test Procedure}

In the third series of tests, the deviator load was applied until about one third the maximum shear stress of the dry soil was reached. At that point the load remained constant while the creep or relaxation was allowed to take place, which took about five minutes. Water was then added while the machine remained off. When the collapse appeared to cease, the increase in applied load continued while the characteristics of the material in a saturated state were recorded. Throughout the entire procedure the EDGGE remained active in gathering data. 


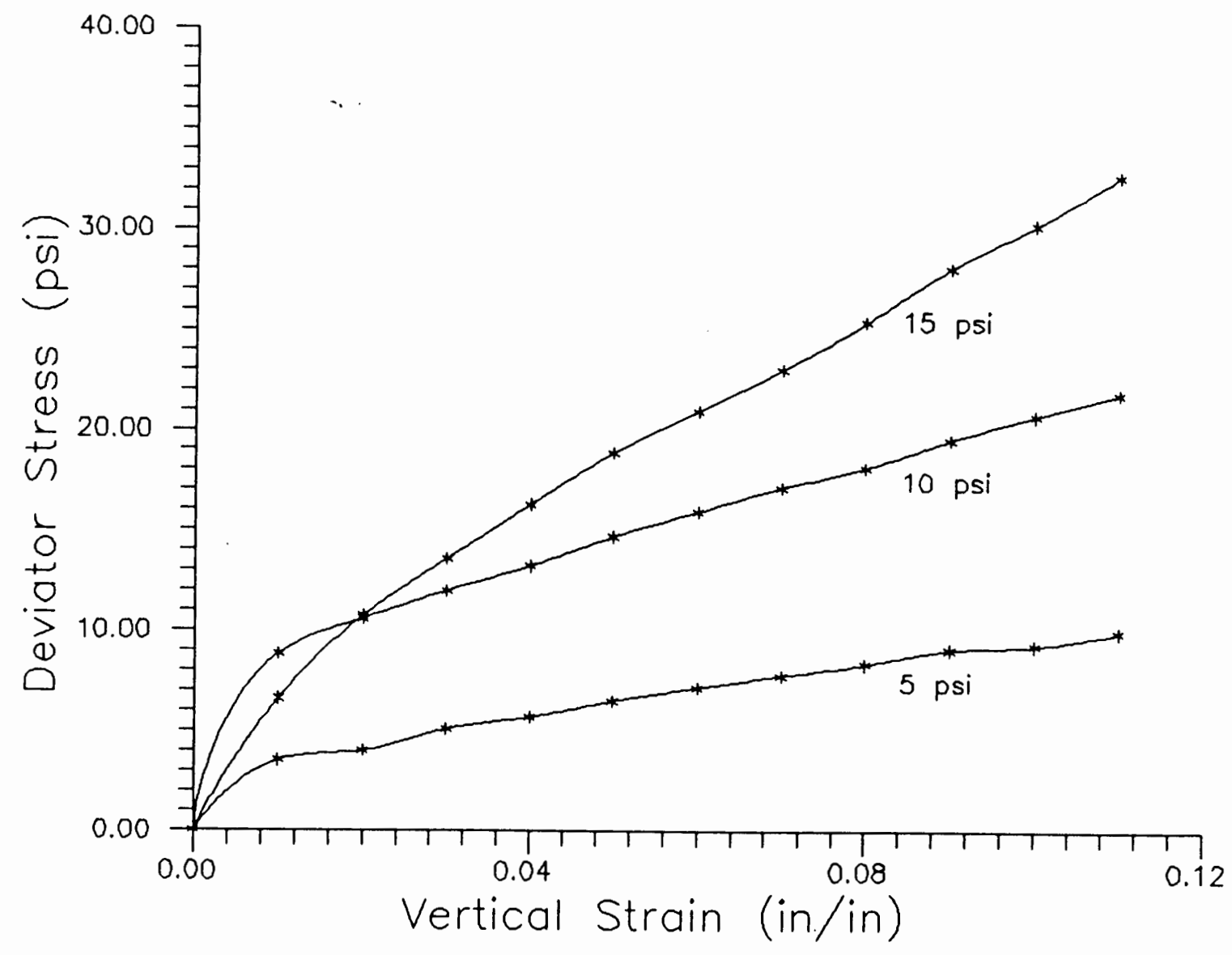

Eigure 38. Deviator stress verses vertical strain for the saturated soil at 5.0,10.0 \& 15.0 psi confining pressures. 


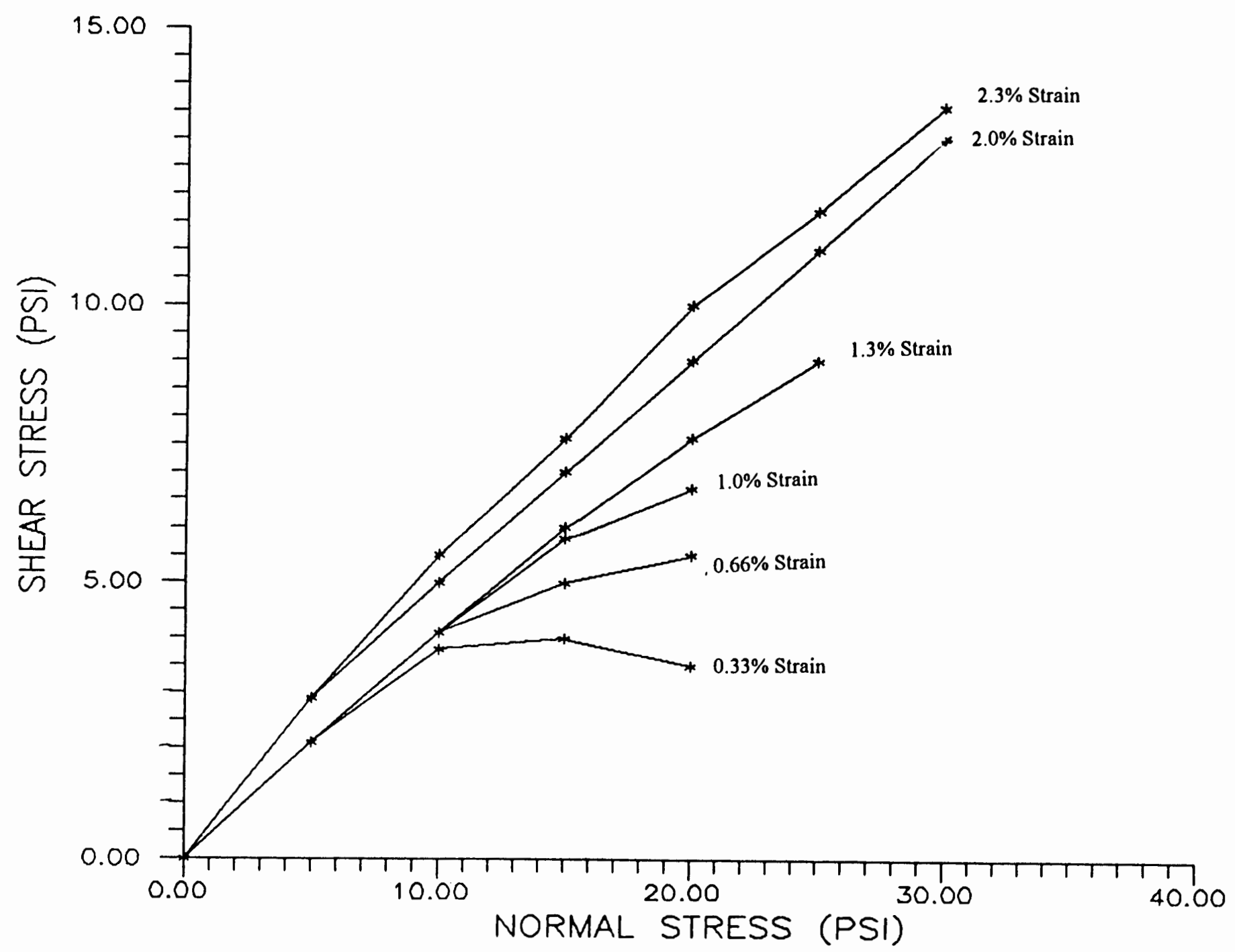

Figure 39. Failure surfaces for Mohr Circle with 5, 10, and 15 psi confining stress and .33\%-2.3\% strain on saturated material. 


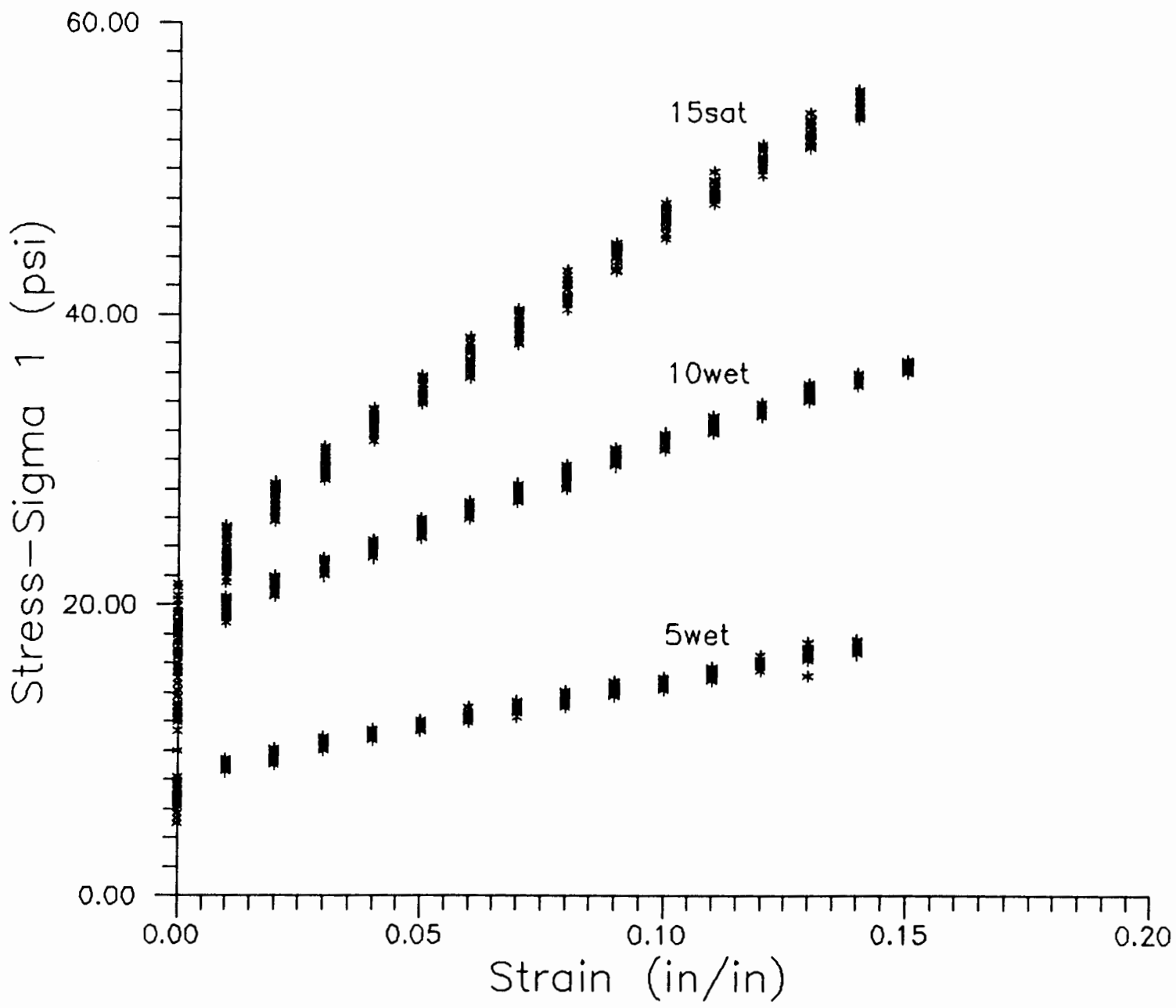

Fioure 40 Triaxial testing on saturated CVD at 5.0, 10.0. and 15.0 psi confining stress. 


\section{Series 3 Test Results}

The results for the Series 3 Tests can be seen in Figures 41 through 43 . As can be seen, the strength of the material prior to wetting appears to be stronger then immediately after. Superimposing these curves over the stress vs. strain curves for the dry and saturated tests show that there is a range of strain where the material does loose strength upon wetting. But, eventually the shear capacity of the wetted soil exceeds the capacity of the dry material. From this, it can be concluded that the material eventually becomes stronger from consolidation after wetting. This is in agreement with the finding in the pressuremeter testing. Comparing the differences in strength using the q-p space stress paths shows that in the region that is less then $2.3 \%$ strain the surface which represents the failure surface for the drier material has a greater shear capacity then the saturated material. Going beyond $2.3 \%$ strain shows that the shear capacity of the dry and saturated material start converging. Figures 44 through 46 show the q-p stress paths for the dry and saturated soil at $2.33,4.0$, and 6.67 percent strain.

\section{CREEP TESTS}

\section{Creep Test Procedure}

Tests conducted to determine the amount of creep and the effect that machine rate would have on creep was first conducted on the dry material and then the saturated material. The samples were set up as before with 5.0 and 15.0 psi confining pressures used. The load and deflection would be allowed to 


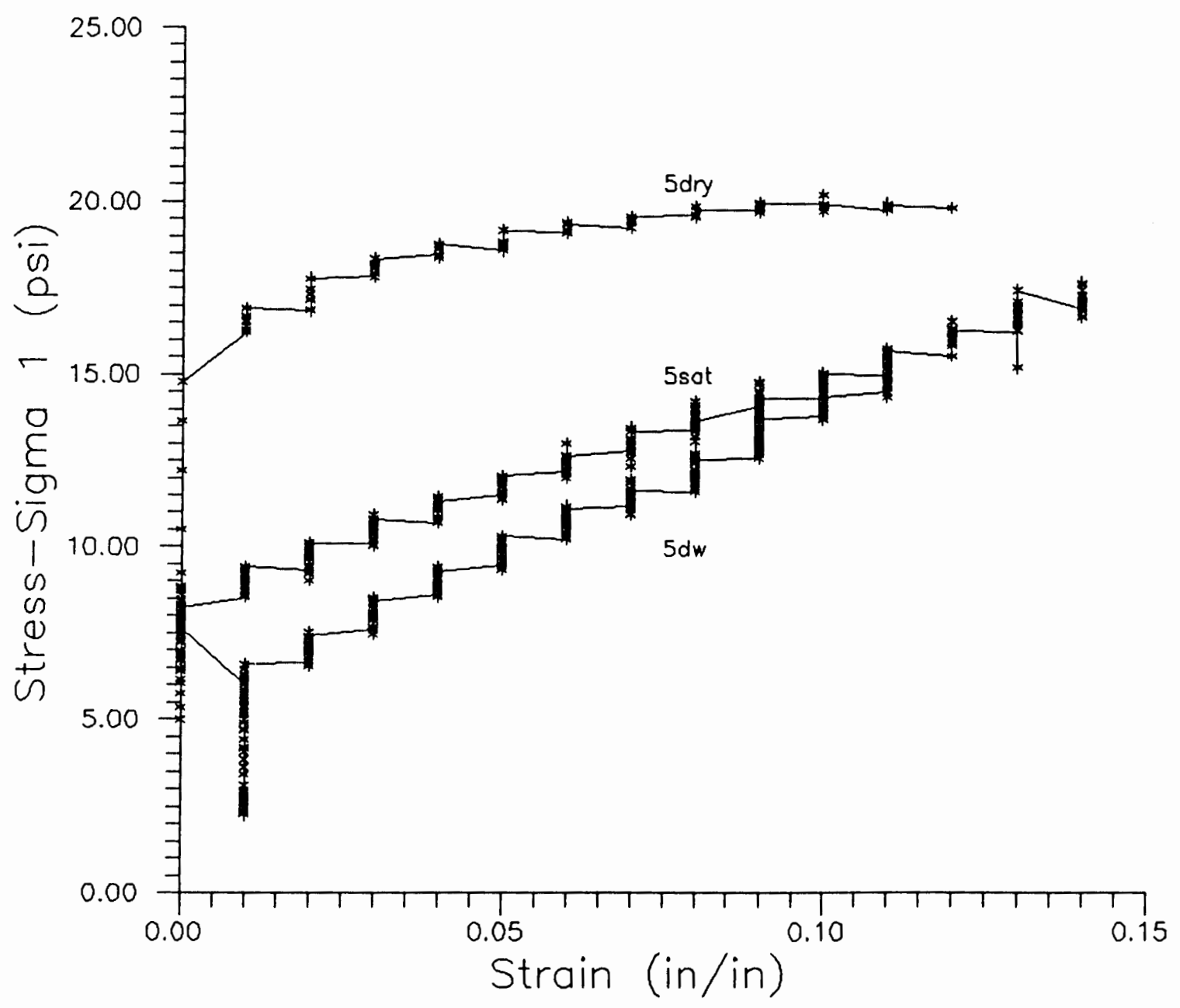

Figure 41. Comparison of results from the Dry, Saturated, and Dry/Saturated tests conducted on CVD ot 5.0 psi confining. 


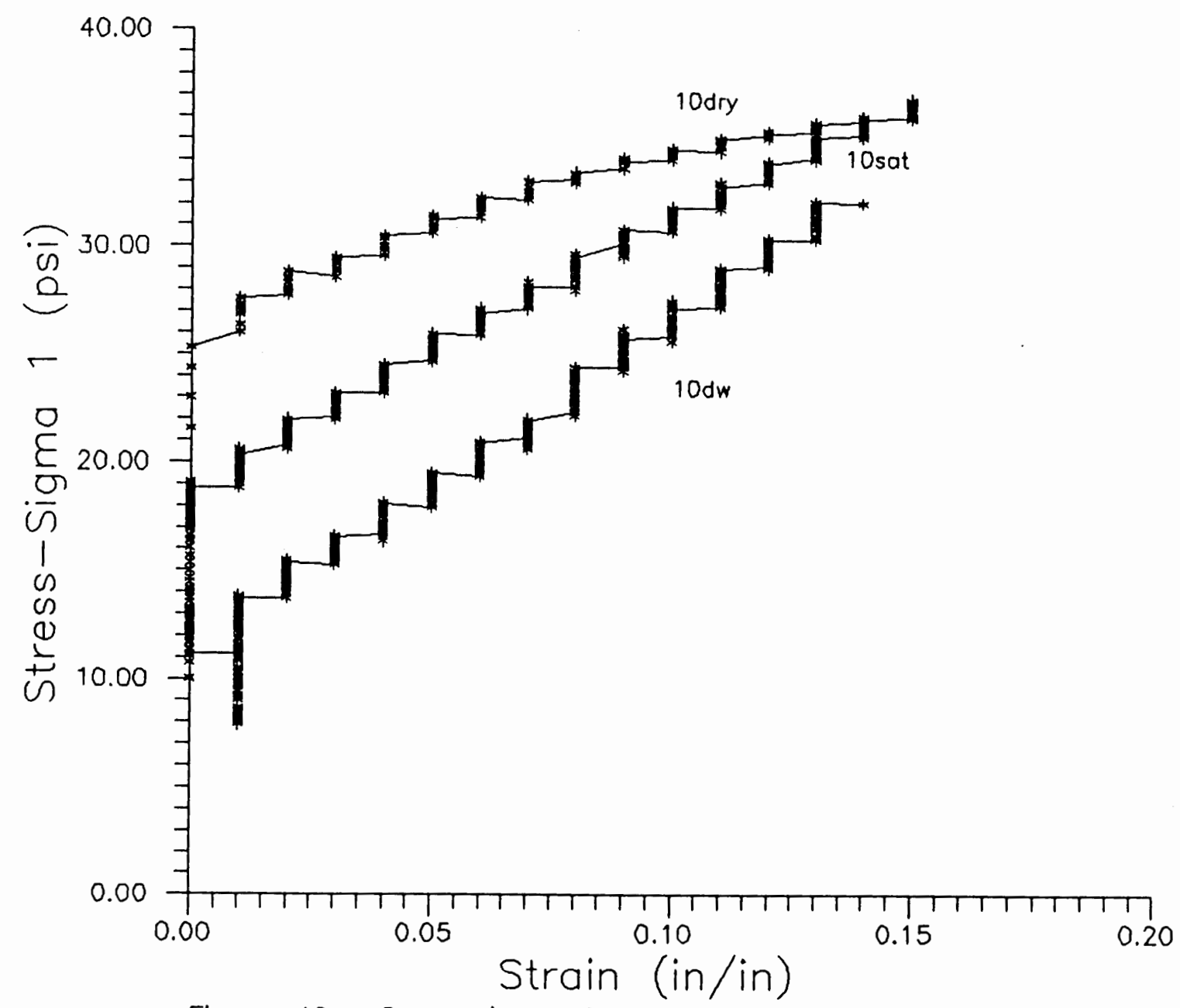

Eiqure 42. Comporison of results from the Dry, Saturated, and Dry/Saturated tests conducted on CVD of $10.0 \mathrm{psi}$ confining stress. 


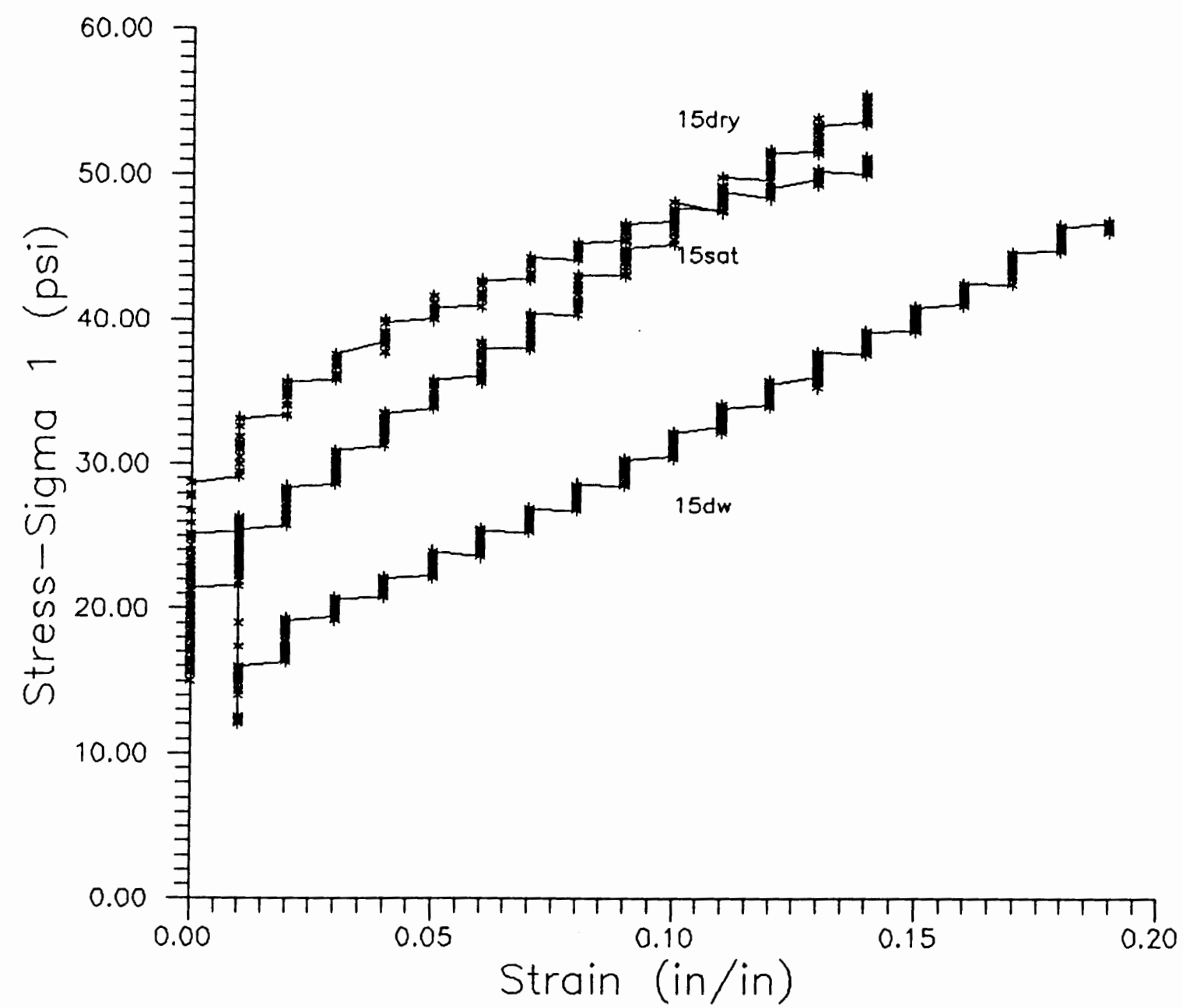

Eiqure 43 Comparison of results from the Dry, Saturated, and Dry/Saturated tests conducted on CVD at 15.0 psi confining stress. 


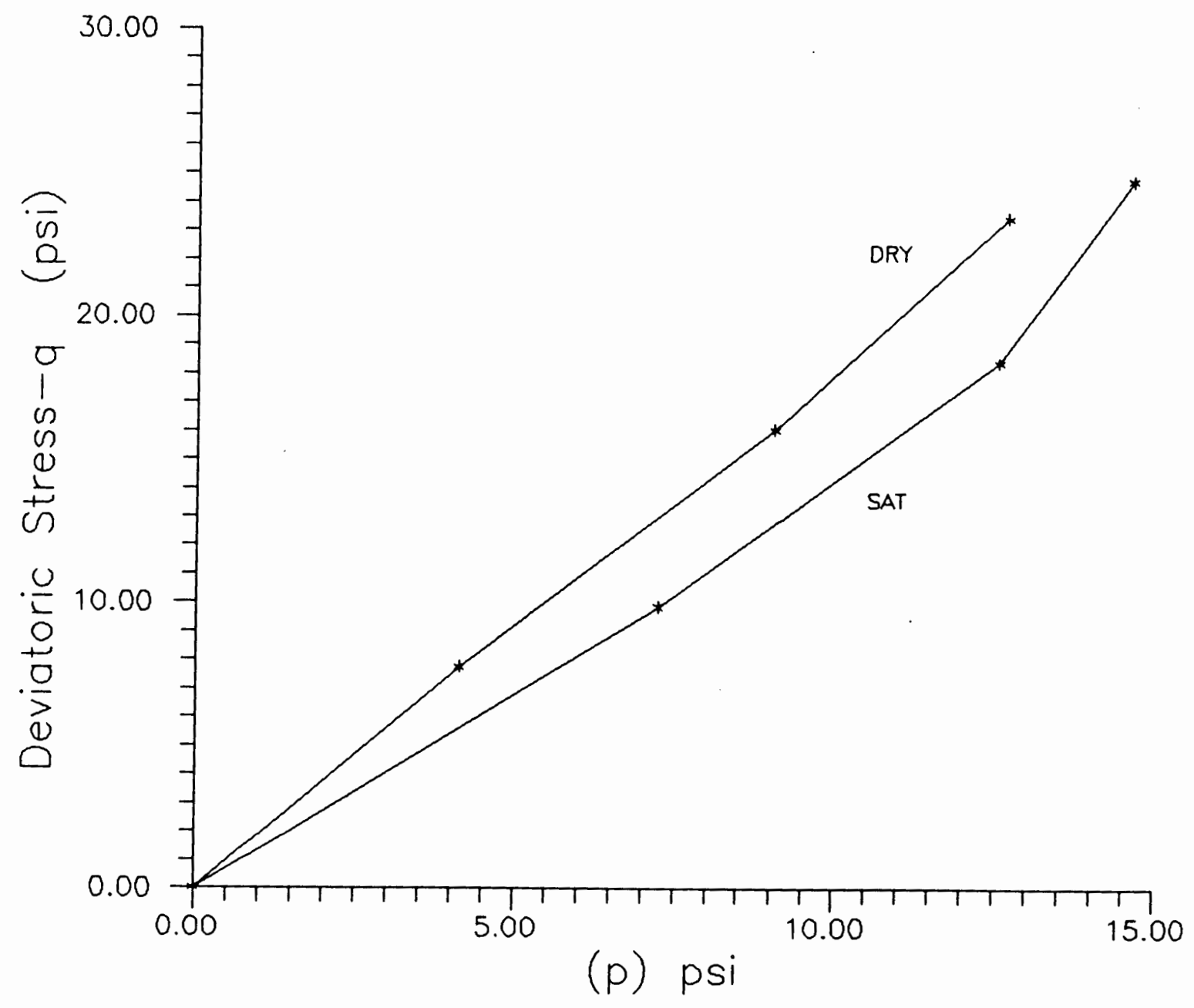

Fiqure 44. Q-p space stress path for 2.33 percent strain. Comparison of paths for dry and saturated material. 


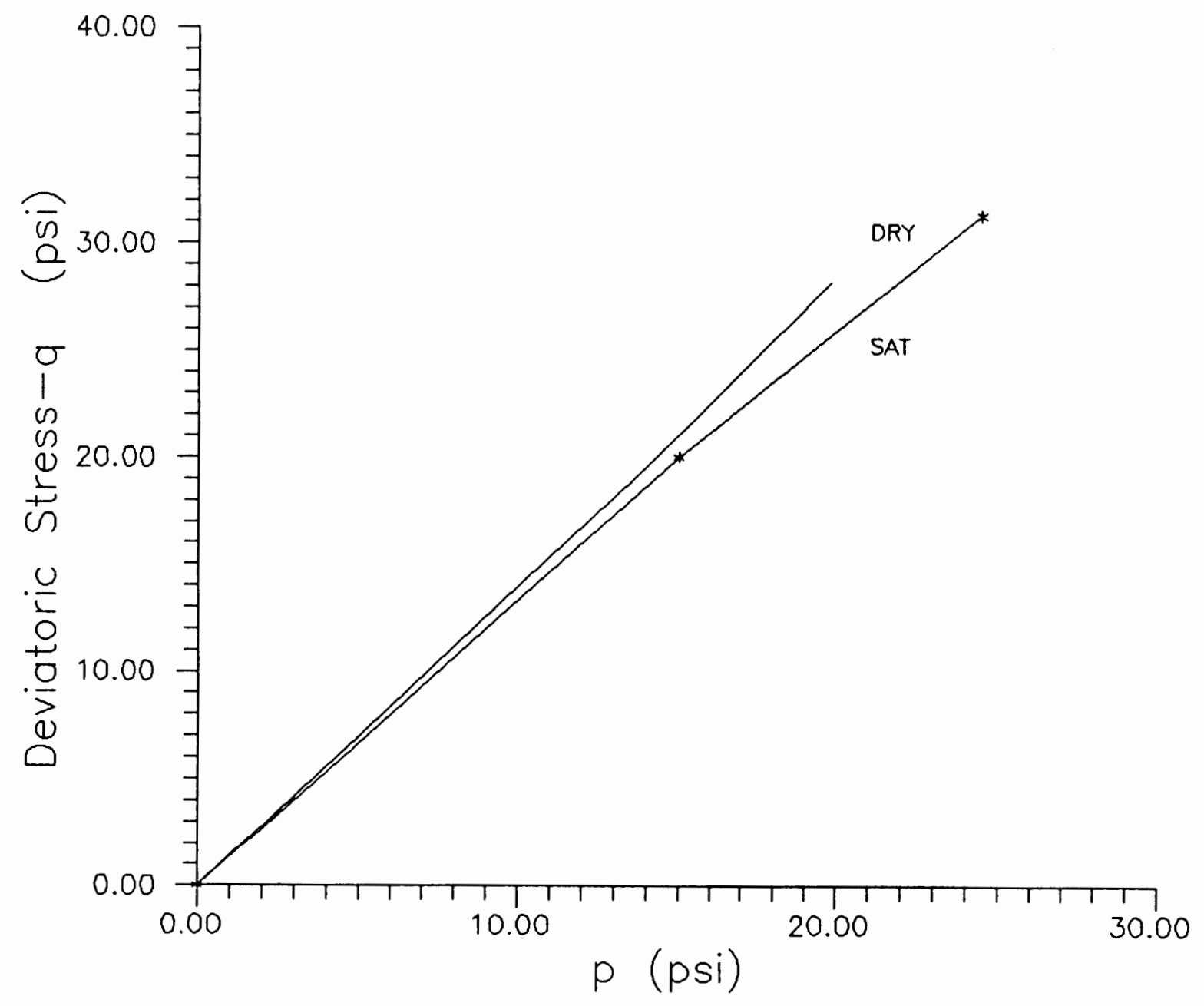

Figure 45. Q-p spoce stress poth for 4.0 percent strain. Comparison of paths for dry and saturated material. 


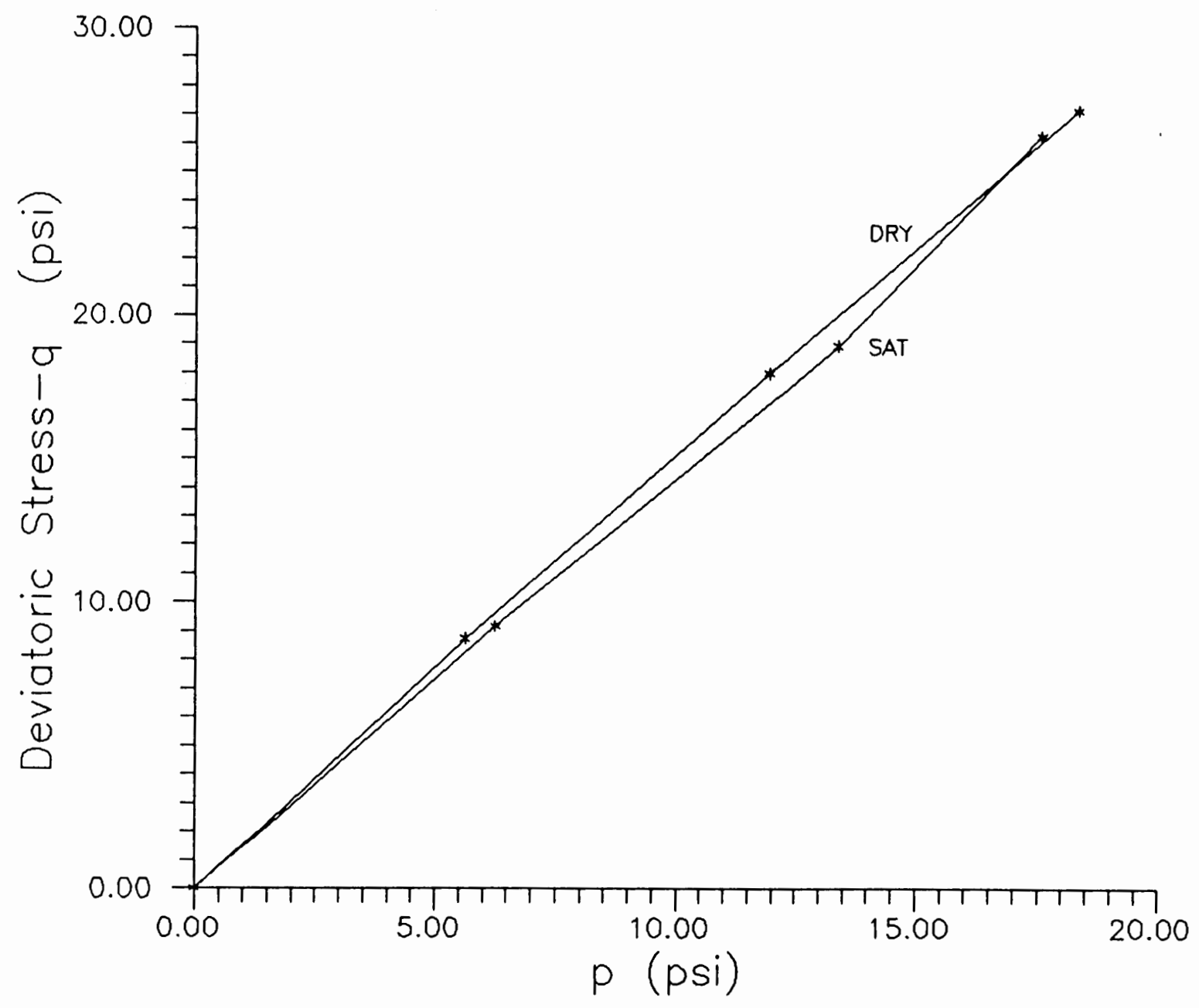

Figure 46. Q-P spoce stress path for 6.67 percent strain. Comparison of paths for dry and saturated material. 
increase for a period of thirty seconds and then the machine turned off for a period of five minutes. This was done until the samples experienced about fifty percent strain.

\section{Creep Test Results}

The results for the creep testing on the dry material at 5.0 and $10.0 \mathrm{psi}$ confining pressures showed a sudden decrease in load with no change in displacement. The only conclusion that can be made is, there appears to be creep. The amount of creep varies with confining pressure, with the maximum amount being at a $15.0 \mathrm{psi}$ confining pressure and the minimum at $5.0 \mathrm{psi}$ confining pressure.

Due to equipment failure, further testing on the creep in the material could not be made.

\section{STRAIN CONTROLLED TEST}

\section{Procedures}

For this test the LVDT and loading rod were removed from the triaxial assembly and the proving ring and load collar put back on. As with the other tests, the sample was set up and a confining pressure applied. Once the sample deformation stabilized, water was added to initiate collapse.

For this test the confining pressure was $15.0 \mathrm{psi}$. To apply a load, dead weights equal to $15.5 \mathrm{lbs}$. were placed on the piston counterbalance hanger. This load along with the cross sectional area of the sample gave an applied stress or 
shear stress of 10.0 psi. Readings were taken from the dial gauge on the proving ring.

\section{Test Results}

The results of the test are shown in Figure 47. As can be seen, that after the water is added the sample experiences a decrease in sigma 1 of about $3.0 \mathrm{psi}$ $\left(20.7 \mathrm{kN} / \mathrm{m}^{2}\right)$ and an increase in strain of about 0.26 inches $(0.66 \mathrm{~cm})$. That is approximately an $8.6 \%$ increase in strain.

At about 0.30 inches $(0.76 \mathrm{~cm})$ of strain is a sudden increase in stress with no corresponding increase in strain. It was at this point that the equipment failed and further triaxial testing was suspended. 


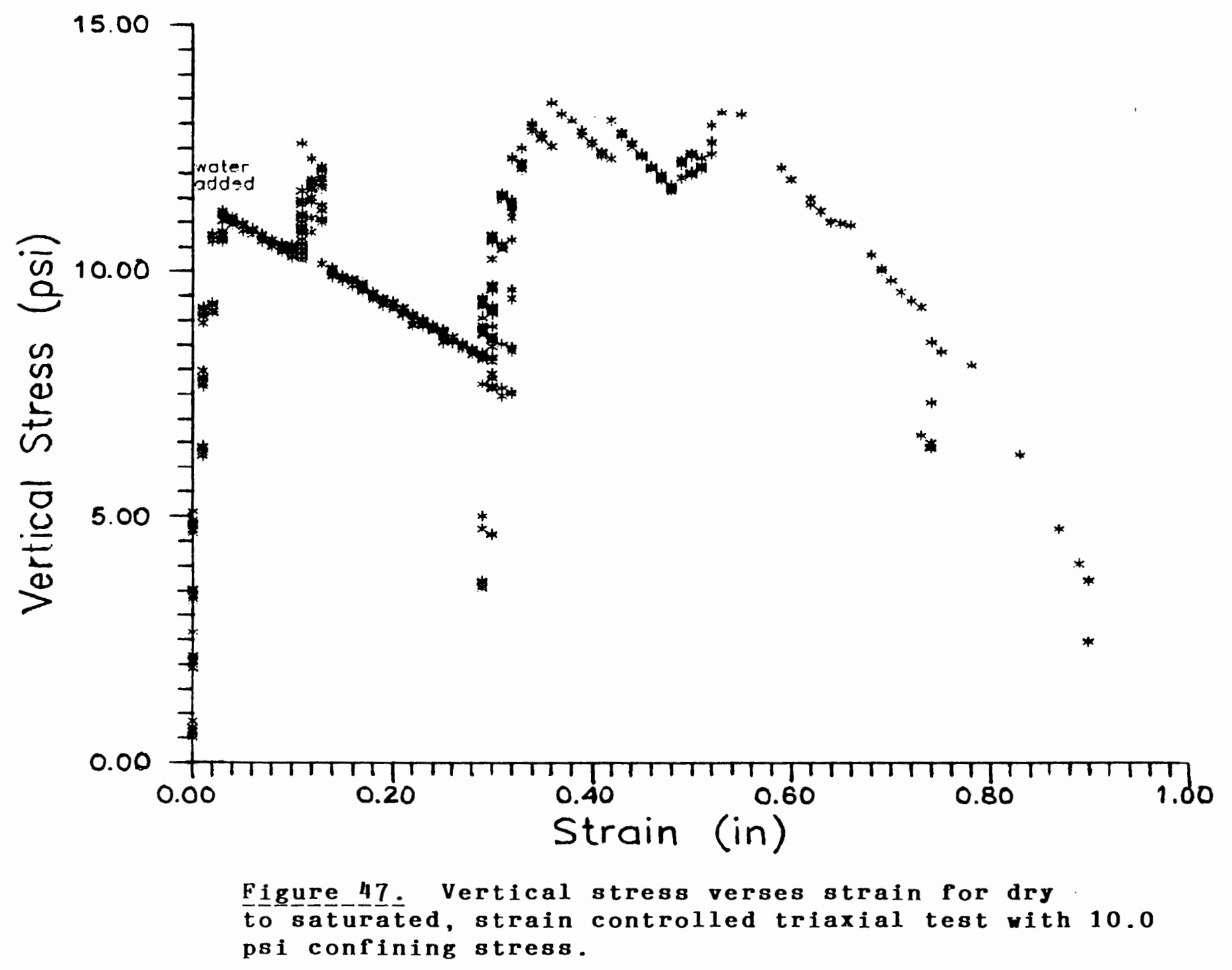




\section{CHAPTER VII}

\section{CONSTITUTIVE MODEL}

\section{INTRODUCTION}

As a result of stress change, soils undergo elastic and plastic strain simultaneously, with the total strain being the sum of the two components. This relationship is presented in Equation 7.1.

$$
d \epsilon_{i j}=d \epsilon_{i j}^{e}+d \epsilon_{i j}^{p}
$$

Elastic strain is recoverable with unloading, follows Hooke's Law and has a nonlinear varying Young's Modulus with stress. Plastic strain occurs after the yield stress has been reached. With soils plastic work occurs which work hardens the material changing the yield point.

Each of the strain components are calculated from functions as proposed by Lade (Lade, 1977, 1988, 1990) in his work developing a constitutive model for cohesive, as well as non-cohesive soils. The model incorporates the use of parameters which are dimensionless soil constants, and may be found by using the principal stress-strain and corresponding invariant behavior from conventional shear and isotropic triaxial tests.

Using results from the triaxial tests on dry and saturated CVD specimens, parameters for Lade's constitutive functions were derived and evaluated. 
Contours for the plastic work and plastic potential function were plotted for the dry and saturated material states, and comparisons of the plots were made to gain an understanding of the change in stress during collapse. This was followed by applying the stress paths of Oedometer and Pressuremeter testing. Finally, the parameters were used in the constitutive model that was developed during the research at Portland State University on collapsible soils (Smith, 1991).

\section{MODEL PARAMETERS}

There are eleven parameters required for the constitutive model, these are:

Elastic Moduli

Yield Criterion

Hardening Function

Plastic Potential

Failure Criterion
$\left(M, \lambda_{1}\right)$

$(\mathrm{h}, \mathrm{\alpha})$

(C,p)

$\left(\psi_{2}, \mu\right)$

$(n, \mathrm{~m}, \mathrm{a})$

(after Lade 1988)

All the parameters can be determined from the maximum vertical and horizontal stresses that occurred during standard shear and isotropic triaxial tests. Using these stresses in equations $7.2 \mathrm{a}$ through $7.4 \mathrm{a}$, the three principal stress invariants are determined. 


$$
\begin{gathered}
I 1=\sigma 1+\sigma 2+\sigma 3 \\
I_{2}=-(\sigma 1 \sigma 2+\sigma 2 \sigma 3+\sigma 3 \sigma 1) \\
I_{3}=\sigma 1 \sigma 2 \sigma 3
\end{gathered}
$$

In the triaxial testing, the sample had an isotropic confining stress, so for this condition $\sigma_{2}$ and $\sigma_{3}$ were equal. The resulting expressions used for the invariants are then given by Equations $7.2 \mathrm{~b}$ through $7.4 \mathrm{~b}$.

$$
\begin{gathered}
I 1=\sigma 1+2 \sigma 3 \\
I_{2}=-\left(2 \sigma 1 \sigma 3+\sigma 3^{2}\right) \\
I_{3}=\sigma 1(\sigma 3)^{2}
\end{gathered}
$$

For CVD it was observed from the Pressuremeter and Triaxial testing that when collapse was initiated, the soil experienced large decreases in stress with small increases in strain. Once this process was completed, and the loading of the sample continued, the slope of the reload stress-strain curve was greater than the initial one. CVD appeared to gain strength after collapse. The zone in which the material was collapsing, and material properties were changing, occurred at about $2 \%$ to $3 \%$ strain. From this, it was felt that the "collapse zone" for the model would be captured. The resulting values for the invariants from the dry and saturated soil, along with the principal stresses, are then given in Table 3 for CVD. 
TABLE III

PRINCIPAL STRESSES AND STRESS INVARIANTS FOR THE CONVENTIONAL TRIAXIAL TEST RESULTS ON CVD AT FAILURE

\begin{tabular}{||l|r|r|r|r|r|r||}
\hline \multirow{2}{*}{ Principal Stresses } & \multicolumn{4}{|c|}{ Dry } & \multicolumn{3}{|c||}{ Saturated } \\
\cline { 2 - 7 } & $\sigma_{1}$ & \multicolumn{1}{|c|}{$\sigma_{2}$} & \multicolumn{1}{c|}{$\sigma_{3}$} & \multicolumn{1}{c|}{$\sigma_{1}$} & \multicolumn{1}{c|}{$\sigma_{2}$} & \multicolumn{1}{c|}{$\sigma_{3}$} \\
\hline 5.0 psi confining & 19.2 & 5.0 & 5.0 & 13.0 & 5.0 & 5.0 \\
\hline 10.0 psi confining & 32.1 & 10.0 & 10.0 & 26.0 & 10.0 & 10.0 \\
\hline 15.0 psi confining & 42.7 & 15.0 & 15.0 & 39.25 & 15.0 & 15.0 \\
\hline \hline \multirow{3}{*}{ Invariants } & \multicolumn{3}{|c|}{ Dry } & \multicolumn{3}{|c|}{ Saturated } \\
\cline { 2 - 8 } & $\mathrm{I}_{1}$ & \multicolumn{1}{|c|}{$\mathrm{I}_{2}$} & $\mathrm{I}_{3}$ & $\mathrm{I}_{1}$ & $\mathrm{I}_{2}$ & $\mathrm{I}_{3}$ \\
\hline 5.0 psi confining & 29.2 & -223 & 479.5 & 23.0 & -155 & 325 \\
\hline 10.0 psi confining & 52.1 & -742 & 3200 & 46.0 & -620 & 2600 \\
\hline 15.0 psi confining & 74.74 & -1506 & 9616.5 & 69.25 & -1402.5 & 8831 \\
\hline
\end{tabular}

Other data required to solve for the values of the constitutive parameters were the volume strains resulting from isotropic compression. There were no such tests conducted on CVD, therefore, the curves of stress verses strain were arrived at through actual test results and inference (Slyh, 1990). Data for dry and saturated soil are given in Figures 48 and 49. 


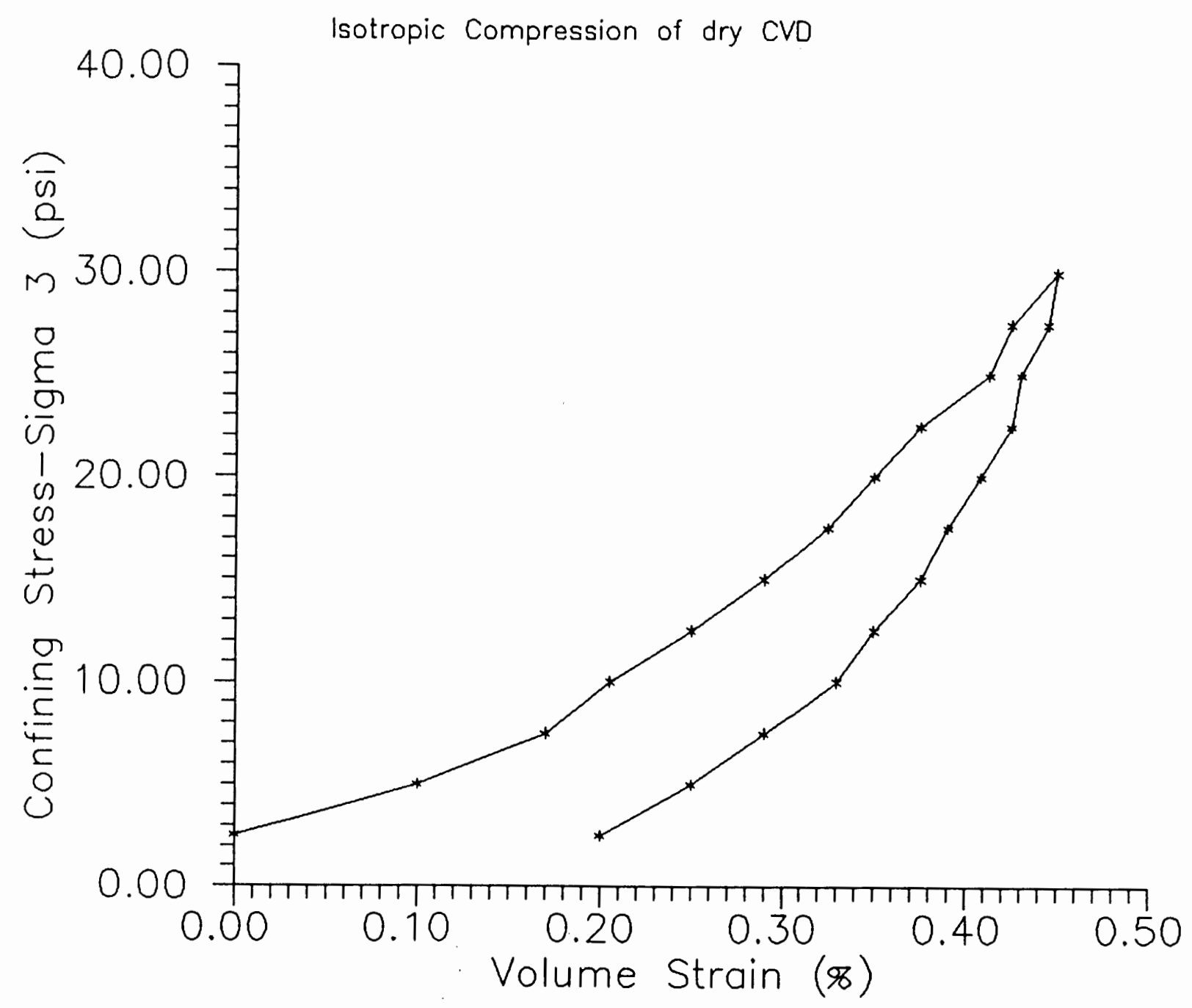

Figure 48. Theoretical isotropic compression curve for the dry material. Confining stress vs. strain ( 8 ). 


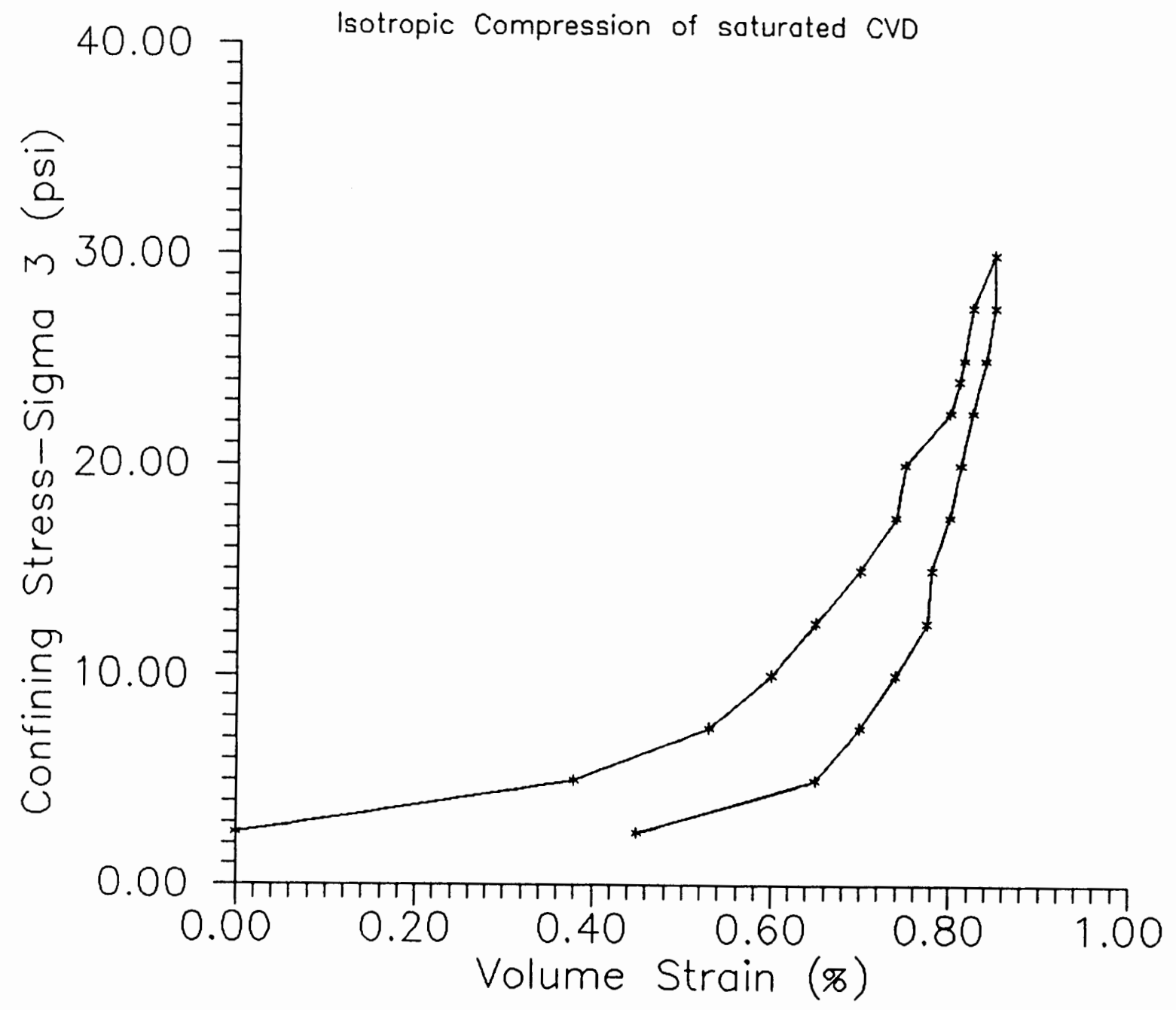

Eiqure 49. Theoretical isotropic compression curve for the saturated material. Confining stress vs. strain ( $x)$. 


\section{$\underline{\text { Elastic Strains }}$}

The constitutive function which describes the variation of the elastic modulus is given in Equation 7.5.

$$
E=M * p_{a}\left[\left(\frac{I_{1}}{p_{a}}\right)^{2}+R\left(\frac{J_{2}^{\prime}}{p_{a}^{2}}\right)\right]^{\lambda}
$$

In this equation, $\mathrm{P}_{a}$ is atmospheric pressure; $\mathrm{J}_{2}{ }^{\prime}$ is the second deviatoric stress invariant; $M$ and $\lambda$ are dimensionless parameters to be determined from triaxial test data. The relations for $\mathrm{R}$ and $\mathrm{J}_{2}{ }^{\prime}$ are given in Equations 7.6 and 7.7.

$$
\begin{gathered}
R=6\left(\frac{1+v}{1-2 v}\right) \\
J_{2}^{\prime}=\frac{1}{6}\left[\left(\sigma_{x}-\sigma_{y}\right)^{2}+\left(\sigma_{y}-\sigma_{z}\right)^{2}+\left(\sigma_{z}-\sigma_{x}\right)^{2}\right]+\tau_{x y}^{2}+\tau_{y z}^{2}+\tau_{z x}^{2}
\end{gathered}
$$

The values for $M$ and $\lambda$ are found by plotting on log-log scales the variation of Young's Modulus verses stresses. From the best fit line, the y intercept gives the value for $M$ and the slope of the line gives the value for $\lambda$. Figures 50 and 51 show the curves for the dry and saturated CVD specimens. Values for M dry and saturated are 60 and 40 , respectively. For $\lambda$, the values for the dry and saturated material are 1.0 and 0.375 , respectively. Using these values in the equations for elastic moduli will give a smaller value for the saturated material than for the dry. This reflects the observed data; the unloading of stress during collapse. These 


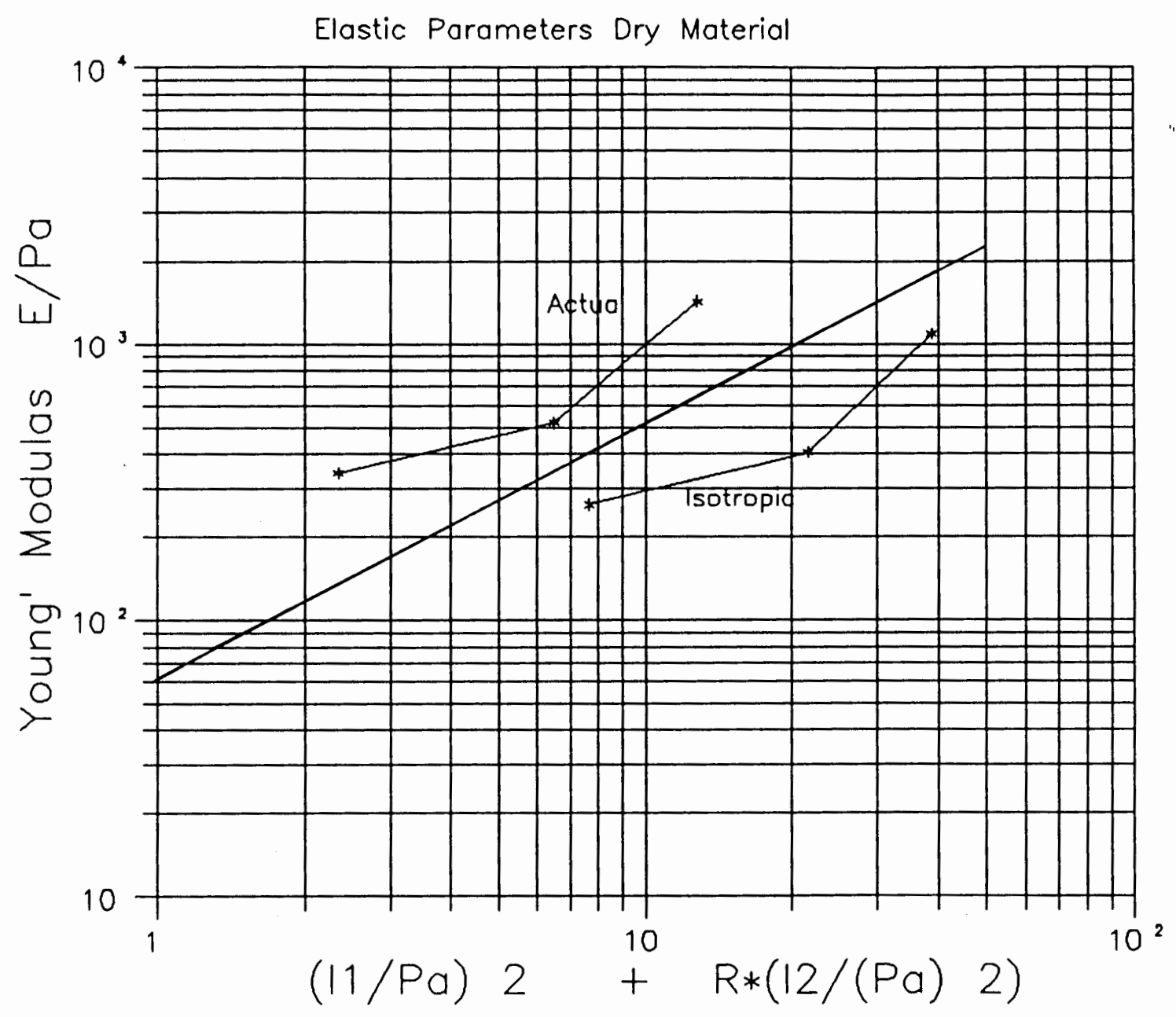

Eiqure 50. Parameters Lamda $(\lambda)$ and $(M)$ for the Elastic Function for the dry CVD. 


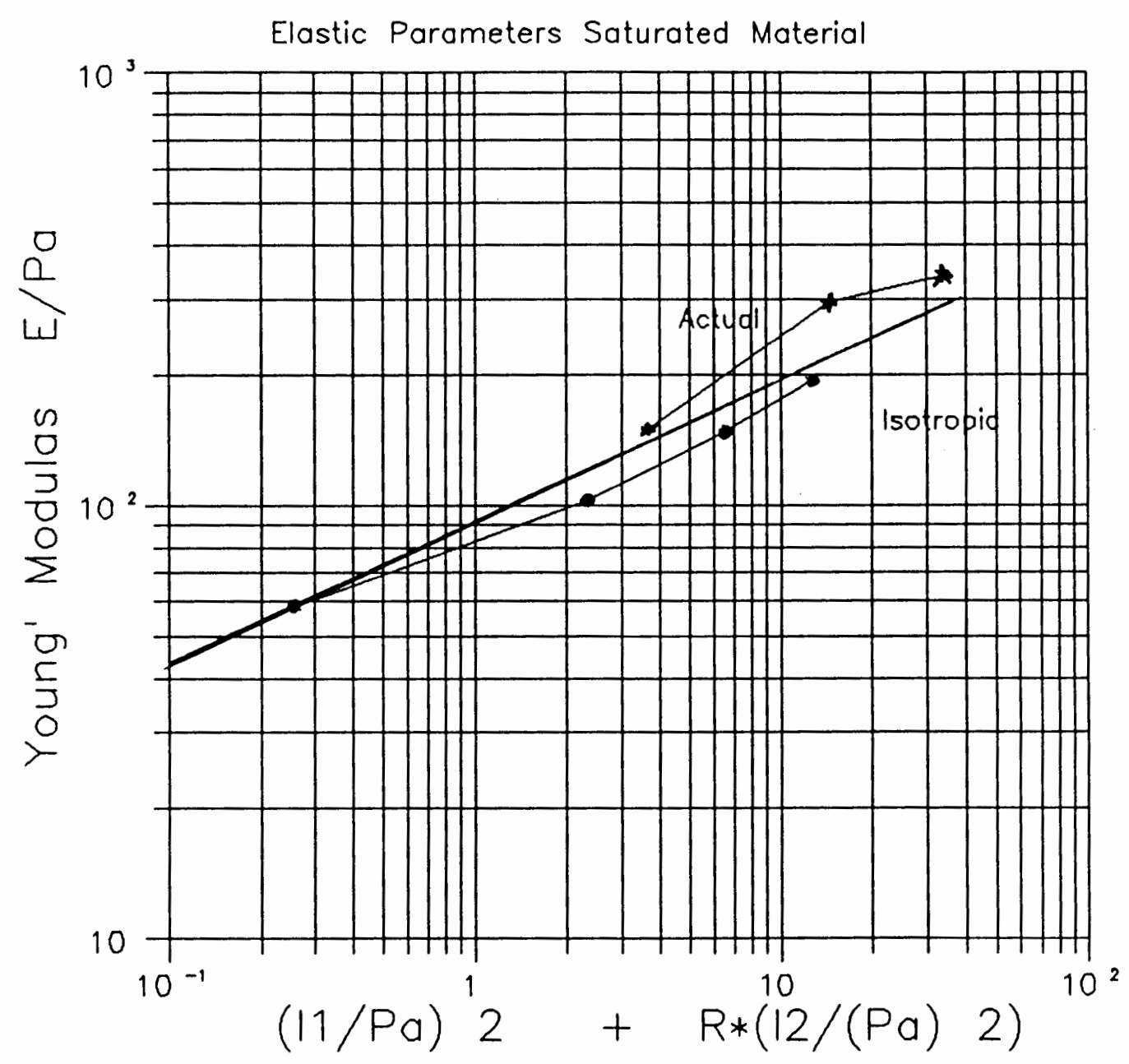

Eiqure 51. Parameters Lamda $(\lambda)$ and $(M)$ for the Elastic Function for the saturated CVD. 
values also compare to Lades values of 30 for $M$ and 0.68 for $\lambda$ for Edgar Plastic Kaolinite. Values of parameters for various frictional materials based on Lade's database is given in Table IV.

\section{Yield Criteria}

The constitutive function for yielding produces a three dimensional surface that Lade describes as an "asymmetric tear drop", (1988) with the apex at the origin of the principal stress axis. It is continuous everywhere except at the origin and has cross sections of smoothly rounded triangles (Lade, 1988).

The Yield Function is given in Equation 7.8.

$$
f_{p}=\left(\Psi_{1} \frac{I_{1}^{3}}{I_{3}}-\frac{I_{1}^{2}}{I_{2}}\right)\left(\frac{I_{1}}{p_{a}}\right)^{k} * e^{q}
$$

Where the parameters $\psi_{1}$ determines the yield surface intersection with the hydrostatic axis, $h$ is a constant, and $q$ varies from a value of 0.00 at the hydrostatic axis to 1.0 at failure. The variables $I_{1}, I_{2}$ and $I_{3}$ are the first, second and third principal stress invariants, respectively.

For cohesionless, granular, soils where there is no distinct yield point, Lade assumes that yield surfaces and plastic work contours are the same in deriving the yield function. Thus, in order for plastic work to occur, yielding must take place. Furthermore, the stress at yielding is always increasing due to hardening of the material, which is due to plastic work. Therefore, incorporated into the yield function is the influence of plastic work. The constitutive function which describes 


\section{TABLE IV}

CONSTITUTIVE PARAMETER VALUES FOR CVD AND

VARIOUS OTHER FRICTIONAL MATERIALS

\begin{tabular}{|c|c|c|c|c|c|c|c|c|c|c|c|c|c|c|}
\hline \multirow[t]{2}{*}{ Material } & \multicolumn{3}{|c|}{ Failure Criterion } & \multicolumn{5}{|c|}{$\begin{array}{c}\text { Elastic } \\
\text { Behavior }\end{array}$} & \multicolumn{2}{|c|}{$\begin{array}{l}\text { Plastic } \\
\text { Potential }\end{array}$} & \multicolumn{2}{|c|}{$\begin{array}{l}\text { Hardening } \\
\text { Function }\end{array}$} & \multicolumn{2}{|c|}{$\begin{array}{l}\text { Yield } \\
\text { Function }\end{array}$} \\
\hline & $\mathbf{a}$ & $\mathrm{m}$ & $\eta_{1}$ & 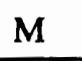 & $\lambda$ & $\mathrm{K}_{\mathrm{ur}}$ & $\mathrm{n}$ & $\lambda$ & $\psi_{2}$ & $\mu$ & C & $\mathrm{p}$ & $\mathrm{h}$ & $\alpha$ \\
\hline Dry CVD & & 0.12 & 40.65 & 100 & 1 & & & & -3.16 & 1.62 & 0.0005 & 1.04 & 0.267 & 0.825 \\
\hline Sat CVD & & 0.012 & 10.8 & 40 & 0.375 & & & & -8.5 & 3.5 & 0.003 & 1.0 & 0.347 & 0.1656 \\
\hline $\begin{array}{l}\text { Edgar Plastic } \\
\text { Kaolinite }\end{array}$ & & 0.54 & 48 & 30 & 0.68 & & & & -3.08 & 2.38 & 0.0030 & 1.48 & 0.81 & 0.50 \\
\hline $\begin{array}{l}\text { Sacramento } \\
\text { River Sand } \\
\text { Dr }=38 \%\end{array}$ & & 0.093 & 28 & & & 1460 & 0.47 & 0.2 & -3.72 & 2.36 & 0.00012 & 1.65 & 0.534 & 0.794 \\
\hline $\begin{array}{l}\text { Painted Rock } \\
\text { Material } \\
\text { Dr }=70 \%\end{array}$ & & 0.16 & 67 & & & 891 & 0.51 & 0.2 & -3.39 & 2.72 & 0.000046 & 1.78 & 0.698 & 0.386 \\
\hline $\begin{array}{l}\text { Monterey Sand } \\
\mathrm{Dr}=27 \%\end{array}$ & & 0.12 & 36 & & & 2300 & 0.80 & 0.2 & -3.6 & 2.5 & .00021 & 1.26 & 0.430 & 0.577 \\
\hline $\begin{array}{l}\text { Fine Silica Sand } \\
\mathrm{Dr}=30 \%\end{array}$ & & 0.1 & 24.7 & & & 1170 & 0.53 & 0.2 & -3.69 & 2.26 & 0.00032 & 1.25 & 0.355 & 0.515 \\
\hline
\end{tabular}

Values of constitutive parameters for the dry and saturated CVD, and for other frictional materials as solved by Lade $(1988,1990)$. 
plastic work is called the Hardening Function, is given in Equation 7.9.

$$
W_{p}=C * p_{\alpha}\left[\frac{I_{1}}{p_{a}}\right]^{p}
$$

To solve for the constants $\mathrm{C}$ and $\mathrm{p}$, the plastic work during an isotropic compression test is plotted against the first principal stress invariant using a log-log relationship. The value of $\mathrm{C}$ is equal to the plastic work when the first principal stress invariant is equal to one, and the value of $p$ is the slope of the log-log line. The resulting curves are presented in Figures 52 and 53. The values for $\mathrm{C}$ and $\mathrm{p}$ are then given in a dry state as 0.0005 and 1.04 ; and in a saturated state as 0.003 and 1.0 respectively. This would indicate that the potential plastic work of the dry material is less then the potential plastic work of the saturated material which was observed during testing. Comparing these values of $\mathrm{C}$ and $\mathrm{p}$ to Lade's (Table IV), show the plastic work of CVD is not as high as in Lade's soil samples. This also agrees with our findings. In the Triaxial testing as the stress unloaded during collapse there was some increase in strain which was plastic.

With the amount of plastic work known, the hardening due to the work and the change in the yield stress can be computed. The parameters in the Yield Function which represent the hardening, Yield Criteria are $h$ and $q$, and are given by Equations 7.10 and 7.11 . 


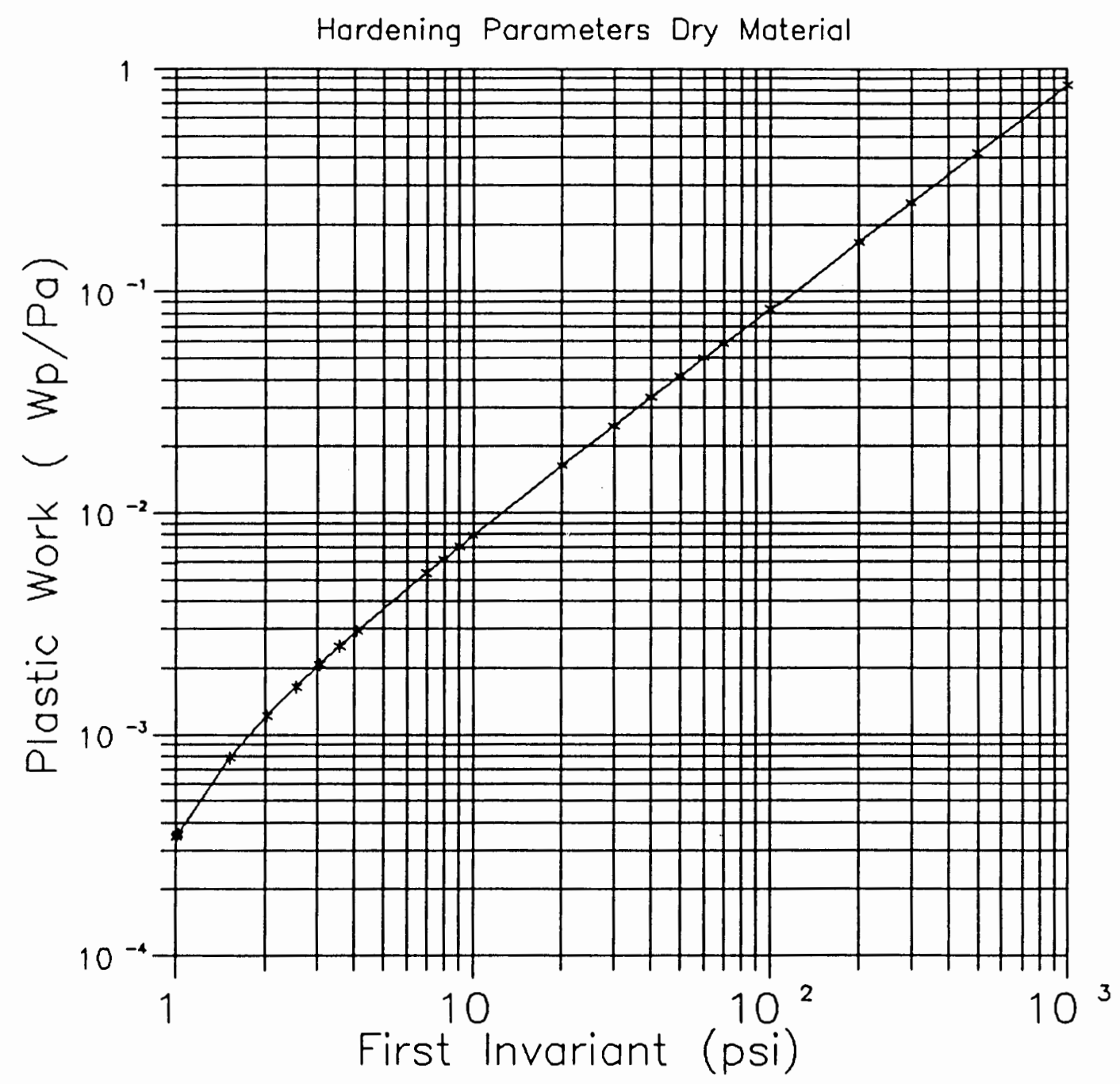

Eiqure 52. Parameters (C) and ( $p$ ) for the Hardening Function for the dry CVD. 


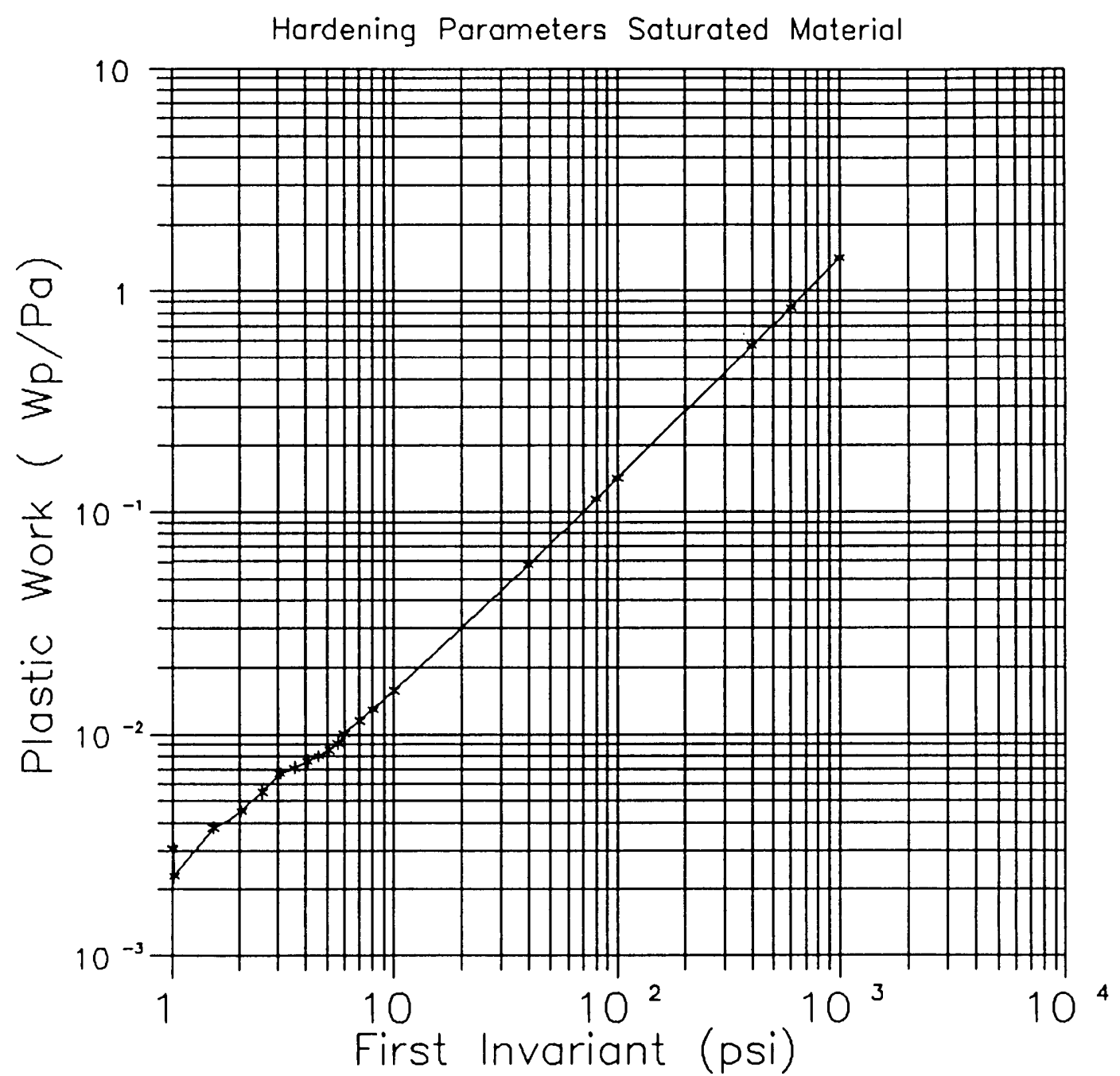

Figure 53. Parameters (C) and ( $p$ ) for the Hardening Function for the saturated CVD. 


$$
\begin{aligned}
& h=\frac{\log \frac{\left[\Psi_{1} \frac{\left(I_{1_{B}}\right)^{3}}{\left(I_{3_{B}}\right)}-\frac{\left(I_{1_{B}}\right)^{2}}{\left(I_{2_{B}}\right)}\right]^{2} * e}{\left[27 \Psi_{1}+3\right]}}{\log \left[\frac{I_{1_{A}}}{I_{1_{B}}}\right]} \\
& q=\ln \frac{\left[\frac{W_{p}}{D * p_{a}}\right]^{\frac{1}{\rho}}}{\left[\Psi_{1} \frac{I_{1}^{3}}{I_{3}}-\frac{I_{1}^{2}}{I_{2}}\right]\left[\frac{I_{1}}{p_{a}}\right]^{p}}
\end{aligned}
$$

In Equation (7.10) the variables $\mathrm{I}_{l A}$ and $\mathrm{I}_{l B}$ are the first principal stress invariants for a point on the hydrostatic axis, point (A), and a point elsewhere in stress space, point (B). Since these points are on the same yield and plastic work contour, the value of the functions are equal and therefore the value of $h$ can be determined. For the CVD specimens, the value for $\mathrm{h}$ was 0.267 for the dry material and 0.347 for the saturated. The variable, $\psi_{1}$, is a Plastic Potential Function parameter. In Equation (7.11) the variables D and $\rho$ are found by evaluating Equations 7.12 and 7.13. 


$$
\begin{gathered}
\rho=\frac{p}{h} \\
D=\frac{C}{\left(27 \Psi_{1}+3\right)^{\rho}}
\end{gathered}
$$

Another way to determine the parameter $q$ is by the relationship between the stress level, S, and q. Equation 7.14 gives this relationship.

$$
S=\frac{q}{(\alpha+(\beta q))}
$$

By plotting S verses $\mathrm{q}$ and solving for $\alpha$ at the (Lade, 1988) recommended 0.8, (this is the best stress to determine $\alpha$ ) the value of $q$ can be found. Figures 54 and 55 show the plots of $S$ verses $q$ for the CVD specimens. From these figures the value of $\alpha$ is found as 0.825 for the dry soil and 0.1656 for the saturated diatomite. These values compare in magnitude to those of Monterey Sand and Fine Silica Sand as shown in Table IV.

\section{$\underline{\text { Failure Criterion }}$}

Lade proposed a constitutive function for Failure Criterion as given in Equation 7.15 .

$$
\eta_{1}=\left[\frac{\left(I_{1}\right)^{3}}{I_{3}}-27\right]\left[\frac{I_{1}}{p_{a}}\right]^{m}
$$




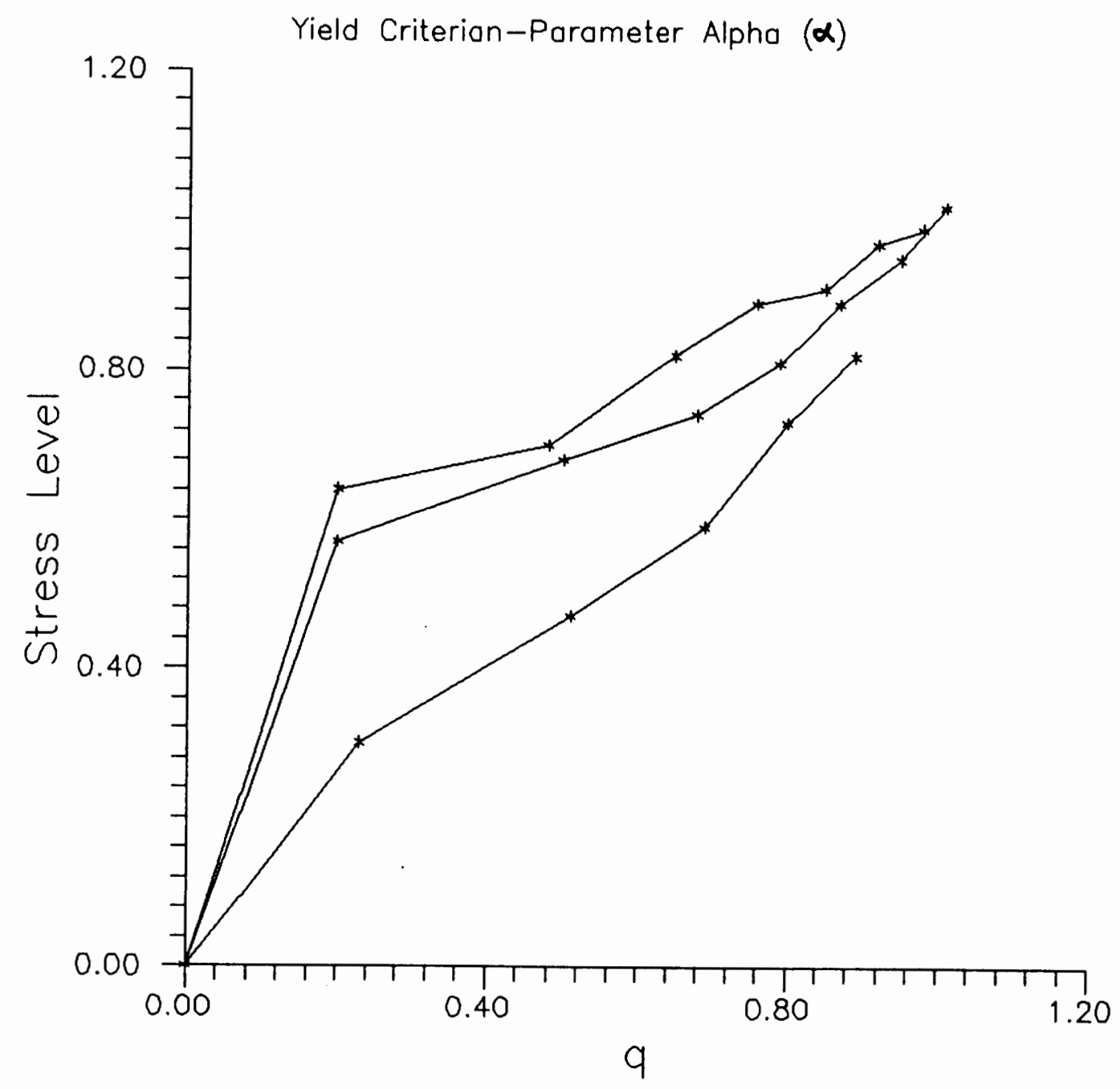

Figure 54. Parameter alpha ( $\alpha$ ) for the dry CVD. 


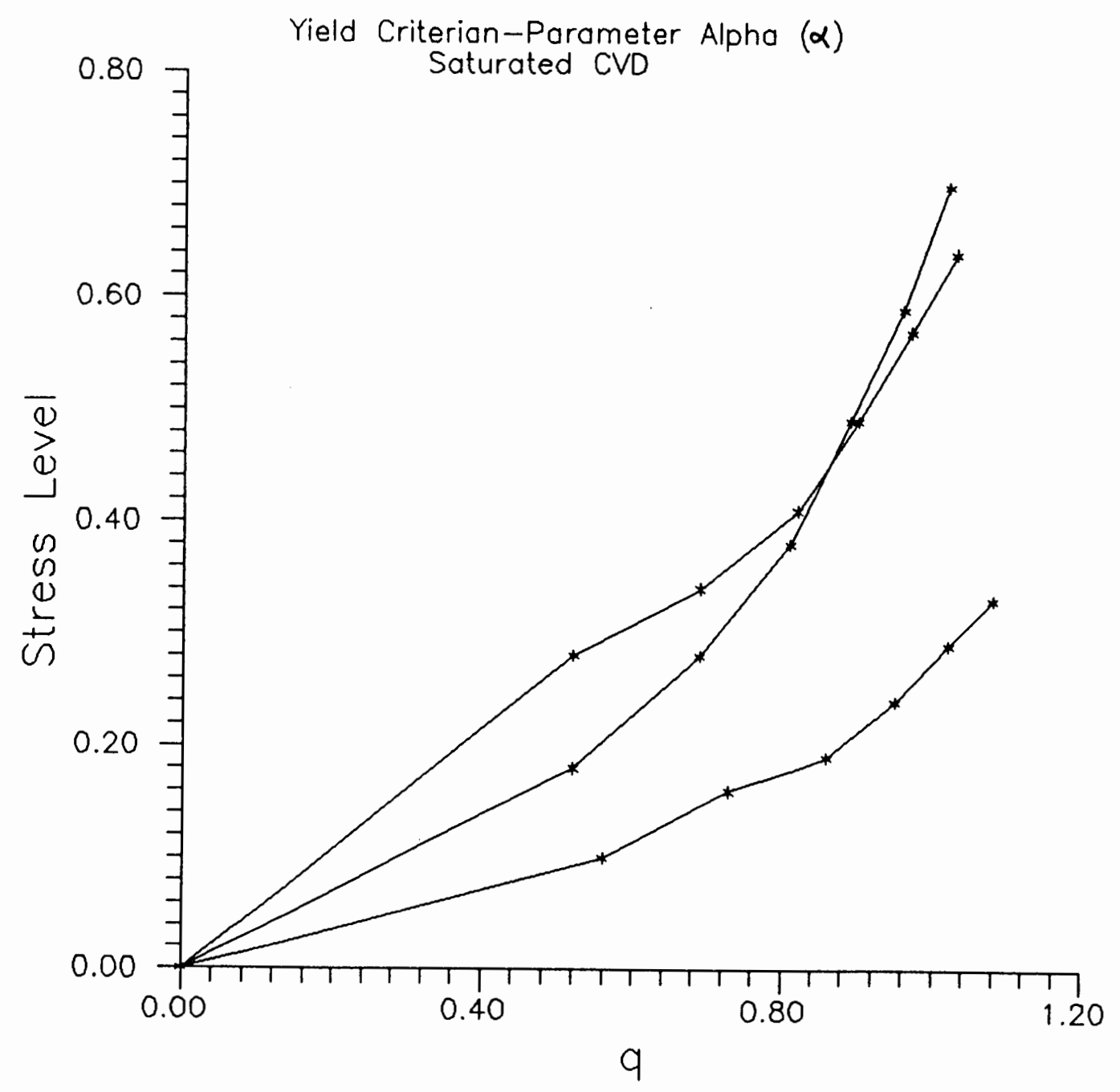

Figure 55. Parameter alpha $(\alpha)$ for the saturated CVD. 
He further describes this function as a surface shaped like a "asymmetric bullet" with the point of the apex at the origin (Lade, 1988). In Equation 7.15, as $\eta_{1}$ increases so does the apex angle. The variable $\mathrm{m}$ is the curvature of the surface which is concave toward the hydrostatic axis. For a value of $m$ at 0.0 , the surface has no curvature. To solve for these parameters, the natural log of the first principal stress invariant verses the natural log of atmospheric pressure divided by the first principal stress invariant is plotted as shown in Figures 56 and 57 for CVD. The value of $\eta_{1}$ corresponds to the point where the natural log of atmospheric pressure is equal to 1 . The value of $\mathrm{m}$ is equal to the slope of the line. The values of $\eta_{1}$ and $\mathrm{m}$ are 40.65 and 0.12 for the dry material and 10.83 and 0.012 for the saturated material, respectively.

The values of these parameters for the dry and saturated CVD imply there is curvature to the surface for the dry material and would have a similar shape as for Monterey Sand. Once the material is saturated, the surface seems to close upon itself with an conical shape and a reduced apex angle.

\section{$\underline{\text { Plastic Potential }}$}

The final component of the elasto-plastic stress-strain relationship is the "flow rule". This is a constitutive function which describes the direction of the plastic work surface to the yield surface. If the work is "associated", the plastic strain increment vector will be perpendicular to the yield surface. This would make the plastic potential surface coincide with the yield surface. 
Foilure Criterion for the Dry CVD

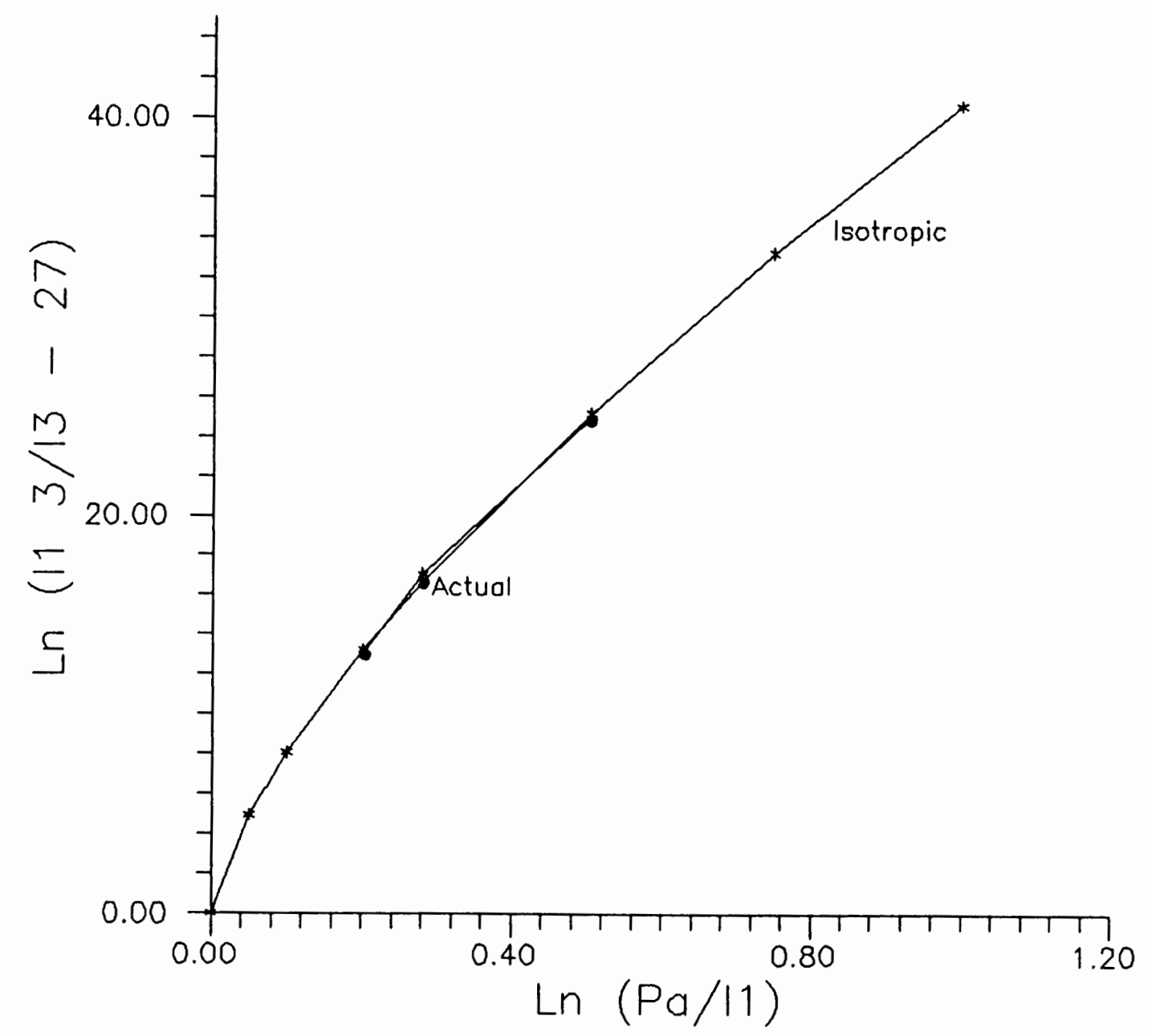

$\frac{\text { Fiqure 56. Parameters }\left(\eta_{1}\right) \text { and }(m) \text { for the Failure }}{\text { Criterian for the dry CVD. }}$ 
Failure Criterian for the Saturoted CVD

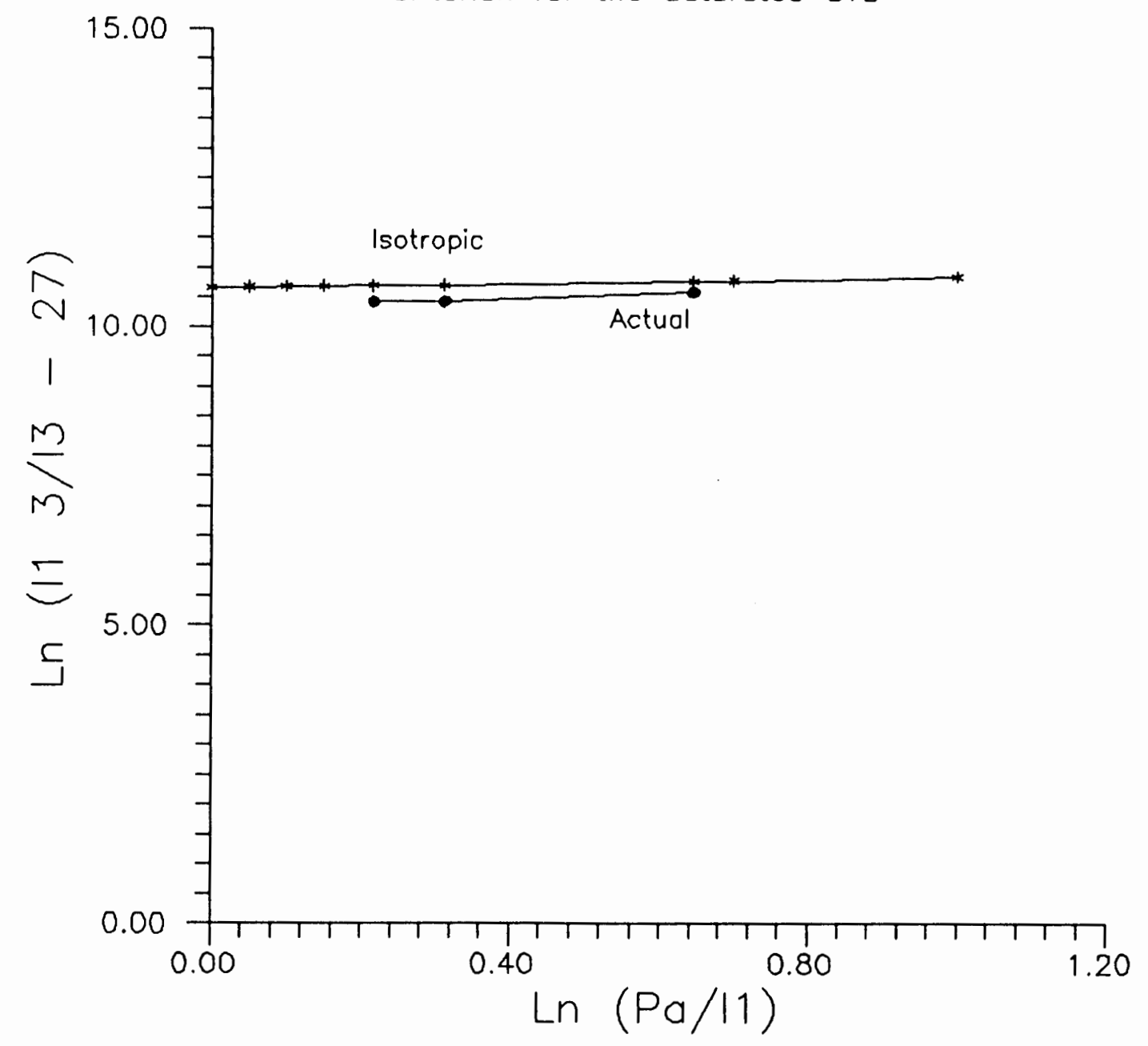

Fiqure 57 Parameters ( $\eta_{1}$ ) and $(m)$ for the Failure Criterian for the saturated CVD. 
In the case of cohesionless soils, the flow is non-associated since the plastic work vectors are not perpendicular to the yield surface and the plastic work surface does not coincide with the yield surface. Lade proposes the flow rule given in Equation 7.16.

$$
d \epsilon_{i j} P=d \lambda_{p}\left[\frac{d g_{p}}{d \sigma_{i j}}\right]
$$

In Equation 7.16 $\lambda_{p}$ is a proportionality constant and $\mathrm{g}_{p}$ is a Plastic Potential function and is given by Equation 7.17.

$$
g_{p}=\left[\Psi_{1} \frac{\left(I_{1}\right)^{3}}{I_{3}}-\frac{\left(I_{1}\right)^{2}}{I_{2}}+\Psi_{2}\right]\left[\frac{I_{1}}{p_{a}}\right]^{\mu}
$$

The parameters $\psi_{1}, \psi_{2}$ determine how the surface intersects with the hydrostatic axis, and $\mu$ determines the curvature of the meridians. They are both constants that can be determined from triaxial test results. $\psi_{1}$ is similar to the Yield Criterion parameter $\mathrm{m}$ in that it is a factor which determines whether the cross section will be triangular or circular. It also effects the curvature of the meridians of the Plastic Potential surface. Knowing m, Equation 7.18 can be used to solve for the value of $\psi_{1}$.

$$
\Psi_{1}=0.00155(m)^{-1.27}
$$

For the dry and saturated CVD specimens, the value of $\psi_{1}$ was 0.0024 and 0.30 , respectively. Lade concluded as the material is more rigid, the value of $\psi_{1}$ 
decreases (1988), and the cross section of the plastic potential function becomes more round. For CVD, the cross sections of the dry material would be round and those of the saturated more triangular in shape.

Once the value of $\psi_{1}$ is known and using the incremental plastic strain ratio and an expression for plastic strain increments, $\phi_{2}$ and $\mu$ can be determined. The expression for the strain ratio and plastic increments is given in Equations 7.19 and 7.20.

$$
\begin{gathered}
v_{p}=-\frac{d \epsilon_{3}^{p}}{d \epsilon_{1}^{p}} \\
\xi_{y}=\frac{1}{\mu} \xi_{x}-\Psi_{2}
\end{gathered}
$$

where

$$
\xi_{x}=\frac{1}{1+v_{p}}\left[\frac{I_{1}^{3}}{I_{2}^{2}}\left(\sigma_{1}+\sigma_{3}+2 v_{p} \sigma_{3}\right)+\Psi_{1} \frac{I_{1}^{4}}{I_{3}^{2}}\left(\sigma_{1} \sigma_{3}+v_{p} \sigma_{3}^{2}\right)\right]-3 \Psi_{1} \frac{I_{1}^{3}}{I_{3}}+2 \frac{I_{1}^{2}}{I_{2}}
$$

and

$$
\xi_{y}=\Psi_{1} \frac{I_{1}^{3}}{I_{3}}-\frac{I_{1}^{2}}{I_{2}}
$$


Plotting the $\xi_{y}$ component of plastic strain verses the $\xi_{x}$ component and using the best fit line, the value of $\psi_{2}$ is the intercept and $\frac{1}{\mu}$ is the slope of the line. Figures 58 and 59 show the plotted strains with resulting values of -3.16 and -8.5 for $\psi_{2}$ for the dry and wet soil. The slope of the curves gives a value of 1.62 and 3.5 for the dry and wet diatomite, respectively.

\section{RESULTING CVD FAILURE MODEL}

\section{Plastic Work}

The resulting Plastic Work Contours for dry and wet CVD are shown in Figure 60. The surfaces are as Lade predicted, which are rounded, asymmetric curves. The curves all converge at the apex and each having similar slopes at this point defines the failure point for the soil. Clearly, these curves depict the limits of the material. Comparing the magnitude of the plastic work between the dry and wet CVD shows that for any given triaxial vertical stress $\sigma_{1}$ and horizontal stress $\sigma_{3}$, the plastic work of the wet soil is greater than the work of the dry soil.

\section{Plastic Potential}

The resulting Plastic Potential Contours is shown in Figure 61. As with the Plastic Work, these contours also show the rounded, asymmetrical contours for the dry and saturated CVD. Again there is a well defined material boundary and an increase in potential in going from a dry to the saturated state. 


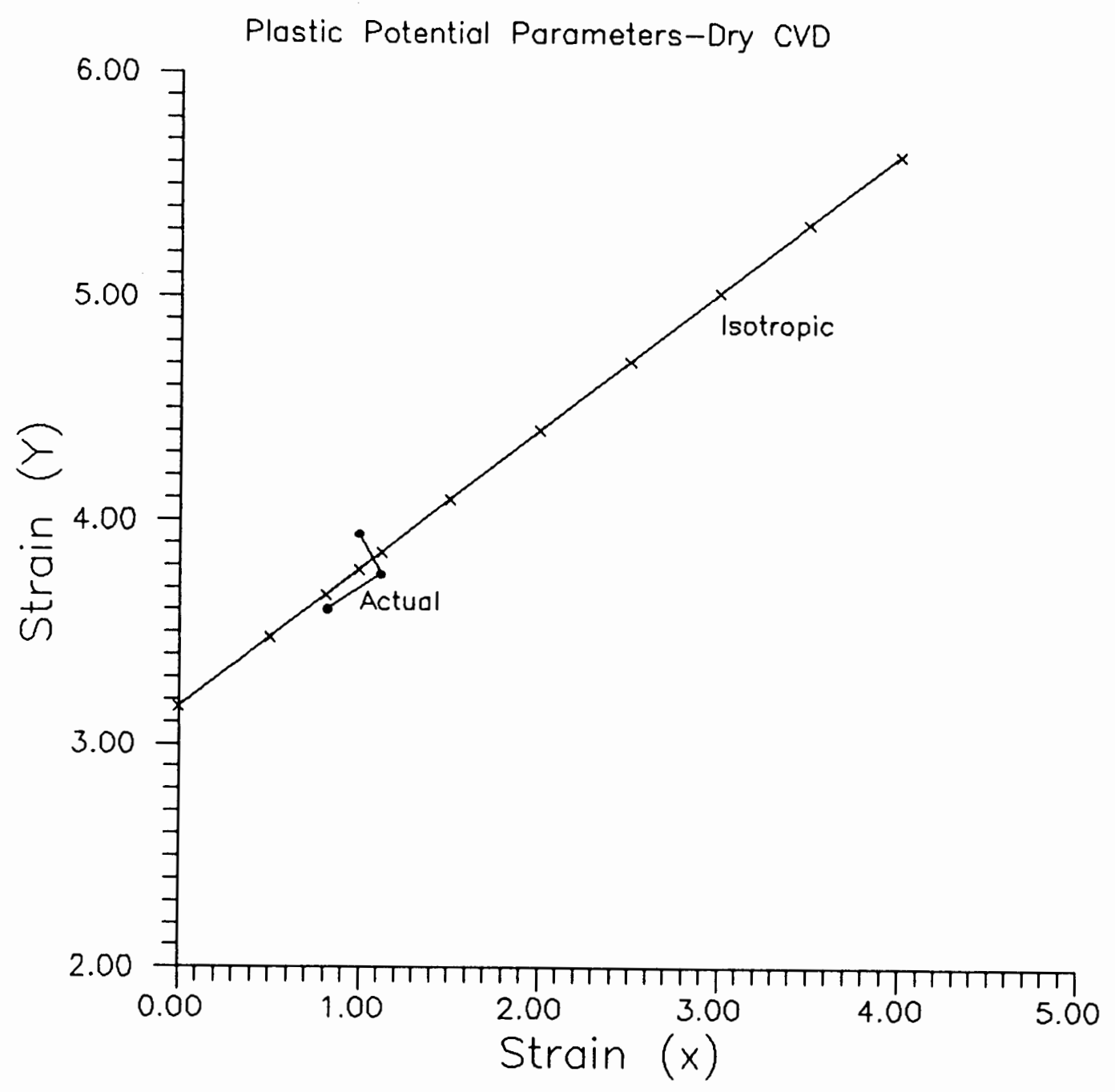
Figure 58. Parameters $\left(\Psi_{2}\right)$ and $(\mu)$ for the Plastic
Potential for the dry CVD. 


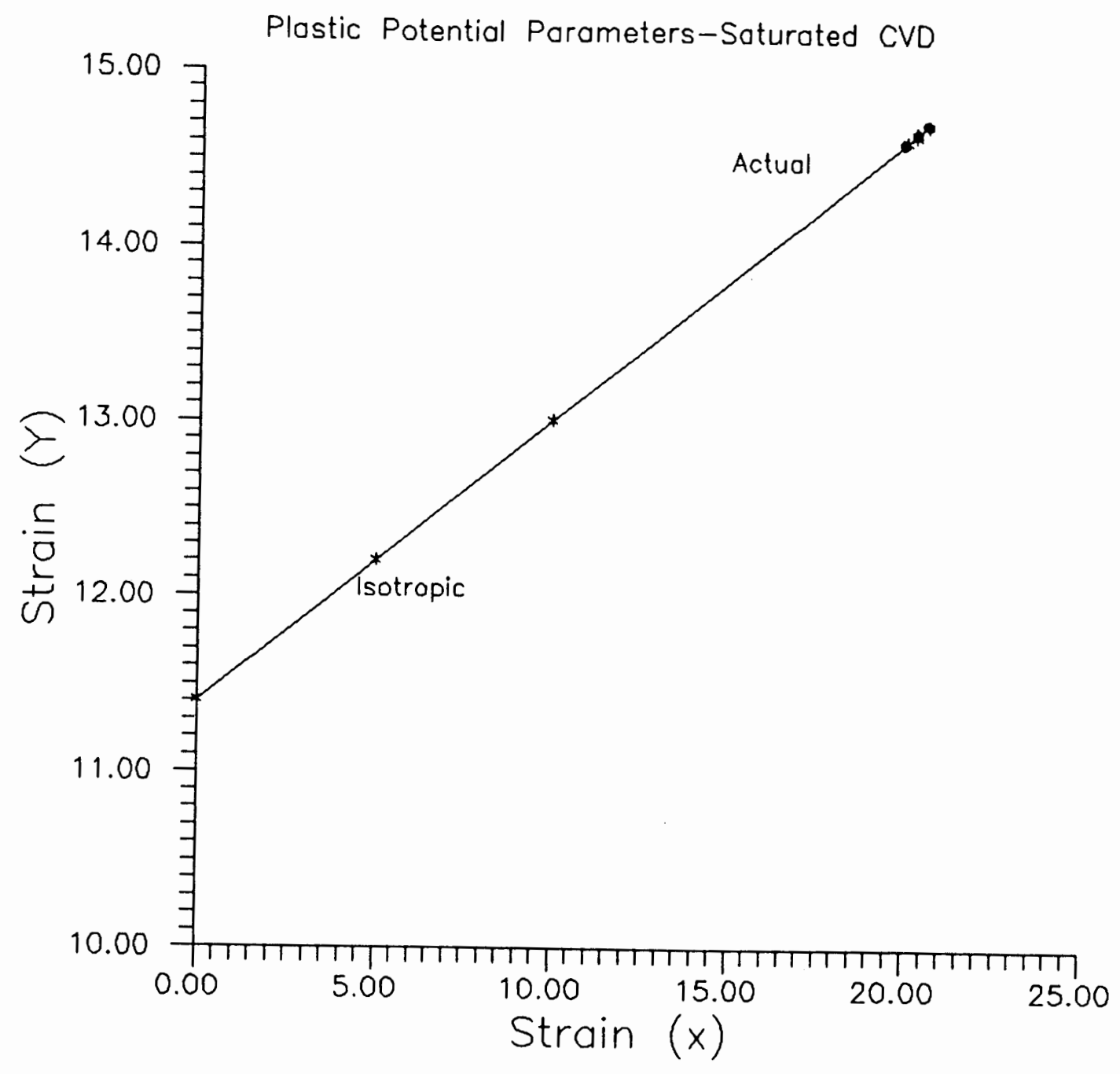

Fiqure 59. Parameters $\left(\psi_{2}\right)$ and $(\mu)$ for the Plastic Potential for the saturated CVD. 

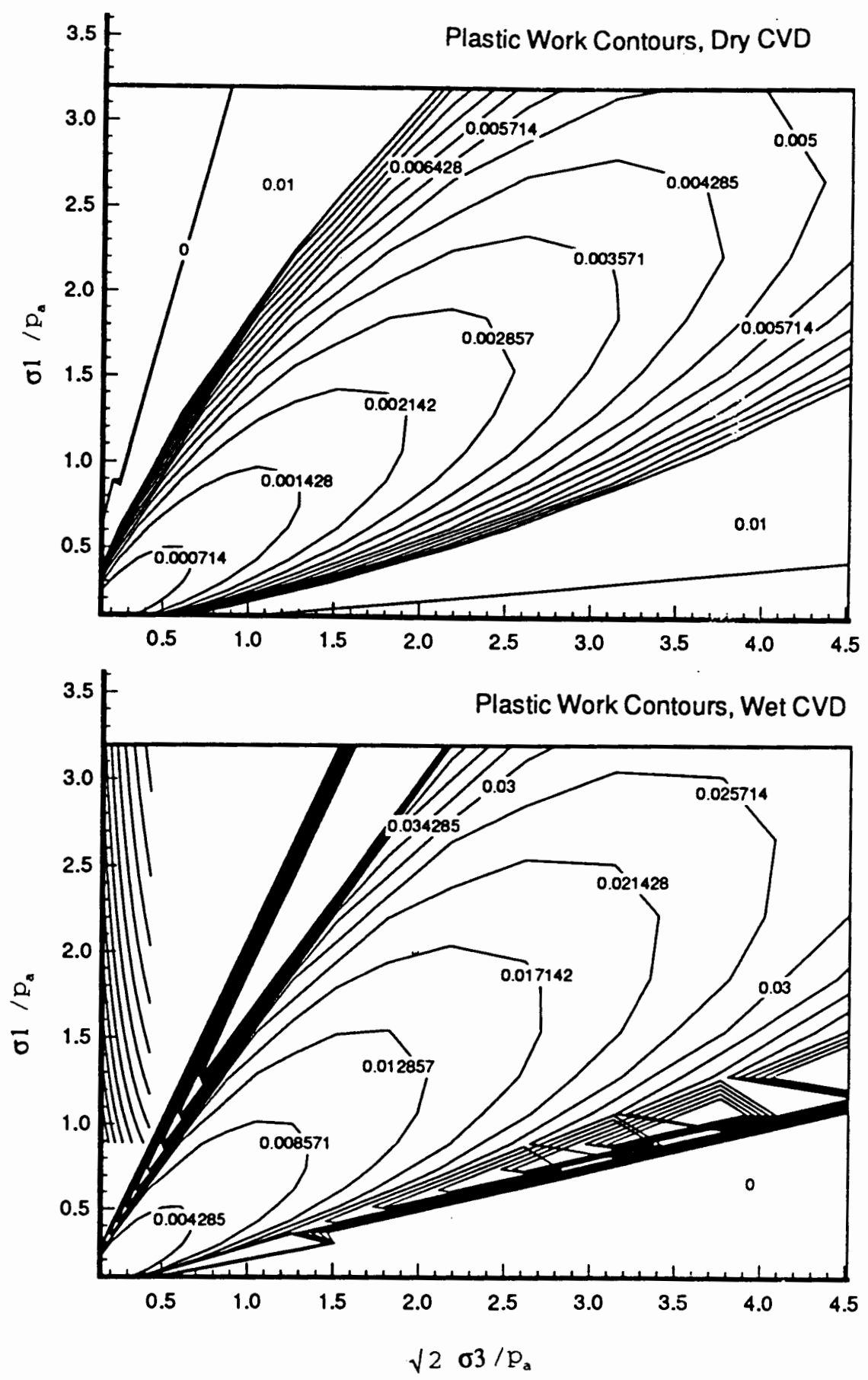

Figure 60. Plastic Work Contours for the dry and saturated CVD. 

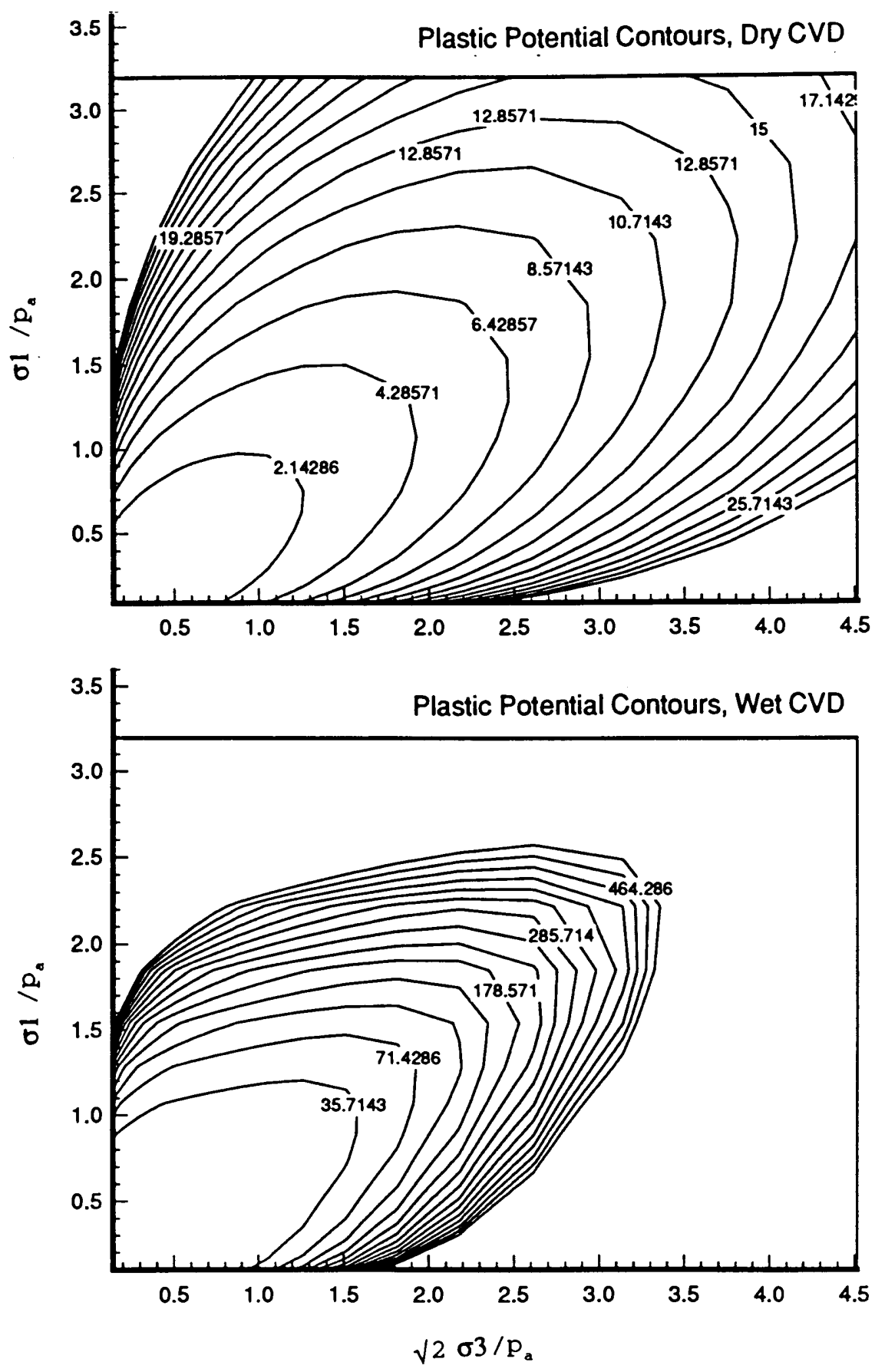

Figure 61. Plastic Potential

contours for dry and saturated CVD. 


\section{$\underline{\text { Oedometer and Pressuremeter }}$}

The derived Plastic Potential and Work contours can also be used to predict the movements of the stress paths of Oedometer and Pressuremeter tests. The stress path in the Oedometer test is an increasing vertical stress along with an increasing horizontal stress with the ratio at $\mathrm{K}_{0}$. With $\sigma_{1}$ increasing and with $\sigma_{2}$ and $\sigma_{3}$ equal, the resulting plastic potential and plastic work contours will be almost the same as Lade's curves.

In the Pressuremeter test, the vertical stress is constant with radial stress increasing and circumferential stress decreasing. In this situation, the contours would be "sliced" at the constant $\sigma_{1}$ value. The resulting failure surface would be sets of curved surfaces with a horizontal surface at the given $\sigma_{1}$ value. 


\section{CHAPTER VIII}

\section{CONCLUSIONS AND RECOMMENDATIONS}

The purpose of this study was to develop a finite element constitutive model using results obtained from laboratory testing of a generic, metastable manufactured soil. In so doing, laboratory testing of collapsible soils was proven to be an important tool in learning about the collapse phenomenon; a manufactured soil could be developed as a useful component in this type of testing; and a constitutive model was developed.

During testing it was found that once moisture was added to a dry, preloaded sample, the collapse of the soil structure occurred within a few seconds. This made reading the strain instruments difficult and usually only 3 or 4 readings could be taken during this process. In the Triaxial testing the EDGGE unit was used to record the axial load and vertical displacement of the sample. With the EDGGE taking continuous readings, all of the strains and corresponding loads once collapse was initiated could be captured. This resulted in very detailed stress-strain curves that enabled isolation of a "collapse zone" in which information necessary to describe the changing material properties during collapse could be obtained.

In this research, direct measurement and observation of the whole collapse process itself, including the soil were required. Oedometer and Triaxial set-ups 
consisted of the dial gauge, or LVDT. The bases of the set-ups are spring loaded so that the base moves with the soil. For testing the vertical strain of collapsible soil, measurements were displayed simultaneously with the movement of the soil, which allowed observation of collapse directly. Once the tests were completed the intact sample could be examined and changes in structure, particle sizes, moisture content and density could be measured. Valuable aspects of the laboratory research include: data relating to the vertical dimension of strain was obtained; tests could be repeated simply and in a timely manner; stress levels could be varied by adding or removing weights and the environment could be strictly controlled.

Part of the success of the laboratory testing was having a generic, manufactured, collapsible soil developed during the work. As with a truly collapsible soil, in the dry state this material was very strong and with the addition of water, it experienced sudden vertical strains with no changes in vertical stress. Using this soil eliminated the variabilities intrinsic in natural soil deposits. It could be transported, broken apart and re-mixed with consistent test results.

Based on the test results, using the manufactured soil, a constitutive model was developed whose parameters parallel those of Lade. In addition, this model had the capability to predict the elastic and plastic strains associated with collapse. These parameters were later employed in the finite element code, Metastable Analysis of DAMs, MADAM, which predict the collapse potential for the design of dams. 
MADAM is currently undergoing validity trials to verify and refine the results of this study. One such test is its use to predict by MADAM the collapse settlement in Oedometer testing, and compare this data with actual test findings.

The input model consists of 12 four-node quadrilateral elements with 20 nodes. Due to symmetry, an axisymetric model is used which simplifies the analysis. Roller boundaries are used on both sides of the mesh with the bottom fixed in both directions.

As in the Oedometer testing, increasing pressure loads of $5,10,20,40,80$, 160 , and $320 \mathrm{kPa}$ are applied to the top of the mesh in successive steps. At a maximum constant pressure of $320 \mathrm{kPa}$, the moisture is added over 6 time history steps beginning at step 4. This will allow smaller changes in material properties to occur within a given step so that MADAM can converge on a solution.

Results of this analysis show $2 \%$ vertical strain during consolidation of the dry material and prior to the addition of moisture. Once collapse is initiated, the soil experiences a further $9 \%$ strain. In the actual test results, the dry consolidation produced $11 \%$ vertical strain and the strain upon collapse an additional $18 \%$. There are considerable differences between the predicted and actual vertical strains that can be accounted for. First, the elastic modulus was increased in the program input since the CVD parameters caused too much strain. In so doing, it has been demonstrated that MADAM is very sensitive to the magnitude of the input elastic modulus. 
Second, is the existence of possible dynamic as well as static forces in the collapse laboratory testing. It is known that the collapse is vertical displacement occurring over a given amount of time, this gives a real soil velocity and, therefore, it is no longer in static equilibrium. This has yet to be explored through research. After adjusting the CVD parameters, the execution of MADAM yielded reasonable results in predicting the vertical strains due to soil collapse. This demonstrates the code versatility, yet the input parameters do need refinement.

It is recommended that further research be made using the triaxial test cell. In future experiments an updated cell should be used. This new cell should have the capacity to measure radial strain so that true volume strain can be computed. Essential to the constitutive model parameters was the plastic work done by isotropic compression. In order to derive the plastic work, the volume strain was needed and the machine used for this research could only measure axial strain.

Oedometer testing is already an industry standard in understanding the collapse phenomenon itself. Therefore, its use in future research would be most useful in trying to measure the correspondence between water content and the amount of vertical strain. It would also be an excellent learning tool.

Some Pressuremeter testing was conducted in this research and was effective in testing the modifications made to the equipment. It also verified the results that showed an increase in strength after collapse which were later confirmed in Triaxial tests. However, faults in the Pressuremeter test cell design limited the contributions of this test. After completion of all scheduled testing, 
one additional test was conducted to determine the vertical stress distribution throughout the cell. A load cell was placed at the same location as where the center of the pressuremeter probe would sit. The surface pressure was brought up from 5.0 to $15.0 \mathrm{psi}$ while the load at the center was recorded. The results of this test were that at a surface pressure of 5.0 psi the stress in the soil was still reading at $0.0 \mathrm{psi}$ and the surface deflection was 1.0 inches. At 15.0 psi the deflection of the surface was 3.6 inches with 1.5 psi in the soil. Obviously, the deflection of the surface and side friction were factors that resisted the applied load thus reducing the stress below the surface.

To improve the performance of this test, it is recommended that a new test cell be constructed of a seamless steel cylinder so that side friction will be minimized and the cell itself will not buckle. The cylinder needs only to be long enough to cover the end of the probe and the membrane. The applied stress would simulate depth and as in the original design, the bottom of the cylinder would be similar to the bottom of a borehole. To insure that the applied stress is uniform throughout the soil, the load should be applied at the bottom of the cylinder as well. An improvement to adding and distributing the water should be found. Using the filter fabric as a wick worked well until the fines of the material plugged up the fabric pores. A possible solution is to make a rubber sock with drainage holes that would fit around the Pressuremeter membrane. This sock would be sealed at the top and bottom of the probe and would be larger in diameter then the membrane so that it does not resist expansion. Water could 
then be added in a similar way. Pressuremeter testing is essential for refining the constitutive model and verification made by applying to actual soils. In addition, since the input to MADAM in field use is to be from Pressuremeter results, it will be a benefit to be able to continue testing in a laboratory setting.

Further laboratory research using the CVD material is still recommended. Even though diatomite does not have the "honeycomb", or "aggregate", structure of collapsible soils it still demonstrated collapse well. The structure of diatomite is silicous and the collapse is due to the water softening causing the particles to break apart, producing collapse. In addition to using this soil, tests involving infield samples should be tried. Some ways in which to prepare the solid, brittle infield samples might be to experiment with the plug drill as a means of cutting samples. Because the edge was sharp and the speed could be controlled, fracturing and sample disturbance might be minimal. In the diatomite, the edges were slightly polished from cutting but the remainder of the sample appeared undisturbed. It is believed that this polishing will be of no consequence to collapse performance. 


\section{REFERENCES USED}

Colbath, G. Kent, Steel, Matthew J., "The Geology of Economically Significant Lower Pliocene Diatomites in the Fort Rock Basin Near Christmas Valley, Lake County, Oregon", Oregon Geology; Vol. 44, No. 10, October 1992, pp. 111-118.

Bishop, A.W., and Henkel, D.J., The Measurement of Soil Properties in the Triaxial Test, 2nd Edition, 1962, pp. 90-94

Day, Robert W., "Sample Disturbance of Collapsible Soil", Journal of

Geotechnical Engineering; Vol. 116, No. 1, January 1990, pp.158-161.

Houston, Sandra L., Houston, William N., Spadola, Donald J., "Prediction of Field Collapse of Soils Due to Wetting", Journal of Geotechnical Engineering; Vol. 114, No. 1, January, 1988, pp. 40-58.

Lade, Poul V.,"Elasto-Plastic Stress-Strain Theory for Cohesionless Soil With Curved Yield Surfaces", Int. J. Solids Structures; Vol. 13, January 1977, pp. 1019-1034.

Lade, P. V., Kim, M.K., "Single Hardening Constitutive Model for Frictional Materials, I. Plastic Potential Function", Computers and Geotechnics; Vol. 5, 1988, pp. 307-324.

Lade, P.V., Kim, M.K.,"Single Hardening Constitutive Model for Frictional Material, II. Yield Criterion and Plastic Work Contours", Computers and Geotechnics; Vol. 6, 1988, pp. 13-29.

Lade, P.V., Kim, M.K., " Single Hardening Constitutive Model for Frictional Material, III. Comparisons with Experimental Data", Computers and Geotechnics; Vol. 6, 1988, pp. 31-47.

Lade, Poul V., "Single-Hardening Model with Application to NC Clay", Journal of Geotechnical Engineering; Vol. 116, No. 3, March, 1990, pp. 394-412.

Lawton, Evert C., Fragaszy, Richard J., Hardcastle, James, "Stress Ratio Effects on Collapse of Compacted Clayey Sand", ASCE Journal of Geotechnical Engineering; Vol. 117, No. 5, May 1991, pp. 714-726. 
Lutenegger, Alan J., and Robert T. Saber; "Determination of Collapse Potential of Soils", ASCE Geotechnical Testing Journal; Vol, 11, No. 3, September 1988, pp. 173-178

Rollins, Kyle M., "Collaborative Research on Collapsible Soil Behavior Techniques for Producing Artificial Collapsible Soils", a paper prepared for Trevor D. Smith, Portland State University, October 15, 1990.

Slyh, Robert, Research Associate, Department of Civil Engineering, Portland State University, Portland, Ore. verbal communication.

Smith, Trevor, Deal, Clifton E., "Cracking Studies at Sand H Basin By the Finite Element Method", Second International Conference on Case Histories in Geotechnical Engineering; June 1-5, 1988

Smith, Trevor D., Boyer, Marcella, Barrows, Richard, "Development of an Electronic Data Gathering System for Geotechnical Engineering (EDGGE) Unit for Highways Systems" Transportation Northwest (TransNow); February 1990.

Smith, Trevor D., Denham, Martha H., "Multicylinder Control Units for Prebored Hydraulic Pressuremeters", ACT Geotechnical Testing Journal; Vol. 14, No. 2, pp. 212-216, June 1991.

Smith, Trevor D., "Metastable Analysis of Dams", Vol. 2, GE-SCS-11-91 Department of Civil Engineering, Portland State University; December 1992.

Smith, T.D., Slyh, R., Deal, C., "Stability of Cracked Earth Dams on Collapsible Debris Fans", Proceedings of XIII International Conference Soil Mechanics and Foundation Engineering.

Talbot, James R., Ralston, David C., "Earth Dam Seepage Control, SCS Experience", Reprinted from Proceedings of Symposium sponsored by GT Div/ASCE, Spring National Convention, Denver, Colorado, May 5, 1985.

Tucker, Larry M., Briaud, Jean-Louis, User's Guide for Presred, A Program for Reducing Pressuremeter Data, August 1986. 